\title{
Breastfeeding and infant atopic manifestations
}

Citation for published version (APA):

Snijders, B. E. P. (2008). Breastfeeding and infant atopic manifestations. [Doctoral Thesis, Maastricht University]. Universiteit Maastricht. https://doi.org/10.26481/dis.20080222bs

Document status and date:

Published: 01/01/2008

DOI:

10.26481/dis.20080222bs

Document Version:

Publisher's PDF, also known as Version of record

\section{Please check the document version of this publication:}

- A submitted manuscript is the version of the article upon submission and before peer-review. There can be important differences between the submitted version and the official published version of record.

People interested in the research are advised to contact the author for the final version of the publication, or visit the DOI to the publisher's website.

- The final author version and the galley proof are versions of the publication after peer review.

- The final published version features the final layout of the paper including the volume, issue and page numbers.

Link to publication

\footnotetext{
General rights rights.

- You may freely distribute the URL identifying the publication in the public portal. please follow below link for the End User Agreement:

www.umlib.nl/taverne-license

Take down policy

If you believe that this document breaches copyright please contact us at:

repository@maastrichtuniversity.nl

providing details and we will investigate your claim.
}

Copyright and moral rights for the publications made accessible in the public portal are retained by the authors and/or other copyright owners and it is a condition of accessing publications that users recognise and abide by the legal requirements associated with these

- Users may download and print one copy of any publication from the public portal for the purpose of private study or research.

- You may not further distribute the material or use it for any profit-making activity or commercial gain

If the publication is distributed under the terms of Article $25 \mathrm{fa}$ of the Dutch Copyright Act, indicated by the "Taverne" license above, 
BREASTFEEDING AND INFANT ATOPIC MANIFESTATIONS 
Breastfeeding and Infant Atopic Manifestations

B.E.P. Snijders

ISBN: 978-90-9022751-1

Cover illustration: Bas Verhage, Maastricht

Lay-out: Jos Bruystens, Maastricht

Printed by: Wilco, Amersfoort

(C) 2008, B.E.P. Snijders

All rights reserved. No part of this thesis may be reproduced or transmitted in any form or by any means, electronic or mechanical, including photocopying, recording or any information storage or retrieval system, without permission in writing from the author, or, when appropriate from the publisher of the publications. 


\section{Breastfeeding and \\ Infant Atopic Manifestations}

\section{PROEFSCHRIFT}

ter verkrijging van de graad van doctor aan

de Universiteit Maastricht,

op gezag van de Rector Magnificus,

Prof. mr. G.P.M.F. Mols,

volgens het besluit van het College van Decanen,

in het openbaar te verdedigen op

vrijdag 22 februari 2008 om 12.00 uur

door:

BIANCA E.P. SNIJDERS

geboren op 23 november 1977 te Taitung Hsien (Taiwan, R.O.C.) 


\section{Promotor:}

Prof. dr. ir. P.A. van den Brandt

\section{Co-promotores:}

Dr. C.T.M.C.N. Thijs

Dr. F.F. Stelma

\section{Beoordelingscommissie:}

Prof. dr. J.W. Cohen Tervaert (voorzitter)

Prof. dr. C.E. Blanco

Prof. dr. D.S. Postma (Rijksuniversiteit Groningen)

Prof. dr. ir. H.F.J. Savelkoul (Wageningen Universiteit)

Prof. dr. C.P. van Schayck

This project was funded by a grant from the Netherlands Organisation for Health Research and Development (ZonMw), program of Innovative Prevention Research (Prevention Program 1, no. 210-00-090).

\section{a. ZonMw}

The studies presented in this thesis were performed at the Department of Epidemiology (Maastricht University), and were embedded in the Care and Public Health Research Institute (CAPHRI) and Nutrition and Toxicology Research Institute Maastricht (NUTRIM). NUTRIM participates in the Graduate School VLAG (Food Technology, Agrobiotechnology, Nutrition and Health Sciences), and the Care and Public Health Research Institute (CAPHRI) participates in the Netherlands School of Primary Care Research (CaRe). VLAG and CaRe are accredited by the Royal Netherlands Academy of Arts and Sciences (KNAW). 
Vroeger was ik een twijfelaar,

$i k$ ben daar nu niet meer zo zeker van.

(bron: onbekend)

Voor mijn ouders 



\section{Contents}

Chapter 1

Chapter 2

Chapter 3

Chapter 4

Chapter 5

Chapter 6
General introduction

Breastfeeding and infant eczema in the first year

of life in the KOALA Birth Cohort Study,

a risk-period specific analysis

Breastfeeding duration and infant atopic

manifestations, by maternal allergic status, in the first two years of life (KOALA Study)

Age at first introduction of cow's milk products and other food products in relation to infant atopic manifestations in the first two years of life, The KOALA Birth Cohort Study

Cytokines and soluble CD14 in breast milk in relation with atopic manifestations in mother and infant (KOALA Study)

CD14 polymorphisms in mother and infant, soluble 107 CD14 in breast milk and atopy development in the infant (KOALA Birth Cohort Study) 
Samenvatting 155

Dankwoord 163

About the author 167

List of publications 169 


\section{LIST OF ABBREVIATIONS}

$95 \% \mathrm{Cl}: 95 \%$ confidence interval

AD UK-WP : Atopic Dermatitis according to UK Working Party criteria

BF : Breastfeeding

IgE : Immunoglobulin E

IL-4 : Interleukin-4

IL-5 : Interleukin-5

IL-10 : Interleukin-10

IL-12 : Interleukin-12

IL-18 : Interleukin-18

ISAAC : International Studies on Asthma and Allergies in Childhood

LPS : Lipopolysaccharide

MD-2 :MD-2 protein

OR : (crude) Odds Ratio

$\mathrm{OR}_{\text {adi }} \quad$ : (adjusted) Odds Ratio

RAST : Radio Allergo Sorbent Test

RIA : Radio Immuno Assay

SCD14 : Soluble CD14

SNP : Single Nucleotide Polymorphism

TGF- $\beta 1$ : Transforming Growth Factor Beta 1

TLR4 : Toll like receptor 4 

1

General Introduction 



\section{BACKGROUND}

Allergic asthma, hay fever (and other airway allergies), eczema and food allergy are collectively known as 'atopic diseases'. A largely unexplained increase in the prevalence of these diseases was noted from the early 1970s, prodominantly in industrialised countries and especially in children.(1, 2) Recently, it has been postulated that a plateau phase has been reached in some countries.(3-5)Currently, atopy is present in about $40 \%$ of the westernised world's population, constituting a large burden from personal, health care and economic perspective. Asthma and other atopic disorders are thought to be the result of complex interactions between genetic predisposition and multiple environmental influences.(6) However, the marked increase in asthma prevalence over recent decades is unlikely to be due to genetic changes, highlighting the contribution of environmental factors.( 7 ) In the present thesis, we have investigated how breastfeeding may play a (protective) role in the development of allergic diseases. In this perspective, we have tested several hypotheses in the KOALA Birth Cohort Study which are outlined in this chapter.

\section{Immunology of atopic diseases}

Allergic diseases are chronic inflammatory disorders caused by aberrant Th2type immune responses against common 'innocuous' environmental antigens (allergens) in susceptible individuals.(8) Viruses, bacteria, and helminths carry distinct signature molecules that interact with dendritic cells resulting into the differentiation of both Th1 and Th2 cytokine-producing cells.(9) Th2 cells produce both IL-4 and IL-13, which in a coordinated fashion regulate the allergic response. IL-4 directs the differentiation of T cells towards a Th2 cytokine profile and acts as a growth factor for the expression of these cells. In addition, IL-4 and IL-13 regulate the synthesis of IgE by B cells.(10) IgE binds with high affinity to receptors (FcERI) found on mast cells leading to immediate and delayed release of inflammatory mediators, initiating hypersensitivity and late-phase reactions. $(8,11)$ Several years ago, the importance of reduced activity of T regulatory (Treg) cells (reduced immune suppression) has been emphasized. $(9,12)$ Early exposure to allergens and pathogens stimulates IL-10 producing T reg cells which down-regulate both Th1 and Th2 cells. $(13,14)$ However, the role of $T$ reg cells on dampening allergen-specific Th2 responses is poorly understood and inconsistent due to the heterogeneity of $T$ reg cells and to the incomplete knowledge of their origin and function. $(8,15)$ 


\section{THE NOMENCLATURE AND DEFINITION OF ATOPIC DISEASES}

The terminology that is used to characterize allergic and allergy like reactions remains confusing. Terms like 'atopic dermatitis', '(intrinsic/extrinsic) atopic eczema', 'allergic eczema/dermatitis syndrome (AEDS)' or 'eczema' and 'atopiform dermatitis' have been used interchangeably.(16-19) In 2004, a committee by the World Health Organization has proposed a new terminology in order to improve the communication between health care professionals within the field of allergies. (20) Consistent with the new nomenclature, dermatitis is divided into eczema, contact eczema or other dermatitis. Eczema can be divided into atopic eczema (IgE-associated) or non-atopic eczema (non-IgE-associated). According to the committee, 'atopy' should be defined as 'a personal and/or familial tendency, usually in childhood or adolescence, to become sensitized and produce Immunoglobulin $\mathrm{E}$ (IgE) antibodies in response to ordinary exposures to allergens, usually proteins'.(20) In addition, the Committee stated that the term 'atopy' should be reserved as a clinical definition to describe the genetic predisposition of individuals to become sensitized to allergens that are commonly occurring in the environment and to which everyone is exposed but to which the majority do not produce a prolonged IgE-antibody response.(20)

\section{Eczema}

Eczema is an inflammatory, chronically relapsing, non-contagious and intensely pruritic skin disease that is often occurring in families with other atopic diseases (bronchial asthma, allergic rhino-conjunctivitis).(21) Eczema is one of the most common skin diseases in infancy. It is known that eczema, asthma and allergic rhinitis tend to cluster in the same families, but the exact relationship between early eczema and subsequent asthma over time is far from clear.(22) The atopic march (i.e. a child who progresses from eczema to asthma and hay fever as he or she becomes older) is a popular but simplified explanation.(23) Atopy is a common finding in patients with eczema.(24) However, the causative role of allergens in eczema, has been disputed. Elicitation of eczematous lesions by means of application of allergen to the skin in atopy patch tests and improvement of skin condition after allergen avoidance might be considered as evidence for causality.(25) The relationship between disease severity and levels of total IgE and IgE antibodies directed against environmental allergens further supports this view. However, a significant proportion of eczema ( $16 \%$ to $45 \%$ in European 
studies) is not associated with increased IgE levels. (26) There have been several explanations for the fact that not all infants with eczema are sensitized. First, Kusel et al hypothesised there may be two forms of eczema i.e. the intrinsic (nonatopic form) and the IgE mediated extrinsic from.(27) Although some studies have defined non-atopic eczema according to low total IgE levels ( $<150 \mathrm{kU} / \mathrm{L})$, others base this classification on a lack of sensitization to inhalant or food allergens.(28) Another explanation was based on a review demonstrating that eczema severity was positively associated with positive skin prick test responses or IgE antibody levels.(29) Therefore, IgE sensitization may be a predictor of eczema severity or even an epiphenomenon.(30) Alternatively, sensitization may be a consequence of eczema rather than a cause since a damaged skin barrier may act as an important route of antigen sensitization. $(31,32)$

\section{Wheeze}

Wheeze, a relative common symptom in infancy, is a continuous, coarse, whistling sound produced in the respiratory airways during breathing. For wheezes to occur, some part of the respiratory tree must be narrowed or obstructed, or airflow velocity within the respiratory tree must be heightened. It has been estimated that wheezing affects between $25-60 \%$ of the infants during the first years of life. However, it is increasingly recognized that wheezing illness in young children represents a heterogeneous group of conditions with distinct patterns associated with different pathogenesis and risk factors.(33, 34) Interestingly, it has been noted that in some young children with mild asthma, wheezing resolves spontaneously; in others, especially those with severe asthma, wheezing continues into adulthood.(35) A recent study, showed that the majority of children who wheezed in the first 2 years of life no longer wheeze in later childhood and that a parental history of asthma, smoking, and infant's atopy seem to be the most important characteristics in persistent wheeze during childhood. (34)

Not all infants who suffer from wheezing illnesses appear to have atopy. $(36,37)$ It has been suggested that infant wheeze is less useful as an indicator of the atopic phenotype since only a weak association was found between wheeze and atopic eczema. Hence infant wheeze was thought not to be etiologically linked to the epidemic of atopic disease.(38) In a cohort exhibiting high prevalences of atopic characteristics, including eczema, allergic sensitization to inhalant and food allergens, it has been shown that the existence of severe intermittent wheezing (as a distinct phenotype of wheezing during early childhood) is particularly 
characterized by more severe acute episodes requiring oral corticosteroids. These findings suggest that in preschool children with intermittent wheezing, episodes can be severe, with greater severity associated with previous episodes (requiring oral corticosteroid use) and associated with allergic sensitization.(39)

\section{Sensitization}

Atopic or allergic sensitization (i.e. increased serum levels of specific IgE antibodies against one or more allergens) in children below the age of 4 occurs predominantly against food allergens. By the age of 2 to 4 years, most children outgrow common food allergies such as to cow's milk and hen's egg.(40) After 6 years of age, atopic sensitization to inhalant allergens such as house dust mite and pollen is more frequently diagnosed than food sensitization.(41) Sensitization has been reported to be strongly associated with eczema, rhinitis and asthma at age four years as well as with adult asthma.(42)

\section{Definitions of atopic outcomes used in the present thesis}

In the present thesis, eczema, atopic dermatitis as defined by the UK Working Party criteria, wheeze and sensitization were all addressed as separate outcomes. The use of the definition for 'atopic dermatitis by UK Working Party' is not consistent with the nomenclature proposed by the committee of the World Health Organization, although we preferred to use this term as it was originally introduced by Williams et al.(43-45) The definition proposed by Williams et al is the only validated classification solely based on clinical signs and symptoms. Infant 'atopic manifestations' or 'atopy development' were used as umbrella terms when reporting on eczema, wheeze, atopic dermatitis by UK Working Party and sensitization.

Figure 1 shows the proportion of infants with atopic sensitization at age 2 years and parental reported eczema and recurrent wheeze during the first 2 years of life in the KOALA Birth Cohort Study. 


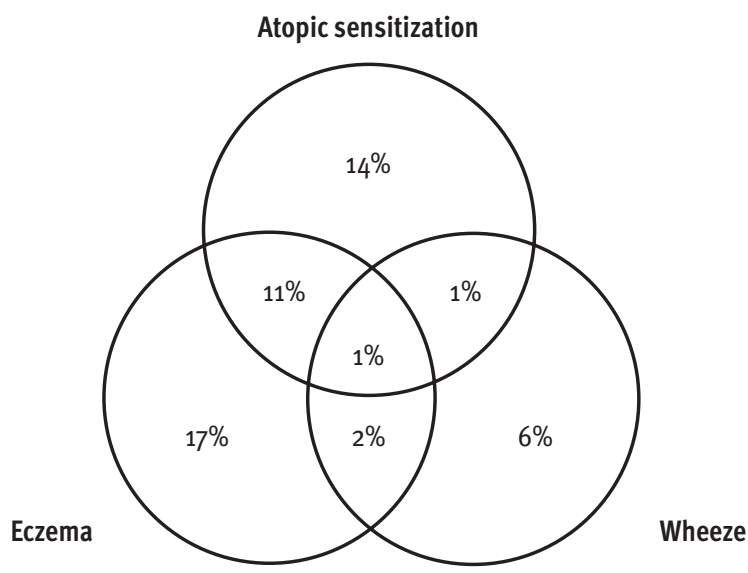

\section{Figure 1}

Venn diagram showing the proportion of infants with atopic sensitization (specific serum IgE to hen's egg, cow's milk, peanut, birch, grass pollen, cat, dog and/or house dust mite) at age 2 year, parental reported eczema or wheeze during the first 2 years of life or any combination of the three conditions in the KOALA study. Subset areas presented above are not proportional to the actual relative subset size.

From this figure, it becomes clear that far from all infants in the KOALA Birth Cohort Study with eczema have raised specific IgE levels. The same is true for infants with recurrent wheeze. Furthermore, figure 1 shows that only a slight percentage of all infants with eczema report wheezing symptoms.

\section{HYGIENE HYPOTHESIS FROM DIFFERENT PERSPECTIVES}

Different hypothesis have been put forward to explain the increasing rise in the incidence of atopic disease: Initially, a link between the increasing incidence of allergies and the modern lifestyle was suggested, giving rise to the socalled hygiene hypothesis proposing that reduced exposure to infections in early childhood owing to a combination of diminishing family size, improved living standards and higher personal hygiene might result in increased risk of developing allergic disease. $(46,47)$ However, 15 years after the formulation of the hygiene hypothesis, a pro/con debate is still going on. $(48,49)$ It has been 
stated that this hypothesis was mainly based on observational studies and could largely be explained by confounding by indication. $(50,51)$ In contrast, from an immunological viewpoint this hypothesis is very much alive.(52-54) Also, it has been shown from epidemiologic studies that atopic and nonatopic subjects differ in gut flora composition (55), and hygiene-associated deviation in gut microflora has been hypothesized to be one of the key environmental factors underlying development of atopy in genetically predisposed individuals.(56) Furthermore, it has become increasingly clear that the hygiene hypothesis requires more insight in gene-environment interactions in order to determine the outcome of immune responses. For example, by the analysis of genetic variants in $\mathrm{CD}_{14}$, a component of the TLR signaling complex that facilitates endotoxin responsiveness through the TLR4-MD2 complex.(57)

\section{THE ROLE OF BREASTFEEDING}

Breastfeeding has been considered as the optimal source of infant nutrition and it has been shown to protect the infant against infectious diseases ( 58 , $59)$, obesity $(60,61)$ and several chronic illnesses $(62,63)$ including allergic symptoms, especially childhood asthma.(64) Two meta-analyses showed that exclusive breastfeeding during the first three months of life was associated with lower incidence rates of atopic dermatitis and also with lower asthma rates. This was the case in children of a general population but especially this was seen in children with a family history of atopy. $(65,66)$ However, studies on the effects of breastfeeding on the development of allergy have yielded controversial results, some studies indicating an allergy-preventive effect (67-69), while others could not confirm this $(70,71)$, or the protective effect has been limited to early childhood, long-term follow-up indicating increased atopic symptoms among the breastfed subjects (72-75). Health gains for breastfeeding mothers include lactation amenorrhea, early involution of the uterus, enhanced bonding between the mother and the infant, and reduction in incidence of ovarian and breast cancer. From the economic perspective, breastfeeding is less expensive than formula feeding.(76)

There may be several reasons why it can be expected that breastfed infants show a reduced occurrence of atopic diseases. The following mechanisms have been 
proposed: 1) breastfed infants are less or later exposed to food antigens 2) human milk contains factors that promote gastrointestinal mucosa maturation, 3) by decreasing the incidence of infection and possibly altering the gut microflora (77), 4) human milk has functional immunomodulatory and anti-inflammatory factors including cytokines and growth factors that play an important role in modulating the development of asthma and allergic disease.(78)

\section{Immunology of human milk and its relation with the infant:}

Human milk may confer passive support of the host defence in the offspring. The breast-fed infant will receive relevant secretory antibodies (such as secretory $\lg A$ ) directed against the microflora initially colonizing its mucosae (reflecting the mother's microflora) and hence be better protected both in the gut and in the upper airways by secretory IgA and secretory IgM in the same way as the mother's gut mucosa is protected by similar antibodies.(79) Thus the neonatal colonization with the mother's gut bacteria is no threat for the infant, even if pathogens are transferred, provided that the infant is breastfed.(80) The passive support is regulated by the integration of mucosal immunity between mother and the newborn (so called enteromammaric link). Primed B (and probably T) cells migrate from the gut-associated lymphoid tissue (GALT) such as Peyer's patches, via lymph and peripheral blood to lactating mammary gland. $(81,82)$ This distribution of precursors for IgA plasma cells beyond the gut mucosa is crucial for glandular production and subsequent occurrence in breast milk of secretory antibodies (slgA and slgM) specific for enteric antigens (microorganisms and food proteins).

The immature immune system in neonates may be reflected in low a cytokine production.(83) This may in part be compensated by cytokines in the human milk and may actively stimulate the infant's immune system by the uptake of these milk cytokines. Therefore, the breastfed child continues to be better protected against various infections.(80) Some of the cytokines are bound to other proteins, e.g. to their receptors $(84,85)$ and are hence protected from digestion. In addition, human milk contains antiproteases interfering with proteolysis, and the digestive capacity is not yet fully developed in newborns (86).

Transforming growth factor $\beta$ (TGF- $\beta$ ) is a predominant anti-inflammatory cytokine in human milk (87). TGF- $\beta$ has a potent immunosuppressive action in the gut that prevents from sensitization to food allergens and inhibits T-cell activation (88). 
Also, TGF- $\beta$ may act with interleukin-10 (89) resulting in increased IgA production by naïve $B$ cells $(86,90,91)$, promoting specific IgA production (92) which reduces susceptibility to both enteric and respiratory infections. In addition, interleukin10 (an anti-inflammatory cytokine) and interleukin-12 (an pro-inflammatory cytokine) are both present in human milk. $(84,93)$

\section{SCOPE OF THE THESIS: EXPLAINING THE CONTROVERSY OVER BREASTFEEDING AND ATOPY}

In 1988, Kramer (94) in his paper 'Does breast feeding help protect against atopic disease? Biology, methodology, and a golden jubilee of controversy' developed 12 standards pertaining to both biologic and methodologic aspects of exposure (infant feeding), outcome (atopic conditions), and statistical analysis for new studies in an attempt to end the controversy concerning the possible protective effect of breast feeding on subsequent atopic disease (94). Despite several new studies that complied with these standards, the controversies are not yet resolved and several studies have focused on other methodological explanations for the inconsistent results which are outlined below.(95-97)

\section{* Reverse causation}

Bias as a result of reverse causation has been proposed as one of the explanations of the unsolved controversy. In other words, the relationship between breastfeeding and infant atopic outcomes may be disturbed since it is known that mothers may alter their feeding behaviour to what is their perception to be the best for their infant. For example, mothers may prolong breastfeeding if their infant shows symptoms of eczema or food allergy. In the present thesis, we have explored whether our data have been prone to reverse causation by assessing the relationship between breastfeeding and eczema in the first year of life by a risk-period specific analyses, i.e. taking into account only those infants that develop symptoms after the occurrence of the exposure (breastfeeding) (chapter 2).

Reverse causation has also been proposed in the literature as an explanation for the fact that some studies have found an increased risk of atopy by a delayed introduction of cow's milk or food allergens.(98) Previously, it was accepted that 
(exclusive) breastfeeding or less exposure to foreign antigens (like cow's milk protein triggering the induction of allergic sensitization) would be beneficial for the infant. More recently, some studies have found the opposite effect of what can be regarded as desirable for the exclusively breastfed infant, namely an increased risk of allergic disorders for breastfed infants. $(70,72)$ Another explanation for this increased risk, is the induction of 'oral tolerance' (opposite mechanism of sensitization) by introducing cow's milk of food allergens at an early age. $(99,100)$ In the present thesis, we have explored the age of introduction of solids and other food products on the relation of infant atopic manifestations (chapter 4).

\section{* The role of the maternal allergic status as an effect modifier}

Another explanation that has been proposed for the inconsistent findings on breastfeeding and atopy is effect modification. Previously, it has been shown that breastfeeding is associated with decreased IgE levels in children of mothers with low IgE levels, as opposed to elevated IgE levels among children of mothers with high IgE levels.(101) Therefore it has been thought that the protection by breastfeeding may depend on maternal allergic status. (102) In addition to genetic inheritance, the mechanisms for conferring early-life risk preferentially through the maternal line may include transplacental transfer of antigens, maternal antibodies, or maternally derived cytokines.(103) In the current thesis, we have therefore investigated whether maternal allergic status (allergic, asthmatic of high total IgE levels) modifies the effect of the breastfeeding on the development of infant atopic manifestations in the first two years of life (chapter 3).

In a different way, a maternal allergic status may explain the controversies in the poorly understood relationship between breastfeeding and infant allergy. Namely, the immunoprotection conferred by human milk may vary between mothers (104). For example, the concentrations of interleukin-4, interleukin-5 and interleukin-13 were higher in colostrum from allergic mothers compared with nonallergic mothers.(105-107) Hence, breastfed infants may be differently equipped by immunological factors, depending on the allergic status of the mother. In the present thesis, we have investigated whether the mother's atopic constitution influences milk levels of several immune factors (chapter 5).

Of special interest is soluble CD14 which is the soluble form of the protein receptor CD14 that is present in breast milk. Soluble CD14 may act as a receptor through 
binding to CD14-negative cells, such as intestinal epithelial and dendritic cells, enabling these cells to respond to endotoxin stimuli and to affect the immune system in postnatal maturation.(108)

There may be an interaction between genetic constitution and effect of immune factors in breast milk and it may provide a link between maternal genetic constitution and the child's allergic risk next to genetic inheritance. This might explain the stronger maternal than paternal inheritance of allergy.(103) The CD14 gene is one of the many genes that is currently in the focus of asthma and allergy research. In fact, $C D 14$ is located on chromosome 5931.33, an area where linkage to Th2 prevalent phenotypes such as high total serum IgE and allergic asthma has been reported.(109) Genetic variation in the $C D_{14}$ gene may modify the interaction between e.g. environmental tobacco smoking, endotoxin exposure and allergic diseases.(110) In this thesis we have investigated different CD14 polymorphisms in order to test weather these polymorphisms were associated with the level of SCD14 in breast milk (chapter 6).

\section{KOALA BIRTH COHORT STUDY}

KOALA is Dutch for 'Kind Ouder en gezondheid Aandacht voor Leefwijze en Aanleg' (which is an acronym for Child, Parent and health: Lifestyle and Genetic Constitution). The KOALA Study is an ongoing prospective birth cohort study in the Netherlands. It aims to identify factors that influence the clinical expression of atopic disease with a main focus on lifestyle (vaccinations, antibiotics, dietary habits, breastfeeding and breast milk composition, intestinal microflora composition, infections during the first year of life, and gene-environment interactions).(111)

\section{Design of the study}

Pregnant women have been recruited from an ongoing prospective cohort study $(\mathrm{n}=7020)$ on pregnancy-related pelvic girdle pain (PPGP study) among pregnant women in the Netherlands.(112) Enrolment started in October 2000 and aimed at women at 14-16 weeks of gestation. At 34 weeks of gestation, PPGP subjects were asked to participate in the KOALA study ('conventional participants'). Additionally, recruitment of pregnantwomen with alternative lifestyles ('alternative participants') started through several 'alternative' recruitment channels, i.e., 
posters in organic shops, anthroposophic doctors and midwives, anthroposophic under-five clinics, Steiner schools, and magazines for special interest groups. Like for the PPGP cohort, in this alternative population pregnant women were enrolled at 14-18 weeks of gestation. Perinatal determinants and exposure data on determinants of atopy (hygiene, infections, nutritional data, child rearing, and other lifestyle characteristics) were collected for all members of the cohort by repeated questionnaires during pregnancy and during the first 2 years of the infant's life at 3, 7, 12 and 24 months post-partum. Follow-up at 3 and 7 months post-partum was completed with high response rates (respectively $90 \%$ and $88 \%$ for conventional participants, and $97 \%$ and $95 \%$ for alternative participants).

Participants recruited from January 2002 onwards were asked to consent to maternal blood sampling around $36 \mathrm{wk}$ of gestation (for determination of IgE). Furthermore, they were asked to consent to collecting of capillary blood at the age of $1 \mathrm{yr}$, venous blood at the age of $2 \mathrm{yr}$ (for the determination of infection serology and the measurement of total and specific IgE levels) and from October 2002 onwards breast milk. Finally, buccal swabs from trios (the child and both parents) as source of DNA for genetic analysis were collected. All biosamples have been stored frozen in a biobank to which access is granted to the participating research groups.(111)

Questionnaires were sent to all participants around the child's age of 7,12 , and 24 months. At $2 \mathrm{yr}$ of age, children whose parents gave permission to withdraw blood samples were visited at home. During these home visits a clinical examination was performed by the research nurse to establish atopic dermatitis using the UK Working Party criteria.(43-45) Furthermore, total and specific IgE was assessed at age 1 and $2 \mathrm{yr}$ in those infants who received a home visit.

\section{Home visits for breast milk sampling}

From October 2002, participants that were selected for a home visit to collect maternal venous blood were also asked to consent to sampling infant's breast milk samples at 1 month post-partum (for measurement of immunologic markers and fatty acids; $n=315$ ). Mothers with intention to breastfeed and who agreed to participate were asked to inform the investigators as soon as possible after their child was born. Home visits to collect a breast milk samples were planned at 1 month postpartum. 


\begin{abstract}
AIM OF THIS THESIS
In the present thesis we have studied the role of breastfeeding and its relation with atopy development during the first two years of life. Especially, we have focussed on the aspects that may clarify the controversies that are reported in the literature, addressing both methodological explanations: reverse causation (chapter 2), effect modification (chapter 3), and independent effects of duration of breastfeeding and introductions of solids (chapter 4); as well as biological explanations: immune factors in breast milk (chapter 5) and genetic factors (chapter 6). Finally we discuss the main findings of this thesis in the context of the current scientific knowledge and provide suggestions for future research (chapter 7).
\end{abstract}




\section{GENERAL INTRODUCTION}

\section{REFERENCES}

1. Magnus P, Jaakkola JJ. Secular trend in the occurrence of asthma among children and young adults: critical apprais1al of repeated cross sectional surveys. Bmj 1997;314(7097):17959.

2. Nakagomi T, Itaya H, Tominaga T, Yamaki M, Hisamatsu S, Nakagomi O. Is atopy increasing? Lancet 1994;343(8889):121-2.

3. Nowak D, Suppli Ulrik C, von Mutius E. Asthma and atopy: has peak prevalence been reached? Eur Respir J 2004;23(3):359-60.

4. Ronchetti R, Villa MP, Barreto M, Rota R, Pagani J, Martella S, et al. Is the increase in childhood asthma coming to an end? Findings from three surveys of schoolchildren in Rome, Italy. Eur Respir J 2001;17(5):881-6.

5. Zollner IK, Weiland SK, Piechotowski I, Gabrio T, von Mutius E, Link B, et al. No increase in the prevalence of asthma, allergies, and atopic sensitization among children in Germany: 1992-2001. Thorax 2005;60(7):545-8.

6. Postma DS. [Current opinions about asthma: genetic factors]. Verh K Acad Geneeskd Belg 1999;61(5):575-91.

7. Upham JW, Holt PG. Environment and development of atopy. Curr Opin Allergy Clin Immunol 2005;5(2):167-72.

8. Romagnani S. Regulatory T cells: which role in the pathogenesis and treatment of allergic disorders? Allergy 2006;61(1):3-14.

9. Yazdanbakhsh M, Kremsner PG, van Ree R. Allergy, parasites, and the hygiene hypothesis. Science 2002;296(5567):490-4.

10. Wills-Karp M. IL-12/IL-13 axis in allergic asthma. J Allergy Clin Immunol 2001;107(1):9-18.

11. Prussin C, Metcalfe DD. 5. IgE, mast cells, basophils, and eosinophils. Journal of Allergy and Clinical Immunology

Mini-Primer on Allergic and Immunologic Diseases 2006;117(2, Supplement 2):S450S456.

12. Wills-Karp M, Santeliz J, Karp CL. The germless theory of allergic disease: revisiting the hygiene hypothesis. Nat Rev Immunol 2001;1(1):69-75.

13. Damoiseaux J. Regulatory T cells: back to the future. Neth J Med 2006;64(1):4-9.

14. Akbari O, Stock P, DeKruyff RH, Umetsu DT. Role of regulatory T cells in allergy and asthma. Curr Opin Immunol 2003;15(6):627-33.

15. Romagnani S. The increased prevalence of allergy and the hygiene hypothesis: missing immune deviation, reduced immune suppression, or both? Immunology 2004;112(3):35263. 


\section{CHAPTER 1}

16. Brown S, Reynolds NJ. Atopic and non-atopic eczema. Bmj 2006;332(7541):584-8.

17. Johansson SG, Hourihane JO, Bousquet J, Bruijnzeel-Koomen C, Dreborg S, Haahtela T, et al. $\mathrm{A}$ revised nomenclature for allergy. An EAACl position statement from the EAACI nomenclature task force. Allergy 2001;56(9):813-24.

18. Folster-Holst R, Pape M, Buss YL, Christophers E, Weichenthal M. Low prevalence of the intrinsic form of atopic dermatitis among adult patients. Allergy 2006;61(5):629-32.

19. Bos JD. Atopiform dermatitis. Br J Dermatol 2002;147(3):426-9.

20. Johansson SG, Bieber T, Dahl R, Friedmann PS, Lanier BQ, Lockey RF, et al. Revised nomenclature for allergy for global use: Report of the Nomenclature Review Committee of the World Allergy Organization, October 2003. J Allergy Clin Immunol 2004;113(5):832-6.

21. Reefer AJ, Satinover SM, Wilson BB, Woodfolk JA. The relevance of microbial allergens to the IgE antibody repertoire in atopic and nonatopic eczema. J Allergy Clin Immunol 2007.

22. Williams $\mathrm{H}$, Flohr $\mathrm{C}$. How epidemiology has challenged 3 prevailing concepts about atopic dermatitis. J Allergy Clin Immunol 2006;118(1):209-13.

23. Spergel JM, Paller AS. Atopic dermatitis and the atopic march. J Allergy Clin Immunol 2003;112(6 Suppl):S118-27.

24. Hanifin JM. An overview of atopic dermatitis. Dermatol Nurs 2003;Suppl:6-9.

25. Ring J, Darsow U, Behrendt H. Role of aeroallergens in atopic eczema: proof of concept with the atopy patch test. J Am Acad Dermatol 2001;45(1 Suppl):S49-52.

26. Schmid-Grendelmeier P, Simon D, Simon HU, Akdis CA, Wuthrich B. Epidemiology, clinical features, and immunology of the 'intrinsic' (non-IgE-mediated) type of atopic dermatitis (constitutional dermatitis). Allergy 2001;56(9):841-9.

27. Kusel MM, Holt PG, de Klerk N, Sly PD. Support for 2 variants of eczema. Journal of allergy and clinical immunology 2005;116(5):1067-72.

28. Novak N, Bieber T. Allergic and nonallergic forms of atopic diseases. J Allergy Clin Immunol 2003;112(2):252-62.

29. Flohr C, Johansson SG, Wahlgren CF, Williams H. How atopic is atopic dermatitis? J Allergy Clin Immunol 2004;114(1):150-8.

30. Williams HC, Johansson SG. Two types of eczema--or are there? J Allergy Clin Immunol 2005;116(5):1064-6.

31. Simpson EL, Hanifin JM. Atopic dermatitis. Med Clin North Am 2006;90(1):149-67, ix.

32. Akdis CA, Akdis M, Bieber T, Bindslev-Jensen C, Boguniewicz M, Eigenmann P, et al. Diagnosis and treatment of atopic dermatitis in children and adults: European Academy of Allergology and Clinical Immunology/American Academy of Allergy, Asthma and Immunology/PRACTALL Consensus Report. J Allergy Clin Immunol 2006;118(1):152-69.

33. Henderson J, North K, Griffiths M, Harvey I, Golding J. Pertussis vaccination and wheezing 


\section{GENERAL INTRODUCTION}

illnesses in young children: prospective cohort study. The Longitudinal Study of Pregnancy and Childhood Team. BMJ 1999;318(7192):1173-6.

34. De Sario M, Di Domenicantonio R, Corbo G, Forastiere F, Pistelli R, Rusconi F, et al. Characteristics of early transient, persistent, and late onset wheezers at 9 to 11 years of age. J Asthma 2006;43(8):633-8.

35. Martinez FD. What have we learned from the Tucson Children's Respiratory Study? Paediatr Respir Rev 2002;3(3):193-7.

36. Sicherer SH, Leung DY. Advances in allergic skin disease, anaphylaxis, and hypersensitivity reactions to foods, drugs, and insects. J Allergy Clin Immunol 2005;116(1):153-63.

37. Kusel MM, de Klerk NH, Kebadze T, Vohma V, Holt PG, Johnston SL, et al. Early-life respiratory viral infections, atopic sensitization, and risk of subsequent development of persistent asthma. J Allergy Clin Immunol 2007;119(5):1105-10.

38. Linneberg A, Simonsen JB, Petersen J, Stensballe LG, Benn CS. Differential effects of risk factors on infant wheeze and atopic dermatitis emphasize a different etiology. J Allergy Clin Immunol 2006;117(1):184-189.

39. Bacharier LB, Phillips BR, Bloomberg GR, Zeiger RS, Paul IM, Krawiec M, et al. Severe intermittent wheezing in preschool children: a distinct phenotype. J Allergy Clin Immunol 2007;119(3):604-10.

40. Arshad SH, Gant C. Allergy to nuts: how much of a problem really is this? Clin Exp Allergy 2001;31(1):5-7.

41. Sigurs N, Hattevig G, Kjellman B, Kjellman NI, Nilsson L, Bjorksten B. Appearance of atopic disease in relation to serum IgE antibodies in children followed up from birth for 4 to 15 years. J Allergy Clin Immunol 1994;94(4):757-63.

42. Rhodes HL, Sporik R, Thomas P, Holgate ST, Cogswell JJ. Early life risk factors for adult asthma: a birth cohort study of subjects at risk. Journal of allergy and clinical immunology 2001;108(5):720-5.

43. Williams HC, Burney PG, Hay RJ, Archer CB, Shipley MJ, Hunter JJ, et al. The U.K. Working Party's Diagnostic Criteria for Atopic Dermatitis. I. Derivation of a minimum set of discriminators for atopic dermatitis. British journal of dermatology 1994;131(3):383-96.

44. Williams HC, Burney PG, Strachan D, Hay RJ. The U.K. Working Party‘s Diagnostic Criteria for Atopic Dermatitis. II. Observer variation of clinical diagnosis and signs of atopic dermatitis. British journal of dermatology 1994;131(3):397-405.

45. Williams HC, Burney PG, Pembroke AC, Hay RJ. The U.K. Working Party's Diagnostic Criteria for Atopic Dermatitis. III. Independent hospital validation. British journal of dermatology 1994;131(3):406-16.

46. Strachan DP. Lifestyle and atopy. Lancet 1999;353(9163):1457-8. 


\section{CHAPTER 1}

47. Strachan DP. Hay fever, hygiene, and household size. Bmj 1989;299(6710):1259-60.

48. Patki A. Eat dirt and avoid atopy: the hygiene hypothesis revisited. Indian J Dermatol Venereol Leprol 2007;73(1):2-4.

49. Flohr C, Pascoe D, Williams HC. Atopic dermatitis and the ,hygiene hypothesis': too clean to be true? Br J Dermatol 2005;152(2):202-16.

50. van Schayck CP, Knottnerus JA. Can the ,hygiene hypothesis“ be explained by confounding by behavior? J Clin Epidemiol 2004;57(5):435-7.

51. van Schayck CP. [The hygiene hypothesis is invalid]. Ned Tijdschr Geneeskd 2006; 150(47):2597.

52. Guarner F, Bourdet-Sicard R, Brandtzaeg P, Gill HS, McGuirk P, van Eden W, et al. Mechanisms of disease: the hygiene hypothesis revisited. Nat Clin Pract Gastroenterol Hepatol 2006;3(5):275-84.

53. Savelkoul HF. [The hygiene hypothesis: a fruitful concept in immunological research]. Ned Tijdschr Geneeskd 2006;150(47):2596.

54. Vercelli D. Mechanisms of the hygiene hypothesis--molecular and otherwise. Curr Opin Immunol 2006;18(6):733-7.

55. Kalliomaki M, Isolauri E. Role of intestinal flora in the development of allergy. Curr Opin Allergy Clin Immunol 2003;3(1):15-20.

56. Gore C, Johnson RJ, Caress AL, WoodcockA, Custovic A. The information needs and preferred roles in treatment decision-making of parents caring for infants with atopic dermatitis: a qualitative study. Allergy 2005;60(7):938-43.

57. Finberg RW, Kurt-Jones EA. CD14: chaperone or matchmaker? Immunity 2006;24(2):127-9.

58. Bhandari N, Bahl R, Mazumdar S, Martines J, Black RE, Bhan MK. Effect of communitybased promotion of exclusive breastfeeding on diarrhoeal illness and growth: a cluster randomised controlled trial. Lancet 2003;361(9367):1418-23.

59. Bachrach VR, Schwarz E, Bachrach LR. Breastfeeding and the risk of hospitalization for respiratory disease in infancy: a meta-analysis. Arch Pediatr Adolesc Med 2003;157(3):23743.

6o. Weyermann M, Rothenbacher D, Brenner H. Duration of breastfeeding and risk of overweight in childhood: a prospective birth cohort study from Germany. Int J Obes (Lond) 2006;30(8):1281-7.

61. Scholtens S, Gehring U, BrunekreefB, Smit HA, de Jongste JC, KerkhofM, etal. Breastfeeding, weight gain in infancy, and overweight at seven years of age: the prevention and incidence of asthma and mite allergy birth cohort study. Am J Epidemiol 2007;165(8):919-26.

62. Virtanen SM, Knip M. Nutritional risk predictors of beta cell autoimmunity and type 1 diabetes at a young age. Am J Clin Nutr 2003;78(6):1053-67. 


\section{GENERAL INTRODUCTION}

63. Corrao G, Tragnone A, Caprilli R, Trallori G, Papi C, Andreoli A, et al. Risk of inflammatory bowel disease attributable to smoking, oral contraception and breastfeeding in Italy: a nationwide case-control study. Cooperative Investigators of the Italian Group for the Study of the Colon and the Rectum (GISC). Int J Epidemiol 1998;27(3):397-404.

64. van Odijk J, Kull I, Borres MP, Brandtzaeg P, Edberg U, Hanson LA, et al. Breastfeeding and allergic disease: a multidisciplinary review of the literature (1966-2001) on the mode of early feeding in infancy and its impact on later atopic manifestations. Allergy 2003;58(9):833-43.

65. Gdalevich M, Mimouni D, David M, Mimouni M. Breast-feeding and the onset of atopic dermatitis in childhood: a systematic review and meta-analysis of prospective studies. J Am Acad Dermatol 2001;45(4):520-7.

66. Gdalevich M, Mimouni D, Mimouni M. Breast-feeding and the risk of bronchial asthma in childhood: a systematic review with meta-analysis of prospective studies. Journal of pediatrics 2001;139(2):261-6.

67. Saarinen UM, Kajosaari M, Backman A, Siimes MA. Prolonged breast-feeding as prophylaxis for atopic disease. Lancet 1979;2(8135):163-6.

68. Saarinen UM, Kajosaari M. Breastfeeding as prophylaxis against atopic disease: prospective follow-up study until 17 years old. Lancet 1995;346(8982):1065-9.

69. Oddy WH, Holt PG, Sly PD, Read AW, Landau LI, Stanley FJ, et al. Association between breast feeding and asthma in 6 year old children: findings of a prospective birth cohort study. BMJ Clinical research ed 1999;319(7213):815-9.

70. Wetzig H, Schulz R, Diez U, Herbarth O, Viehweg B, Borte M. Associations between duration of breast-feeding, sensitization to hens' eggs and eczema infantum in one and two year old children at high risk of atopy. Int J Hyg Environ Health 2000;203(1):17-21.

71. Bergmann RL, Diepgen TL, Kuss O, Bergmann KE, Kujat J, Dudenhausen JW, et al. Breastfeeding duration is a risk factor for atopic eczema. Clinical and experimental allergy journal of the British Society for Allergy and Clinical Immunology 2002;32(2):205-9.

72. Sears MR, Greene JM, Willan AR, Taylor DR, Flannery EM, Cowan JO, et al. Long-term relation between breastfeeding and development of atopy and asthma in children and young adults: a longitudinal study. Lancet 2002;360(9337):901-7.

73. Wright AL, Holberg C), Taussig LM, Martinez FD. Factors influencing the relation of infant feeding to asthma and recurrent wheeze in childhood. Thorax 2001;56(3):192-7.

74. Wright AL, Holberg CJ, Martinez FD, Morgan WJ, Taussig LM. Breast feeding and lower respiratory tract illness in the first year of life. Group Health Medical Associates. Bmj 1989;299(6705):946-9.

75. Miyake Y, Yura A, Iki M. Breastfeeding and the prevalence of symptoms of allergic disorders 


\section{CHAPTER 1}

in Japanese adolescents. Clin Exp Allergy 2003;33(3):312-6.

76. Leung AK, Sauve RS. Breast is best for babies. J Natl Med Assoc 2005;97(7):1010-9.

77. Penders J, Thijs C, Vink C, Stelma FF, Snijders B, Kummeling I, et al. Factors influencing the composition of the intestinal microbiota in early infancy. Pediatrics 2006;118(2):511-21.

78. Oddy WH. A review of the effects of breastfeeding on respiratory infections, atopy, and childhood asthma. J Asthma 2004;41(6):605-21.

79. Brandtzaeg PE. Current understanding of gastrointestinal immunoregulation and its relation to food allergy. Ann N Y Acad Sci 2002;964:13-45.

8o. Hanson LA, Korotkova M, Telemo E. Breast-feeding, infant formulas, and the immune system. Ann Allergy Asthma Immunol 2003;90(6 Suppl 3):59-63.

81. Hanson LA, Korotkova M, Haversen L, Mattsby-Baltzer I, Hahn-Zoric M, Silfverdal SA, et al. Breast-feeding, a complex support system for the offspring. Pediatr Int 2002;44(4):347-52.

82. Hanson LA, Korotkova M, Lundin S, Haversen L, Silfverdal SA, Mattsby-Baltzer I, et al. The transfer of immunity from mother to child. Ann N Y Acad Sci 2003;987:199-206.

83. Ehlers S, Smith KA. Differentiation of T cell lymphokine gene expression: the in vitro acquisition of T cell memory. J Exp Med 1991;173(1):25-36.

84. Garofalo R, Chheda S, Mei F, Palkowetz KH, Rudloff HE, Schmalstieg FC, et al. Interleukin10 in human milk. Pediatr Res 1995;37(4 Pt 1):444-9.

85. Rudloff HE, Schmalstieg FC, Jr., Mushtaha AA, Palkowetz KH, Liu SK, Goldman AS. Tumor necrosis factor-alpha in human milk. Pediatr Res 1992;31(1):29-33.

86. Goldman AS, Chheda S, Garofalo R, Schmalstieg FC. Cytokines in human milk: properties and potential effects upon the mammary gland and the neonate. J Mammary Gland Biol Neoplasia 1996;1(3):251-8.

87. Saito S, Yoshida M, Ichijo M, Ishizaka S, Tsujii T. Transforming growth factor-beta (TGFbeta) in human milk. Clin Exp Immunol 1993;94(1):220-4.

88. Stoeck M, Ruegg C, Miescher S, Carrel S, Cox D, Von Fliedner V, et al. Comparison of the immunosuppressive properties of milk growth factor and transforming growth factors beta 1 and beta 2. J Immunol 1989;143(10):3258-65.

89. Jutel M, Akdis M, Budak F, Aebischer-Casaulta C, Wrzyszcz M, Blaser K, et al. IL-10 and TGFbeta cooperate in the regulatory $T$ cell response to mucosal allergens in normal immunity and specific immunotherapy. Eur J Immunol 2003;33(5):1205-14.

90. Kim PH, Kagnoff MF. Transforming growth factor beta 1 increases IgA isotype switching at the clonal level. J Immunol 1990;145(11):3773-8.

91. Ogawa J, Sasahara A, Yoshida T, Sira MM, Futatani T, Kanegane H, et al. Role of transforming growth factor-beta in breast milk for initiation of IgA production in newborn infants. Early Hum Dev 2004;77(1-2):67-75. 


\section{GENERAL INTRODUCTION}

92. Kalliomaki M, Ouwehand A, Arvilommi H, Kero P, Isolauri E. Transforming growth factorbeta in breast milk: a potential regulator of atopic disease at an early age. Journal of allergy and clinical immunology 1999;104(6):1251-7.

93. Bryan DL, Hawkes JS, Gibson RA. Interleukin-12 in human milk. Pediatr Res 1999;45(6):8589.

94. Kramer MS. Does breast feeding help protect against atopic disease? Biology, methodology, and a golden jubilee of controversy. J Pediatr 1988;112(2):181-90.

95. Kull I, Almqvist C, Lilja G, Pershagen G, Wickman M. Breast-feeding reduces the risk of asthma during the first 4 years of life. J Allergy Clin Immunol 2004;114(4):755-60.

96. Laubereau B, Brockow I, Zirngibl A, Koletzko S, Gruebl A, von Berg A, et al. Effect of breastfeeding on the development of atopic dermatitis during the first 3 years of life--results from the GINI-birth cohort study. J Pediatr 2004;144(5):602-7.

97. Zutavern A, Brockow I, Schaaf B, Bolte G, von Berg A, Diez U, et al. Timing of Solid Food Introduction in Relation to Atopic Dermatitis and Atopic Sensitization: Results From a Prospective Birth Cohort Study. Pediatrics 2006;117(2):401-411.

98. WHO. Fifty-fourt World Health Assemby. WHA54.2. Agenda item 13.1. Infant and young children nutrition.

99. van Wijk F, Knippels L. Initiating mechanisms of food allergy: Oral tolerance versus allergic sensitization. Biomed Pharmacother 2007;61(1):8-20.

100. Poole JA, Barriga K, Leung DY, Hoffman M, Eisenbarth GS, Rewers M, et al. Timing of initial exposure to cereal grains and the risk of wheat allergy. Pediatrics 2006;117(6):2175-82.

101. Wright AL, Sherrill D, Holberg CJ, Halonen M, Martinez FD. Breast-feeding, maternal IgE, and total serum IgE in childhood. Journal of allergy and clinical immunology 1999;104(3 Pt 1):589-94.

102. Bjorksten B. Immunological interaction between the mother and her infant in relation to the development of food allergy. Monogr Allergy 1996;32:16-24.

103. Litonjua AA, Carey VJ, Burge HA, Weiss ST, Gold DR. Parental history and the risk for childhood asthma. Does mother confer more risk than father? American journal of respiratory and critical care medicine 1998;158(1):176-81.

104. Bottcher MF. Cytokines and chemokines in breast milk from allergic and nonallergic mothers. ACI International 2000;12(4):153-160.

105. Bottcher MF, Jenmalm MC, Garofalo RP, Bjorksten B. Cytokines in breast milk from allergic and nonallergic mothers. International archives of allergy and immunology 1999;118(24):319-20.

106. Bottcher MF, Jenmalm MC, Garofalo RP, Bjorksten B. Cytokines in breast milk from allergic and nonallergic mothers. Pediatric research 2000;47(1):157-62. 


\section{CHAPTER 1}

107. Bottcher MF, Jenmalm MC, Bjorksten B, Garofalo RP. Chemoattractant factors in breast milk from allergic and nonallergic mothers. Pediatric research 2000;47(5):592-7.

108. Labeta MO, Vidal K, Nores JE, Arias M, Vita N, Morgan BP, et al. Innate recognition of bacteria in human milk is mediated by a milk-derived highly expressed pattern recognition receptor, soluble CD14. Journal of experimental medicine 2000;191(10):1807-12.

109. Baldini M, Vercelli D, Martinez FD. CD14: an example of gene by environment interaction in allergic disease. Allergy 2002;57(3):188-92.

110. Braun-Fahrlander C, Riedler J, Herz U, Eder W, Waser M, Grize L, et al. Environmental exposure to endotoxin and its relation to asthma in school-age children. N Engl J Med 2002;347(12):869-77.

111. Kummeling I, Thijs C, Penders J, Snijders BE, Stelma F, Reimerink J, et al. Etiology of atopy in infancy: the KOALA Birth Cohort Study. Pediatr Allergy Immunol 2005;16(8):679-84.

112. Bastiaanssen JM, de Bie RA, Bastiaenen CH, Heuts A, Kroese ME, Essed GG, et al. Etiology and prognosis of pregnancy-related pelvic girdle pain; design of a longitudinal study. BMC public health 2005;5(1). 
Breastfeeding and infant eczema in the first year of life in the KOALA Birth Cohort Study, a risk-period specific analysis

Bianca EP Snijders

Carel Thijs

Ischa Kummeling

John Penders

Piet A van den Brandt

Pediatrics 2007 Jan; 119(1):e137-e141 


\section{ABSTRACT}

\section{Objective}

Breastfeeding may have a protective effect on infant eczema. More awareness of health promoting effects of breastfeeding could lead to a prolonged or limited duration of breastfeeding. Breastfeeding mothers may change their feeding habits as a result of symptoms of eczema. Consequently, bias as a result of reverse causation may explain the inconsistent results in the infant. We studied the association between breastfeeding and eczema taking into account the possible influence of reverse causation by risk-period specific analyses.

\section{Patients and methods}

Information on breastfeeding, determinants and outcomes at age one year was collected by repeated questionnaires in $\mathbf{2 4 0 5}$ mother-infant-pairs participating in the KOALA birth cohort study. Using multivariate logistic regression analysis, we compared an overall analysis with risk-period specific analyses.

\section{Results}

At the age of 1 year, 535 infants had developed eczema (22.2\%). In an overall analysis, we found a weak, non-significant, trend towards a reduced risk of eczema in the first year of life with increasing duration of breastfeeding (lowest risk at $\geq 7$ months breastfed versus never breastfed: adjusted odds ratio [aOR] $0.80 ; 95 \%$ confidence interval $[\mathrm{Cl}] 0.57-1.12), \mathrm{p}$ for trend $=0.13$. In the risk-period specific analysis (confined to infants 'at risk' for eczema onset after age 3 months), no indication for reverse causation was found (results were not very different compared to overall analysis ( $p$ for trend $=0.14$ ). Infants who were breastfed from birth on had a slightly increased risk (although not statistically significant) for eczema in the first 3 months of life compared to infants who were formula fed from birth on (aOR 1.30, 95\% Cl 0.96-1.77).

\section{Conclusions}

Our results indicate that no strong effect of breastfeeding on eczema in the first year of life was present. This conclusion was strengthened by risk-period specific analysis which made the influence of reverse causation unlikely. 


\section{INTRODUCTION}

The results of studies addressing the effect of breastfeeding on the development of allergic diseases have been controversial so far $(1,2)$. The discussion of this topic revived after several studies reported that breastfeeding appeared as a risk factor, instead of a protective factor in the development of allergic diseases (3-6). Criteria for improved study design were already proposed by Kramer in 1988 as an attempt to solve the inconsistencies (1). Recently, several studies focused on other methodological explanations for the inconsistent results (7-10).

Bias may occur as a result of disease-related modification of exposure, a concept introduced by Kull et al (7), also known as reverse causation (8) or protopathic bias in the literature (11). It is widely known that prolonged breastfeeding has many health benefits for the child. It is possible that mothers extend their breastfeeding if their child has suspected symptoms of eczema (4). On the other hand, mothers may also cease breastfeeding because the child has persistence of allergic symptoms as a result of sensitization to dietary antigens of the mother's diet that are present in breast milk $(12,13)$.

In this study we assess the association between breastfeeding and the development of allergic disease in infants aged 1 year avoiding reverse causation by a risk-period specific analysis. 


\section{METHODS}

\section{Study objects}

The KOALA Birth Cohort study is a prospective birth cohort study in the Netherlands. Design, inclusion- and exclusion criteria have been described, in detail, elsewhere (14). Briefly, from October 2000 until December 2002 we recruited participants with diverse lifestyles (conventional and alternative). Pregnant women with a conventional lifestyle $(n=2343)$ were recruited from an ongoing prospective cohort study on Pregnancy-related Pelvic Girdle Pain (PPGP) in the Netherlands (15). Enrolment of pregnant women aimed at 14-16 weeks of gestation. At 34 weeks of gestation, PPGP subjects were asked to participate in the KOALA study. Additionally, pregnant women with an alternative lifestyle $(n=491)$ were recruited through several 'alternative' channels: organic food shops, anthroposophic doctors and midwifes, Steiner Schools, and magazines. The KOALA study was approved by the Ethical Committee of the University Hospital Maastricht and all parents signed informed consent for the study.

\section{Data collection}

During pregnancy and during the first two years postpartum, information on breastfeeding, other determinants and allergic outcome were collected for all members of the cohort by repeated questionnaires at 34 weeks of gestation and at 3, 7, 12 and 24 months. On date of analysis, the 12 months follow-up was completed. In the present study, the presence of all questionnaires at ' 3 months' and ' 7 months' and ' 1 year' postpartum was used as a criterion for selecting participants to analyze the relationships of interest.

\section{Definitions of exposures}

Breastfeeding was categorized (according to timing of our questionnaires) as follows; the category 'never' serves as the reference category and consisted of all infants that never received breastfeeding. All breastfed infants were categorized into the following categories according to age at which any breastfeeding was quitted: 'quitted before age 4 months', '4-6 months' and ' $\geq 7$ months'.

\section{Outcome measurements}

Information on the development of eczema (based on ISAAC questions) was obtained in the 3, 7 and 12 months questionnaires. For the overall analysis we 
defined 'eczema in the first year' based on the 7 and 12 months questionnaires. Parents were asked; "has your child ever had an itchy rash that was coming and going in the past months'? If this question was answered affirmatively, infants were defined as having developed eczema in the first year of life. Cases of only diaper rash, rash around the eyes and/or scalp scaling were excluded.

For the risk-period specific analyses, we distinguished two risk-periods: '0-3 months' (cases of eczema started in the first 3 months, including cases that did not persist after 3 months) and ' 4 + months' (cases of eczema started after age 3 months).

\section{Definitions of confounders}

Adjustments were made for the following potential confounders: 'Age of first introduction of solids', defined in periods (after age of 4 months, after age of 5 months, after age of 6 months, and after age of 7 months) i.e. the period in which the infant received any solid food (i.e. dairy, porridge, fruit mash) for the first time, gender of infant (boys, girls), recruitment group (conventional cohort, alternative cohort), maternal smoking during pregnancy (yes, no), infant's exposure to ETS (environmental tobacco smoke) (yes, no), maternal age at delivery (in years), maternal education (primary school, preparatory vocational or lower general secondary education [low], vocational education, higher general secondary or pre-university education [middle], higher vocational or academic education [high]), presence of parental allergic disease i.e. self reported eczema, hay fever, house dust (mite) allergy, food and /or asthma (both parents non-allergic, only father allergic, only mother allergic, both parents allergic), number of siblings (zero siblings, one sibling, two or more siblings) and presence of older allergic siblings (no siblings, older allergic sibling(s), older non-allergic sibling(s)).

\section{Statistical methods}

Relationships were analyzed using logistic regression, and results are presented as odds ratios (OR) with corresponding $95 \%$ confidence intervals $(95 \% \mathrm{Cl})$ and were adjusted for potential confounders that were put in the logistic regression model simultaneously. Effect modification by recruitment group (conventional or alternative), presence of an allergic parent or an allergic sibling was assessed by the likelihood ratio test, comparing models with and without interaction terms. In order to avoid an influence of disease onset on exposure (reverse causation), we did risk-period specific analyses, considering exposure only before the risk-period. 


\section{RESULTS}

Of the 2834 infants enrolled at birth, 2405 parents had completed the three questionnaires at infant's age of 1 year (3 months, 7 months and 12 months postpartum) i.e. 1941/2343 (83\%) participants of the conventional cohort and 464/491 (95\%) participants of the alternative cohort who were eventually included in our analyses. The participation rate of KOALA participants recruited from the PPGP study was $39 \%$. The response rates of the 3,7 and 12 months questionnaires were $94 \%, 92 \%$ and $90 \%$ respectively.

Table 1 shows the baseline characteristics of both recruitment groups combined. We noted several differences between both cohorts; mothers in the alternative cohort had a higher rate and longer duration of breastfeeding compared to the conventional cohort ( $\geq 7$ months: $71 \%$ versus $28 \%$, respectively). Also, they showed more delay in the age of first introduction of solid foods ( $>7$ months: $39 \%$ versus $21 \%$, respectively). Other characteristics that differed between the alternative cohort and the conventional cohort were maternal smoking during pregnancy (yes: $<1 \%$ versus $8 \%$, respectively), exposure to ETS ( $<1 \%$ versus $4 \%$, respectively), maternal age (mean 34 years versus 32, respectively), maternal education (high education: $73 \%$ versus $43 \%$, respectively) and the number of siblings ( $\geq 2$ siblings: $21 \%$ versus $13 \%$, respectively). In all analyses, we considered 'recruitment group' as a potential effect modifier for the relationship between breastfeeding and eczema. However, we found no significant interaction between 'recruitment group' and breastfeeding in the logistic regression models ( $p$ interaction always larger than 0.5). Hence we present all results for the groups combined. Also, no interaction between breastfeeding and the presence of an allergic parent or an older allergic sibling was found ( $p$ always larger than 0.28 ). 


\section{Table 1}

Baseline characteristics $(\mathrm{N}=\mathbf{2 4 0 5})$

$n *$

\section{Breastfeeding}

\begin{tabular}{|c|c|c|}
\hline Never & 358 & $(15 \%)$ \\
\hline $0-3$ months & 745 & (31\%) \\
\hline 4-6 months & 430 & $(18 \%)$ \\
\hline$\geq 7$ months & 872 & $(36 \%)$ \\
\hline Age of first introduction solid foods, mean (sd) in months & $3(1)$ & \\
\hline Gender of infant (number of boys) & 1231 & $(51 \%)$ \\
\hline Maternal smoking (during pregnancy (34 weeks)) & 150 & $(6 \%)$ \\
\hline Infant's exposure to ETS at age 1 (yes) & 88 & $(4 \%)$ \\
\hline Maternal age (at time of delivery), mean (sd) in years & $32(4)$ & \\
\hline \multicolumn{3}{|l|}{ Maternal education } \\
\hline Low & 222 & $(9 \%)$ \\
\hline Middle & 1009 & $(42 \%)$ \\
\hline High & 1174 & $(49 \%)$ \\
\hline \multicolumn{3}{|l|}{ Parental allergic disease } \\
\hline Both parents non-allergic & 1165 & $(48 \%)$ \\
\hline Only father allergic & 460 & $(19 \%)$ \\
\hline Only mother allergic & 510 & $(21 \%)$ \\
\hline Both parents allergic & 270 & $(11 \%)$ \\
\hline \multicolumn{3}{|l|}{ Number of siblings } \\
\hline o siblings & 1058 & $(44 \%)$ \\
\hline 1 sibling & 966 & $(40 \%)$ \\
\hline 2 or more siblings & 358 & $(15 \%)$ \\
\hline \multicolumn{3}{|l|}{ Presence of older allergic siblings } \\
\hline No siblings & 1058 & $(44 \%)$ \\
\hline Older non-allergic sibling(s) & 947 & $(39 \%)$ \\
\hline Older allergic sibling(s) & 377 & $(16 \%)$ \\
\hline
\end{tabular}

* May not add up to the total number because of missing values

(\%)

$(49 \%)$

$(11 \%)$

$(44 \%)$

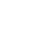

\%)


The results of the overall analysis are presented in Table 2 . The results show a tendency towards a lower risk of eczema in the first year of life associated with breastfeeding, but this was not statistically significant. For the risk period ' $4+$ months', we only considered eczema cases that started after 3 months and combined the exposure categories ' $4-6$ months' and ' $\geq 7$ months' into one category ' $\geq 4$ month' to avoid reverse causation. The results again show a tendency towards a lower risk of eczema developed between 4 and 12 months of life associated with breastfeeding, but was neither statistically significant (Table 3).

\section{Table 2}

Overall analysis*: 'Breastfeeding and incidence of eczema in the first year of life'

\begin{tabular}{|c|c|c|c|c|c|}
\hline \multirow[t]{2}{*}{ Breastfeeding } & \multirow[b]{2}{*}{$\mathbf{N}$} & \multirow[b]{2}{*}{$\mathrm{n}$} & \multirow[b]{2}{*}{ (\%) } & \multicolumn{2}{|c|}{ Eczema in the first year of life } \\
\hline & & & & OR $(95 \% \mathrm{Cl})$ & $\mathrm{aOR}^{\dagger}(95 \% \mathrm{Cl})$ \\
\hline Never & 358 & 79 & $(22 \%)$ & 1.0 (reference) & 1.0 (reference) \\
\hline $0-3$ months & 745 & 168 & $(23 \%)$ & $1.02(0.76-1.39)$ & $0.98(0.71-1.34)$ \\
\hline 4-6 months & 430 & 100 & $(23 \%)$ & $1.07(0.77-1.50)$ & $0.94(0.66-1.34)$ \\
\hline \multirow[t]{2}{*}{$\geq 7$ months } & 872 & 188 & $(22 \%)$ & $0.97(0.72-1.31)$ & $0.80(0.57-1.12)$ \\
\hline & & & $P_{\text {trend }}$ & 0.76 & 0.13 \\
\hline Total & 2405 & 535 & $(22 \%)$ & & \\
\hline
\end{tabular}

OR (unadjusted) Odds Ratio

aOR Adjusted Odds Ratio

$\mathrm{Cl}$ confidence interval

* $\quad$ All infants were included in the analysis

$+\quad$ Adjusted for: age of first introduction of solid foods, gender, recruitment group, maternal smoking during pregnancy, infant's exposure to Environmental Tobacco Smoke (ETS), maternal age, maternal education, parental allergic disease, number of siblings, presence of older allergic siblings 


\section{Table 3}

Period specific (4+ months) analysis ${ }^{*}$ : 'Breastfeeding and incidence of eczema between 4-12 months'

\begin{tabular}{|c|c|c|c|c|c|}
\hline \multirow[t]{2}{*}{ Breastfeeding } & \multirow[b]{2}{*}{$\mathbf{N}$} & \multirow[b]{2}{*}{$\mathbf{n}$} & \multirow[b]{2}{*}{ (\%) } & \multicolumn{2}{|c|}{ Eczema between 4-12 months } \\
\hline & & & & OR $(95 \% \mathrm{Cl})$ & $\mathrm{aOR}^{\dagger}(95 \% \mathrm{Cl})$ \\
\hline Never & 578 & 79 & $(14 \%)$ & 1.0 (reference) & 1.0 (reference) \\
\hline $0-3$ months & 1019 & 126 & $(12 \%)$ & $1.00(0.68-1.46)$ & $0.98(0.66-1.46)$ \\
\hline \multirow[t]{2}{*}{$\geq 4$ months } & 578 & 79 & $(14 \%)$ & $0.84(0.59-1.20)$ & $0.77(0.52-1.15)$ \\
\hline & & & $P_{\text {trend }}$ & 0.22 & 0.14 \\
\hline Total & 1891 & 246 & $(13 \%)$ & & \\
\hline
\end{tabular}

$\begin{array}{ll}\text { OR } & \text { (unadjusted) Odds Ratio } \\ \text { aOR } & \text { Adjusted Odds Ratio } \\ \mathrm{Cl} & \text { confidence interval } \\ * & \text { Incidence of eczema in risk period of 4-12 months i.e. excluding infants with onset of eczema after } \\ & \text { age } 3 \text { months } \\ & \text { Adjusted for: age of first introduction of solid foods, gender, recruitment group, maternal smoking } \\ & \text { during pregnancy, infant's exposure to Environmental Tobacco Smoke (ETS), maternal age, maternal } \\ & \text { education, parental allergic disease, number of siblings, presence of older allergic siblings }\end{array}$

Subsequently, the effect of starting breastfeeding on early development of eczema ('0-3 months'; $n=514$ ) was analyzed, namely those infants that were excluded in the risk-period (4+ months) specific analysis mentioned above. A slightly higher risk of early eczema was found between breastfed from birth on (ever breastfed) versus infants who were formula fed from birth on (never breastfed), but this was not statistically significant (early eczema in ever breastfed infants $(450 / 2047=22.0 \%)$ versus never breastfed $(64 / 358=17.9 \%)$; adjusted odds ratio [aOR] 1.30, 95\% confidence interval [CI] 0.96-1.77). Notably, the risk of infants whose mothers attempted breastfeeding but could not establish it (breastfeeding $<4$ weeks, $22 \%$ cases of eczema), did not essentially change from those who managed breastfeeding $>4$ weeks but ceased before age 4 months ( $23 \%$ cases of eczema). 


\section{DISCUSSION}

In the present study we found no association between breastfeeding and the development of eczema in the first year of life. We found a tendency towards a lower risk of eczema that started from age 4 months and, on the contrary, a tendency for a higher risk of early eczema, but both were not statistically significant. When comparing the overall analysis and the risk-period (4+ months) specific analysis, the results were not very different. Therefore we conclude that there was no substantial reverse causation. An advantage of our study is the relatively short time intervals between subsequent follow-up questionnaires, which makes the influence of recall bias less likely. Follow-up rates were high which limits the possibility of differential bias regarding baseline characteristics or outcomes. However, families with allergic complaints tend to be over-represented in studies on etiology of atopy. The difference between the participants and non-participants may be explained by self selection, because people with a positive family history of allergic disease tend to be more interested in participating in a study on health related topics. Also, participants in the KOALA study had more intention to breastfeed than non-participants (14). Relative risk associations are however not biased to our opinion, since relative risks are based upon proportions and not on absolute numbers.

Two other studies also found no relationship between breastfeeding and eczema $(16,17)$. Other observational studies and a meta analysis have found a protective effect between duration of breastfeeding and eczema $(8,18-23)$. Some studies even found breastfeeding to be a risk factor for the development of eczema $(3,4$, 6). For example, Bergmann et al showed that the prevalence of atopic eczema in the first seven years increased with $3 \%$ by each additional month of breastfeeding (4). However, they suggested that it could not be ruled out that their results were influenced by reverse causation. The idea that early atopic symptoms influence the duration of breastfeeding was recently demonstrated by Lowe et al (24). Reverse causation could be an explanation for the inconsistent results between different studies (4, 7-9). Also, reverse causation may be more likely to be evident in the relationship between exclusive breastfeeding and risk of developing eczema. Recently, Zutavern et al put forward that reverse causation is a relatively new problem because in older studies the public awareness of health promoting effects of breastfeeding was smaller (9). 
Two solutions have been proposed in the literature to avoid reverse causation. First, survival analysis (Cox regression) is a suitable method to consider only breastfeeding before the appearance of eczema (17). However, survival analysis requires the data on the exact onset of eczema in small time intervals, which many studies lack. Second, it can be avoided by excluding infants with onset of disease during lactation $(7,9,25)$. This is equivalent to a risk-period specific analysis confined to infants at risk (this avoiding overlap between exposure and disease outcome). Such an analysis has the additional advantage that it keeps track of infants with early symptoms (such as the infants with early eczema in our study).

In the present study, the results of such a risk-period specific analysis did not change substantially compared to the overall analysis. To our opinion, we have demonstrated that our main finding (breastfeeding does not influence the risk of eczema in the first year of life), is unlikely to be biased by reverse causation. In addition, we examined more specifically all infants with reported eczema in the first three months (i.e. those infants with early symptoms that were excluded in the risk-period (4+ months) specific analysis). Infants that were ever breastfed had a slightly increased risk (although not statistically significant) for eczema at the age of 3 months compared to completely formula fed infants (from birth). With regard to this finding, our analysis did not address both the duration of breastfeeding and the onset of eczema. To avoid reverse causation, the discrimination between starting breastfeeding versus formula feeding from birth is the only useful comparison. Namely, no overlap occurs between exposure immediately after birth and onset of disease. In other words, since the disease is not yet present immediately after birth, the choice of the feeding regiment immediately after birth cannot be biased by disease.

In conclusion, we found no strong evidence for a protective effect of breastfeeding and eczema in the first year of life. We believe that our results were strengthened by avoiding reverse causation as a potential bias. Controlling for reverse causation can be accomplished by risk-period specific analyses in which only exposure before the risk-period is taken into account. Our findings do not necessarily mean that reverse causation will be absent in other study populations where the presumed protective effect of breastfeeding is more widely advocated. Thus, in studies addressing the controversial relationship between breastfeeding 
duration and the development of allergic diseases, exploring reverse causation is a prerequisite to retrieve results with a minimum chance of bias.

\section{ACKNOWLEDGEMENTS}

We thank Frans Tan and Monique Mommers for their useful comments. 


\section{REFERENCES}

1. Kramer MS. Does breast feeding help protect against atopic disease? Biology, methodology, and a golden jubilee of controversy. J Pediatr 1988;112(2):181-90.

2. Saarinen UM, Kajosaari M. Breastfeeding as prophylaxis against atopic disease: prospective follow-up study until 17 years old. Lancet 1995;346(8982):1065-9.

3. Wetzig H, Schulz R, Diez U et al. Associations between duration of breast-feeding, sensitization to hens' eggs and eczema infantum in one and two year old children at high risk of atopy. Int J Hyg Environ Health 2000;203(1):17-21.

4. Bergmann RL, Diepgen TL, Kuss 0 et al. Breastfeeding duration is a risk factor for atopic eczema. Clinical and experimental allergy journal of the British Society for Allergy and Clinical Immunology 2002;32(2):205-9.

5. Sears MR, Greene JM, Willan AR et al. Long-term relation between breastfeeding and development of atopy and asthma in children and young adults: a longitudinal study. Lancet 2002;360(9337):901-7.

6. Purvis DJ, Thompson JM, Clark PM et al. Risk factors for atopic dermatitis in New Zealand children at 3.5 years of age. Br J Dermatol 2005;152(4):742-9.

7. Kull I, Almqvist C, Lilja G et al. Breast-feeding reduces the risk of asthma during the first 4 years of life. J Allergy Clin Immunol 2004;114(4):755-6o.

8. Laubereau B, Brockow I, Zirngibl A et al. Effect of breast-feeding on the development of atopic dermatitis during the first 3 years of life--results from the GINI-birth cohort study. J Pediatr 2004;144(5):602-7.

9. Zutavern A, Brockow I, Schaaf B et al. Timing of Solid Food Introduction in Relation to Atopic Dermatitis and Atopic Sensitization: Results From a Prospective Birth Cohort Study. Pediatrics 2006;117(2):401-411.

10. Wright AL, Holberg C), Taussig LM et al. Factors influencing the relation of infant feeding to asthma and recurrent wheeze in childhood. Thorax 2001;56(3):192-7.

11. Horwitz RI, Feinstein AR. The problem of «protopathic bias» in case-control studies. Am J Med 1980;68(2):255-8.

12. Isolauri E, Tahvanainen A, Peltola T et al. Breast-feeding of allergic infants. J Pediatr 1999;134(1):27-32.

13. Jarvinen KM, Suomalainen H. Development of cow's milk allergy in breast-fed infants. Clinical and experimental allergy journal of the British Society for Allergy and Clinical Immunology 2001;31(7):978-87.

14. Kummeling I, Thijs C, Penders J et al. Etiology of atopy in infancy: the KOALA Birth Cohort Study. Pediatr Allergy Immunol 2005;16(8):679-84. 


\section{CHAPTER 2}

15. Bastiaanssen JM, de Bie RA, Bastiaenen $\mathrm{CH}$ et al. Etiology and prognosis of pregnancyrelated pelvic girdle pain; design of a longitudinal study. BMC public health 2005;5(1).

16. Ludvigsson JF, Mostrom M, Ludvigsson J et al. Exclusive breastfeeding and risk of atopic dermatitis in some 8300 infants. Pediatr Allergy Immunol 2005;16(3):201-8.

17. Benn CS, Michaelsen KF. Does the effect of breast-feeding on atopic dermatitis depend on family history of allergy? J Pediatr 2005;147(1):128-9; author reply 129.

18. Kull I, Wickman M, Lilja G et al. Breast feeding and allergic diseases in infants-a prospective birth cohort study. Arch Dis Child 2002;87(6):478-81.

19. Kull I, Bohme M, Wahlgren CF et al. Breast-feeding reduces the risk for childhood eczema. J Allergy Clin Immunol 2005;116(3):657-61.

20. van Odijk J, Kull I, Borres MP et al. Breastfeeding and allergic disease: a multidisciplinary review of the literature (1966-2001) on the mode of early feeding in infancy and its impact on later atopic manifestations. Allergy 2003;58(9):833-43.

21. Gdalevich M, Mimouni D, David $M$ et al. Breast-feeding and the onset of atopic dermatitis in childhood: a systematic review and meta-analysis of prospective studies. J Am Acad Dermatol 2001;45(4):520-7.

22. Kerkhof M, Koopman LP, van Strien RT et al. Risk factors for atopic dermatitis in infants at high risk of allergy: the PIAMA study. Clin Exp Allergy 2003;33(10):1336-41.

23. Schoetzau A, Filipiak-Pittroff B, Franke $K$ et al. Effect of exclusive breast-feeding and early solid food avoidance on the incidence of atopic dermatitis in high-risk infants at 1 year of age. Pediatr Allergy Immunol 2002;13(4):234-42.

24. Lowe AJ, Carlin JB, Bennett CM et al. Atopic disease and breast-feeding-cause or consequence? J Allergy Clin Immunol 2006;117(3):682-7.

25. Wickman M, Kull I, Pershagen $\mathrm{G}$ et al. The BAMSE project: presentation of a prospective longitudinal birth cohort study. Pediatr Allergy Immunol 2002;13 Suppl 15:11-3. 
Breastfeeding duration and infant atopic manifestations, by maternal allergic status, in the first two years of life (KOALA Study)

Bianca EP Snijders

Carel Thijs

Pieter C Dagnelie

Foekje F Stelma

Monique Mommers

Ischa Kummeling

John Penders

Ronald van Ree

Piet A van den Brandt

Journal of Pediatrics 2007;151(4):347-351 


\section{ABSTRACT}

\section{Objective}

To investigate potential effect modification by maternal allergic status on the relation between breastfeeding duration and infant atopic manifestations in the first two years of life.

\section{Study design}

Data from 2705 infants of the KOALA Birth Cohort Study (The Netherlands) were analyzed. Data was collected by repeated questionnaires at 34 weeks of gestation, 3, 7, 12 and 24 months postpartum. Total and specific IgE measurements were done in venous blood collected during home visits at age 2 years. Relationships were analyzed using logistic regression analyses.

\section{Results}

Longer duration of breastfeeding was associated with a lower risk for eczema in infants of mothers without allergy or asthma ( $\left.p_{\text {trend }} 0.01\right)$ and slightly in mothers with allergy but no asthma ( $\left.\mathrm{p}_{\text {trend }} 0.14\right)$. For asthmatic mothers, there was no such association ( $p_{\text {trend }} 0.87$ ). Longer breastfeeding duration lowers the risk on recurrent wheeze independent of maternal allergy $\left(p_{\text {trend }}=0.02\right)$ or asthma status $\left(p_{\text {trend }}=0.06\right)$.

\section{Conclusion}

Our findings show that only the relationship between breastfeeding and infant eczema in the first two years of life may be modified by maternal allergic status. The protective effect of breastfeeding on recurrent wheeze may be the result of protection against respiratory infections. 


\section{INTRODUCTION}

The role of breastfeeding in allergic disease is still a matter of debate. The postulated protective effect of breastfeeding may act through several mechanisms. One possible mechanism is through the exclusion of potentially allergic components, like cow's milk or food products introduced in the infant's diet. Alternatively, breastfeeding provides the infant with immunomodulatory, anti-inflammatory, nutritional, or other components present in human breast milk.

Methodological flaws in study design have been proposed as an explanation for inconsistent results. Of special interest in the current literature, is the question whether the relationship between breastfeeding and allergic disease can be modified by maternal constitution. Previously, Wright et al showed higher IgE levels in breastfed versus never breastfed children, among children of mothers with high IgE levels (1). A Bavarian farmers' study found an increased risk for doctor-diagnosed asthma related to breastfeeding in children whose mothers had asthma themselves (2). Among children of asthmatic mothers, longer exclusive breastfeeding was found to be associated with a higher risk of asthma, but asthma was unrelated to feeding status for children without maternal asthma (3). In contrast, in an Australian study, exclusive breastfeeding was associated with a statistically significant lower risk of asthma which was independent of maternal asthma and the child's atopic status (4).

In the present study we examined whether maternal allergy or asthma status is an effect modifier in the relation between breastfeeding duration and the development of infant atopic manifestations (eczema, recurrent wheeze) in the first two years of life. Also, we studied the relations between breastfeeding duration and infants increased total IgE levels and allergic sensitization at age two, in mothers with and without increased total IgE levels or sensitization. 


\section{METHODS}

\section{Study population}

Study subjects are mother-infant pairs previously enrolled in the KOALA Birth Cohort Study during the years 2000-2002 (5). At 34 weeks of gestation, we recruited participants with diverse lifestyles (conventional and alternative). Pregnant women with a conventional lifestyle $(n=2343)$ were recruited from an ongoing prospective cohort study on Pregnancy-related Pelvic Girdle pain in the Netherlands. Additionally, pregnant women with an alternative lifestyle $(n=491)$ were recruited through several 'alternative' channels: organic food shops, anthroposophic doctors and midwives, Steiner Schools, and magazines. The study was approved by the ethics committee of Maastricht University and all parents signed written informed consent.

\section{Data collection}

During pregnancy and during the first two years of life, information on breastfeeding, other determinants and atopic manifestations was collected for all members of the cohort by repeated questionnaires at 34 weeks of gestation and at 3, 7, 12 and 24 months. Home visits at age 2 years started from September 2004 onwards in order to collect blood samples and for clinical examination of the infants by trained nurses, using UK Working Party (UK-WP) Criteria. All infants of participants $(n=2834)$ with a completed informed consent and the presence of the first questionnaire 34 weeks of gestation) were included. We excluded infants with congenital diseases known to be related to immune development, such as Down's syndrome and those with missing information on the main determinant breastfeeding.

\section{Breastfeeding exposure}

Breastfeeding was categorized into the following categories, according to the age at which breastfeeding was quitted: 'never breastfed' (reference category); '0-3 months'; '4-6 months'; ‘7-9 months' and '> 9 months'.

\section{Maternal allergic history}

In order to study effect modification by maternal allergy or asthma on the relationship between breastfeeding duration and infant eczema and recurrent wheeze, we defined 3 strata: (1) no maternal allergy or asthma, (2) maternal allergy, no asthma; defined as self reported doctor's diagnosed eczema, allergy for house dust mite/pets, or allergic rhino conjunctivitis (such as hayfever), (3) maternal 
asthma; defined as self reported doctor's diagnosed asthma, irrespective of other allergic diseases. Maternal increased total IgE levels and/or sensitization were both defined as present (yes/no).

\section{Infant atopic manifestations}

'Eczema (by questionnaires, adapted from ISAAC)': In the 7, 12 and 24 months postpartum questionnaires, parents were asked; 'has your child ever had an itchy rash that was coming and going in the past months'? If this question was answered affirmatively at least once, infants were defined as having developed eczema in the first two years of life. Cases of only diaper rash, rash around the eyes and/or scalp scaling were excluded.

'Atopic Dermatitis according to UK Working Party criteria': To specify eczema reported by parents as described above, we defined atopic dermatitis according to UK-WP criteria (6) for all infants who were visited at home at age 2 years. In this study, infants with a UK-WP probability score of atopic dermatitis (AD) > 0.9 were regarded as infants with 'probable presence of atopic dermatitis'.

'Recurrent wheezing in the first two years of life' was defined as reported presence of wheezing with at least 4 attacks between 0-7 months, mentioned in the 7 months postpartum questionnaire and/or between 7-12 months of life, mentioned in the 12 months postpartum questionnaire and/or between 13-24 months, mentioned in the 24 months postpartum questionnaire.

\section{Measurements and definitions of allergic sensitization (mother and infant)}

Maternal venous blood samples were obtained during home visits at 34-36 weeks of gestation. Infants' venous blood samples were obtained during home visits at 2 years post partum. Total IgE levels were analyzed as described earlier $(7,8)$. For values $<150 \mathrm{IU} / \mathrm{ml}$ a sandwich RIA was used (7), for values $>150 \mathrm{IU} / \mathrm{ml}$ a competitive RIA (8). All blood samples were analyzed for specific IgE against hen's eggs, cow's milk, peanuts, birch, grass pollen, cat, dog and house dust mite using RAST as described earlier (8). Calculation was performed by means of a standard curve that was obtained by RAST with a dilution series of a chimeric monoclonal IgE antibody against the major allergen Der $\mathrm{p} 2$ and Sepharose-coupled recombinant Der p 2 (9). The detection limits for total and specific IgE were $0.50 \mathrm{IU} / \mathrm{ml}$ and 0.10 $\mathrm{IU} / \mathrm{ml}$, respectively. High maternal total IgE was arbitrarily defined as total IgE level $>100 \mathrm{IU} / \mathrm{ml}$. High total IgE for infants was arbitrarily defined as total IgE level $>10 \mathrm{IU} / \mathrm{ml}$. Mother and infants were considered to be sensitized if specific serum 
IgE-levels were $>0.3 \mathrm{IU} / \mathrm{ml}$ against at least one of the tested food or inhalant allergens.

\section{Statistical analyses}

Relationships were analyzed using logistic regression, and results are presented as unadjusted odds ratios $(\mathrm{OR})$ and adjusted odds ratios $\left(\mathrm{OR}_{\mathrm{adj}}\right)$ with corresponding $95 \%$ confidence intervals $(95 \% \mathrm{Cl})$. All potential confounders were simultaneously included in the logistic regression model in order to adjust the analyses. Potential confounders were: the age at introduction of cow's milk products defined as: artificial formulas (including hypoallergenic formulas), (raw) milk, porridge, yoghurt and other dairy products categorized according to the age at first introduction as: '0-3 months', '4-6 months', '7-9 months', 'after age 9 months'; the age at introduction of other food products (like fruit mash), categorized according to the age at first introduction as: '0-3 months', '4-6' months', 'after age 7 months'. Other potential confounders were: gender of infant (boys, girls); recruitment group (conventional, alternative lifestyle); antibiotic medication (yes, no); maternal smoking during pregnancy (yes, no); infant's exposure to environmental tobacco smoke (ETS) (yes, no); maternal age at delivery; maternal education (primary school, preparatory vocational or lower general secondary education [low], vocational education, higher general secondary or pre-university education [middle], higher vocational or academic education [high]); presence of paternal allergic disease (yes, no); number of siblings (no siblings, one sibling, two or more siblings); and presence of older allergic siblings (no siblings, older allergic sibling(s), older non-allergic sibling(s)). In order to assess whether our results were prone to reverse causation (by introducing hypoallergenic formulas after the development of eczema) we explored the use of hypoallergenic formulas associated with atopic manifestations. For the test for trend, we repeated the logistic regression analyses with the categories of breastfeeding duration (coded as 1 to 5 ) as a continuous variable in the logistic regression analyses, again adjusting for all potential confounders. Effect modification by recruitment group was assessed by using the likelihood ratio test, comparing models with and without interaction terms.

\section{RESULTS}

Of the 2834 infants enrolled at birth, three infants were excluded because of 
Down's syndrome and 126 because of missing information on breastfeeding, leaving 2705 infants for the present study. The response rate of the questionnaire at age two years was 93\% $(n=2516)$. Home visits at age 2 years were made in 818 infants. Most infants were breastfed $(85 \%, n=2287)$. Mothers in the alternative recruitment group had a higher rate and a longer duration of breastfeeding compared to the conventional recruitment group (Table 1). Also, they showed more delay in the age at introduction of cow's milk products (Table 1). Other characteristics that differed between both groups were maternal age, maternal smoking during pregnancy, environmental tobacco smoking, maternal education, number of siblings, and antibiotic medication use (Table 1 ).

Table 1

Baseline characteristics in both recruitment groups

\begin{tabular}{|c|c|c|c|c|c|c|}
\hline & \multicolumn{2}{|c|}{$\begin{array}{l}\text { CONVENTIONAL } \\
\qquad(\mathrm{N}=\mathbf{2 2 2 9})\end{array}$} & \multicolumn{2}{|c|}{$\begin{array}{l}\text { ALTERNATIVE } \\
\qquad(\mathrm{N}=476)\end{array}$} & \multicolumn{2}{|c|}{$\begin{array}{c}\text { TOTAL } \\
(\mathrm{N}=\mathbf{2 7 0 5})\end{array}$} \\
\hline Never & 407 & $(18 \%)$ & 11 & $(2 \%)$ & 418 & $(16 \%)$ \\
\hline $0-3$ months & 913 & $(41 \%)$ & 64 & $(13 \%)$ & 977 & $(36 \%)$ \\
\hline 4-6 months & 357 & $(16 \%)$ & 71 & $(15 \%)$ & 428 & $(16 \%)$ \\
\hline 7-9 months & 285 & $(13 \%)$ & 115 & $(24 \%)$ & 400 & $(15 \%)$ \\
\hline$>9$ months & 267 & $(12 \%)$ & 215 & $(45 \%)$ & 482 & $(18 \%)$ \\
\hline \multicolumn{7}{|c|}{ Age at introduction of cow's milk products, $n$ (\%) } \\
\hline $0-3$ months & 1016 & $(46 \%)$ & 51 & $(11 \%)$ & 1067 & $(39 \%)$ \\
\hline 4-6 months & 615 & $(29 \%)$ & 137 & $(29 \%)$ & 788 & $(29 \%)$ \\
\hline 7-9 months & 459 & $(21 \%)$ & 242 & $(51 \%)$ & 701 & $(26 \%)$ \\
\hline$>9$ months & 46 & $(2 \%)$ & 28 & $(6 \%)$ & 74 & $(3 \%)$ \\
\hline Unknown & 57 & (3\%) & 18 & $(4 \%)$ & 75 & $(3 \%)$ \\
\hline
\end{tabular}

Use of hypoallergenic formulas, $n$ (\%)

Yes

$163|(7 \%) \quad| \quad 22|(5 \%) \quad| \quad 185 \mid(7 \%)$

Age at introduction of other foods products, $n$ (\%)

Age 3 months
4-6 months
$\geq 7$ months
Unknown

\begin{tabular}{r|l|r|l|r|l}
178 & $(8 \%)$ & 20 & $(4 \%)$ & 198 & $(7 \%)$ \\
1846 & $(83 \%)$ & 411 & $(86 \%)$ & 2257 & $(83 \%)$ \\
48 & $(2 \%)$ & 27 & $(6 \%)$ & 75 & $(3 \%)$ \\
157 & $(7 \%)$ & 18 & $(4 \%)$ & 175 & $(7 \%)$
\end{tabular}




\begin{tabular}{|c|c|c|c|c|c|c|}
\hline \multirow[b]{2}{*}{ Gender of infants, no of boys (\%) } & \multicolumn{2}{|c|}{$\begin{array}{c}\text { CONVENTIONAL } \\
(\mathrm{N}=\mathbf{2 2 2 9})\end{array}$} & \multicolumn{2}{|c|}{$\begin{array}{l}\text { ALTERNATIVE } \\
(\mathrm{N}=476)\end{array}$} & \multicolumn{2}{|c|}{$\begin{array}{c}\text { TOTAL } \\
(\mathrm{N}=\mathbf{2 7 0 5})\end{array}$} \\
\hline & 1133 & $(51 \%)$ & 240 & $(50 \%)$ & 1373 & $(51 \%)$ \\
\hline Maternal age in years, mean (sd) & 31 & $(4)$ & 34 & $(4)$ & 32 & (4) \\
\hline Maternal smoking during pregnancy, n (\%) & 189 & $(9 \%)$ & 3 & $(1 \%)$ & 192 & $(7 \%)$ \\
\hline Environmental tobacco smoking (ETS), $n$ (\%) & 110 & $(5 \%)$ & 2 & $(<1 \%)$ & 112 & $(4 \%)$ \\
\hline \multicolumn{7}{|l|}{ Maternal Education, $\mathrm{n}(\%)$} \\
\hline Low & 256 & $(12 \%)$ & 18 & $(4 \%)$ & 274 & $(10 \%)$ \\
\hline Middle & 857 & $(39 \%)$ & 83 & $(17 \%)$ & 940 & $(35 \%)$ \\
\hline High & 993 & $(45 \%)$ & 362 & $(76 \%)$ & 1355 & $(50 \%)$ \\
\hline Unknown & 123 & $(6 \%)$ & 13 & $(3 \%)$ & 136 & $(5 \%)$ \\
\hline \multicolumn{7}{|l|}{ Parental allergic disease, $n$ (\%) } \\
\hline Both parents non-allergic & 878 & (40\%) & 186 & $(40 \%)$ & 1064 & $(39 \%)$ \\
\hline Only father allergic & 460 & $(21 \%)$ & 110 & $(23 \%)$ & 570 & $(21 \%)$ \\
\hline Only mother allergic & 496 & $(22 \%)$ & 105 & $(22 \%)$ & 601 & $(22 \%)$ \\
\hline Both parents allergic & 288 & $(13 \%)$ & 69 & $(15 \%)$ & 357 & $(13 \%)$ \\
\hline Unknown & 107 & $(5 \%)$ & 6 & $(1 \%)$ & 113 & $(4 \%)$ \\
\hline \multicolumn{7}{|l|}{ Number of siblings, $n(\%)$} \\
\hline o siblings & 1804 & $(81 \%)$ & 369 & $(78 \%)$ & 2173 & $(80 \%)$ \\
\hline 1 sibling & 286 & $(13 \%)$ & 81 & $(17 \%)$ & 367 & $(14 \%)$ \\
\hline 2 or more siblings & 42 & $(2 \%)$ & 22 & $(5 \%)$ & 64 & $(2 \%)$ \\
\hline Unknown & 97 & $(4 \%)$ & 4 & $(1 \%)$ & 101 & $(4 \%)$ \\
\hline \multicolumn{7}{|l|}{ Presence of older allergic siblings, $n$ (\%) } \\
\hline No siblings & 1804 & $(81 \%)$ & 369 & $(78 \%)$ & 2173 & $(80 \%)$ \\
\hline Older non-allergic sibling(s) & 249 & $(13 \%)$ & 71 & $(15 \%)$ & 320 & $(12 \%)$ \\
\hline Older allergic sibling(s) & 85 & $(2 \%)$ & 35 & $(7 \%)$ & 120 & $(4 \%)$ \\
\hline Unknown & 91 & $(4 \%)$ & 1 & $(<1 \%)$ & 92 & $(3 \%)$ \\
\hline \multicolumn{7}{|l|}{ Infant's use of antibiotics, n (\%) } \\
\hline Yes & 430 & $(19 \%)$ & 56 & $(12 \%)$ & 486 & $(18 \%)$ \\
\hline Unknown & 187 & $(8 \%)$ & 15 & $(3 \%)$ & 202 & $(8 \%)$ \\
\hline
\end{tabular}

* Numbers may not add up total, because of missing values 
Infants receiving hypoallergenic formulas at any time between birth and age 3 months $(n=185)$ showed a higher risk of eczema in the first two years of life than infants given non-hypoallergenic formula feeding (unadjusted OR: 1.81; $95 \% \mathrm{Cl}$ : 1.31-2.49) even when adjusting for all potential confounders (adjusted OR: 1.97; $95 \% \mathrm{Cl}: 1.30-3.00$ ). Since these results may be explained by reverse causation (i.e. hypoallergenic formulas were introduced after the development of eczema), we excluded the participants who introduced hypoallergenic formulas (o-3 months) from all subsequent analyses.

Overall, longer breastfeeding duration showed a statistically significant trend towards a lower risk of eczema ( $p$ for trend=0.03, adjusted for confounders). Longer duration of breastfeeding was associated with a statistically significant lower risk for eczema in infants of mothers without allergy or asthma ( $p$ for trend 0.01, Table 2). In mothers with allergy but no asthma the results tended in the same direction, but were not statistically significant ( $p$ for trend 0.14 , Table 2). For asthmatic mothers, there was no (inverse) association between breastfeeding duration and infant eczema ( $p$ for trend 0.87 , Table 2). There was no association between breastfeeding duration and atopic dermatitis according to UK-WP Criteria ( $n=866$; number of cases: 117 ) neither in the overall analysis, nor in the three different maternal strata (results not shown, $\mathrm{p}$ for trend $>0.05$ ).

Longer breastfeeding duration was associated with a lower risk for recurrent wheeze in infants of mothers with no allergy or asthma ( $p$ for trend 0.02), with allergy but no asthma ( $p$ for trend o.02), and with asthma ( $p$ for trend 0.06). The breastfeeding category 7-9 months showed the lowest risk of infant recurrent wheeze in all groups i.e. OR 0.11, 95\% $\mathrm{Cl}$ 0.02-0.70 (Table 2). 


\section{CHAPTER 3}

\section{Table 2}

Associations between breastfeeding duration and the development of infant eczema and recurrent wheeze during the first two years of life according to presence of allergy and/or asthma in the mother

\begin{tabular}{|c|c|c|c|c|c|}
\hline \multirow{2}{*}{\multicolumn{2}{|c|}{ Maternal status }} & \multicolumn{4}{|c|}{ INFANT ECZEMA } \\
\hline & & $\mathbf{N}$ & n (\%) & OR $(95 \% \mathrm{Cl})$ & ORadj $(95 \% \mathrm{Cl})^{*}$ \\
\hline \multicolumn{6}{|c|}{ No allergy, no asthma } \\
\hline \multirow[t]{6}{*}{$B F$} & Never & 231 & $61(26 \%)$ & 1.00 & 1.00 \\
\hline & $0-3$ months & 494 & $132(27 \%)$ & $1.02(0.71-1.45)$ & $0.90(0.61-1.31)$ \\
\hline & 4-6 months & 259 & $70(27 \%)$ & $1.03(0.69-1.54)$ & $0.71(0.42-1.20)$ \\
\hline & 7-9 months & 245 & $74(30 \%)$ & $1.21(0.81-1.80)$ & $0.69(0.40-1.19)$ \\
\hline & $>9$ months & 309 & $75(24 \%)$ & $0.89(0.60-1.32)$ & $0.51(0.29-0.89)$ \\
\hline & \multicolumn{2}{|c|}{$P_{\text {fortrend }}$} & & 0.83 & 0.01 \\
\hline \multicolumn{6}{|c|}{ Maternal allergy, no asthma } \\
\hline \multirow[t]{6}{*}{$\mathrm{BF}$} & Never & 87 & $27(31 \%)$ & 1.00 & 1.00 \\
\hline & $0-3$ months & 215 & $71(33 \%)$ & $1.10(0.64-1.87)$ & $0.90(0.52-1.57)$ \\
\hline & 4-6 months & 111 & $43(39 \%)$ & $1.41(0.78-2.54)$ & $0.86(0.43-1.71)$ \\
\hline & 7-9 months & 114 & $42(37 \%)$ & $1.30(0.72-2.34)$ & $0.68(0.34-1.38)$ \\
\hline & $>9$ months & 125 & $46(37 \%)$ & $1.29(0.72-2.32)$ & $0.63(0.31-1.29)$ \\
\hline & \multicolumn{2}{|c|}{$P_{\text {for trend }}$} & & 0.28 & 0.14 \\
\hline \multicolumn{6}{|c|}{ Maternal asthma } \\
\hline \multirow[t]{6}{*}{ BF } & Never & 27 & $7(26 \%)$ & 1.00 & 1.00 \\
\hline & $0-3$ months & 75 & $28(37 \%)$ & $1.70(0.64-4.53)$ & $1.39(0.51-3.78)$ \\
\hline & 4-6 months & 36 & $15(42 \%)$ & $2.04(0.69-6.05)$ & $1.40(0.44-4.42)$ \\
\hline & 7-9 months & 37 & $12(32 \%)$ & $1.37(0.46-4.13)$ & $0.70(0.22-2.27)$ \\
\hline & $>9$ months & 42 & $22(52 \%)$ & $3.14(1.10-9.00)$ & $1.67(0.53-5.21)$ \\
\hline & \multicolumn{2}{|c|}{$P_{\text {for trend }}$} & & 0.08 & 0.87 \\
\hline
\end{tabular}

may not add up to total numbers because of missing values

BF breastfeeding

OR unadjusted Odds Ratio

ORadj adjusted Odds Ratio 


\begin{tabular}{|c|c|c|c|}
\hline \multicolumn{4}{|c|}{ INFANT RECURRENT WHEEZE } \\
\hline $\mathbf{N}$ & n (\%) & $\mathrm{OR}(95 \% \mathrm{Cl})$ & $0 \operatorname{Radj}(95 \% \mathrm{Cl})^{\star}$ \\
\hline 167 & $25(15 \%)$ & 1.00 & 1.00 \\
\hline 353 & $55(16 \%)$ & $1.05(0.63-1.75)$ & $1.11(0.62-2.00)$ \\
\hline 198 & $24(12 \%)$ & $0.78(0.43-1.43)$ & $0.84(0.36-1.95)$ \\
\hline 194 & $11(6 \%)$ & $0.34(0.16-0.72)$ & $0.37(0.14-1.00)$ \\
\hline \multirow[t]{2}{*}{247} & $17(7 \%)$ & $0.42(0.22-0.80)$ & $0.43(0.16-1.11)$ \\
\hline & & 0.00 & 0.02 \\
\hline 67 & $15(22 \%)$ & 1.00 & 1.00 \\
\hline 139 & $22(16 \%)$ & $0.65(0.31-1.36)$ & $0.56(0.25-1.23)$ \\
\hline 84 & $13(16 \%)$ & $0.63(0.28-1.45)$ & $0.44(0.16-1.26)$ \\
\hline 89 & $6(7 \%)$ & $0.25(0.09-0.69)$ & $0.18(0.05-0.61)$ \\
\hline \multirow[t]{2}{*}{101} & $10(10 \%)$ & $0.38(0.16-0.91)$ & $0.32(0.10-1.00)$ \\
\hline & & 0.01 & 0.02 \\
\hline 16 & $5(31 \%)$ & 1.00 & 1.00 \\
\hline 47 & $13(28 \%)$ & $0.84(0.24-2.89)$ & $0.40(0.10-1.51)$ \\
\hline 24 & $7(29 \%)$ & $0.91(0.23-3.58)$ & $0.48(0.10-2.32)$ \\
\hline 24 & $3(13 \%)$ & $0.31(0.06-1.57)$ & $0.11(0.02-0.70)$ \\
\hline \multirow[t]{2}{*}{35} & $6(17 \%)$ & $0.46(0.12-1.80)$ & $0.22(0.04-1.09)$ \\
\hline & & 0.01 & 0.06 \\
\hline
\end{tabular}

Based on logistic regression analysis adjusted for: the age at introduction of cow's milk products, the age at introduction other food products, gender of infant, recruitment group, infant's use of antibiotics, maternal smoking during pregnancy, infant's exposure to environmental tobacco smoke (ETS), maternal age at delivery, maternal education, presence of paternal allergic disease, number of siblings and presence of older allergic siblings. 
Duration of breastfeeding did not influence the risk of high total IgE levels, either in infants of mothers who had themselves increased total IgE levels, nor in mothers with normal IgE levels (Table 3). Also, we found no association between breastfeeding duration and infant sensitization in infants of mothers with or without sensitization (Table 3).

\section{Table 3}

Associations between breastfeeding duration and infant increased total IgE and sensitization at age 2 years, according to presence of increased total IgE / sensitization in the mother

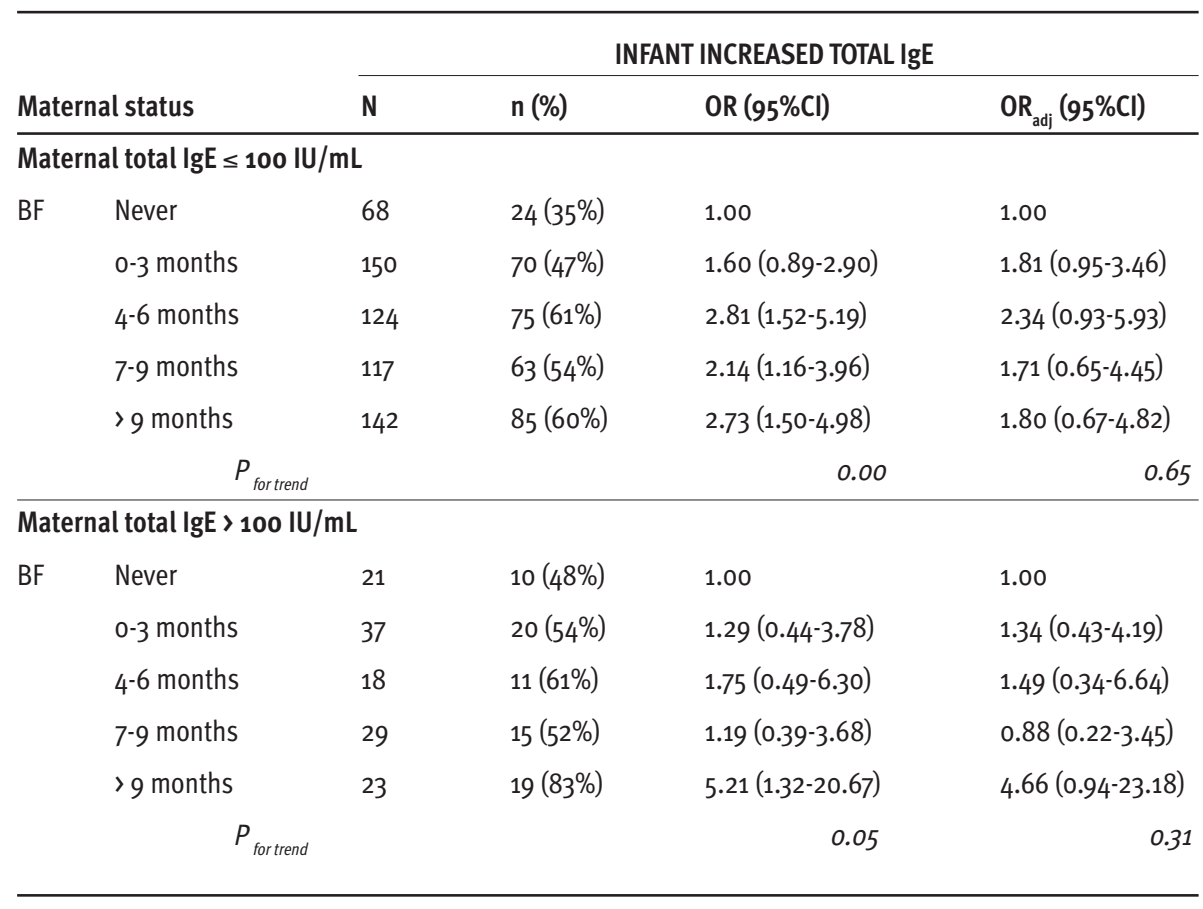

may not add up to total numbers because of missing values

BF breastfeeding

OR unadjusted Odds Ratio

$\mathrm{OR}_{\text {adj }} \quad$ adjusted Odds Ratio 
INFANT SENSITIZATION

\begin{tabular}{|c|c|c|c|c|}
\hline & \\
\hline & $\mathbf{N}$ & n (\%) & OR $(95 \% \mathrm{Cl})$ & $0 \mathrm{R}_{\mathrm{adj}}(95 \% \mathrm{Cl})$ \\
\hline \multicolumn{5}{|c|}{ No maternal sensitization } \\
\hline Never & 52 & $11(21 \%)$ & 1.00 & 1.00 \\
\hline $0-3$ months & 97 & $23(24 \%)$ & $1.35(0.56-3.25)$ & $1.35(0.53-3.43)$ \\
\hline 4-6 months & 81 & $26(32 \%)$ & $1.52(0.60-3.82)$ & $2.03(0.60-6.88)$ \\
\hline 7-9 months & 74 & $17(23 \%)$ & $1.80(0.74-4.39)$ & $2.72(0.80-9.25)$ \\
\hline$>9$ months & 91 & $22(24 \%)$ & $0.98(0.39-2.48)$ & $1.59(0.45-5.66)$ \\
\hline \multicolumn{2}{|c|}{$P_{\text {for trend }}$} & & 1.00 & 0.80 \\
\hline \multicolumn{5}{|c|}{ Maternal sensitization } \\
\hline Never & 35 & $9(26 \%)$ & 1.00 & 1.00 \\
\hline $0-3$ months & 88 & $28(32 \%)$ & $1.16(0.51-2.61)$ & $1.35(0.57-3.18)$ \\
\hline 4-6 months & 61 & $21(34 \%)$ & $1.76(0.78-3.97)$ & $2.86(0.91-8.92)$ \\
\hline 7-9 months & 73 & $28(38 \%)$ & $1.11(0.47-2.62)$ & $1.91(0.58-6.25)$ \\
\hline$>9$ months & 71 & $18(25 \%)$ & $1.19(0.52-2.70)$ & $2.39(0.72-7.96)$ \\
\hline \multicolumn{2}{|c|}{$P_{\text {for trend }}$} & & 0.85 & 0.50 \\
\hline
\end{tabular}

Based on logistic regression analysis adjusted for: the age at introduction of cow's milk products, the age at introduction other food products, gender of infant, recruitment group, infant's use of antibiotics, maternal smoking during pregnancy, infant's exposure to environmental tobacco smoke (ETS), maternal age at delivery, maternal education, presence of paternal allergic disease, number of siblings and presence of older allergic siblings. 
The differences between the odds ratios of unadjusted and adjusted analyses (Table 2) were the result of strong confounding effects of a positive paternal history of allergic disease, the age at introduction of cow's milk and other food products and infant use of antibiotics.

\section{DISCUSSION}

In this study, we found that longer duration of breastfeeding was associated with a decreased risk for recurrent wheeze in the first two years of life, regardless of the allergic history of the mother. Moreover, longer duration of breastfeeding was associated with a decreased risk of eczema (by questionnaire) in infants of mothers without allergy or asthma. If atopic dermatitis according to UK-WP Criteria, increased total IgE levels or sensitization, were taken as outcomes, no associations with breastfeeding duration were found.

Overall, our results for eczema provide evidence for a protective effect of breastfeeding. We found a protective effect of breastfeeding duration and eczema in the first two years of life in mothers without allergy or asthma, that was less clear in mothers with 'allergy but no asthma' and absent in mothers with 'maternal asthma'.

These findings imply effect modification by maternal allergic status for the relationship between breastfeeding and infant eczema. Nevertheless, these results need to be interpreted with caution because only mothers without allergy or asthma who breastfed for $>9$ months showed a statistically significant lower risk for eczema in the first two years of life. In addition, the different results in the 3 maternal strata may be explained by different reporting behaviour on symptoms of infant eczema between mothers with or without allergy and/or asthma.

Infants' eczema and sensitization were considered as separate outcome parameters instead of atopic eczema because sensitized infants do not necessarily show symptoms of eczema or vice versa (10). Consequently, we use the term eczema instead of atopic eczema. On the other hand, we use the term 'atopic dermatitis' for infants fulfilling the UK-WP criteria according to the criteria of Williams et al (6). The associations between breastfeeding and eczema could 
not be confirmed by our results on atopic dermatitis according to UK-WP Criteria. We speculate that breastfeeding is only associated with a milder eczematous condition which has already disappeared at the time of the home-visit. Another explanation for these discrepant findings is that the UK-WP criteria included specific predilection sites of atopic dermatitis (flexural involvement) (6), whereas the questionnaire data were based on the presence of an itchy rash anywhere (except diaper rash, rash around eyes and scalp scaling), and thus may include non-atopic eczema.

Wright et al (3) found an increased risk for asthma and wheeze in breastfed versus never breastfed children whose mothers had asthma themselves. Interestingly, the same authors also reported higher IgE levels in breastfed versus never breastfed children, among children of mothers with high IgE levels (1). In the present study, we found no effect of breastfeeding on high total IgE levels in infants of mothers with or without high total IgE levels. Hence our results provide no evidence that maternal total IgE levels modifies the relation between breastfeeding and infants' increased total IgE levels. Also, we found no effect of breastfeeding on sensitization in the infants of both mothers with and without sensitization, suggesting no effect modification by maternal sensitization. We conclude that maternal atopic status is not a major effect modifier of the effect of breastfeeding on infants' atopic manifestations. However, it should be noted that total and specific IgE levels are only weakly associated with atopic eczema and wheeze (10). Allergic sensitization may not be a prerequisite for childhood eczema (11). An Australian study also showed no statistical interaction between breastfeeding and maternal asthma status for the risk of asthma in childhood (4).

Our results indicate that longer breastfeeding duration protects against recurrent wheeze irrespective of maternal allergic status. Wright et al (12) followed infants during regular visits to a health maintenance organization. In the first 4 months of life, any breastfeeding was associated with a decreased incidence of wheezing illnesses. Another study showed that breastfeeding $\geq 6$ months was slightly protective against transient wheezing, whereas it was a moderate risk factor for late onset wheezing (13). Wheezing in young children may represent a heterogeneous group of conditions (14). It is a relatively common symptom in infancy and not all wheezing will necessarily become asthma in later life. We propose that our 
findings on recurrent wheeze actually reflect that breastfeeding protects against respiratory infections in early childhood. Indeed, infections have been found to be related with wheezing symptoms. For instance, Lemanske et al (15) shows that in the first year of life, in $78 \%$ a virus could be found during a wheezing episode in severe wheezers. During a wheezing episode of mild wheezers, this percentage was still $63 \%$. Previously, Chantry et al (16) found that full breastfeeding for $\geq 6$ months provided more protection against respiratory tract infection than full breastfeeding for $>4$ but $<6$ months.

There are several reasons why effect modification by maternal allergic status is important to address. First, it has been stated that a lack of stratification by maternal asthma and allergic predisposition in the child may have obscured how the relationship between breastfeeding and atopic manifestations changes with the child's age and atopic status (17). Second, the milk composition between allergic and non-allergic mothers may differ in such a way that it affects atopic manifestation in the child (3). Not only cytokines, but also differences in long chain polyunsaturated fatty acids levels may differ between atopic and non-atopic mothers $(18,19,20)$.

Taken together, we demonstrated that only the relationship between breastfeeding and infant eczema in the first two years of life may be modified by maternal allergic status since a protective effect of breastfeeding duration on eczema seemed mainly true for mothers without allergy or asthma, after adjustment for confounders including the age at introduction of cow's milk or other food products. The protective effect of breastfeeding against recurrent wheeze was irrespective of maternal allergic status and we speculate that these results may reflect protection against respiratory illness. 


\section{REFERENCES}

1. Wright AL, Sherrill D, Holberg CJ, Halonen M, Martinez FD. Breast-feeding, maternal IgE, and total serum IgE in childhood. J Allergy Clin Immunol 1999; 104:589-94.

2. Oberle D, Von Kries R, Von Mutius E. Asthma and breast feeding. Thorax 2001;56:896.

3. Wright AL, Holberg C), Taussig LM, Martinez F. Material asthma status alters relation of infant feeding to asthma childhood. Adv Exp Med Biol 2000; 478:131-7.

4. Oddy WH, Peat JK, de Klerk NH. Maternal asthma, infant feeding, and the risk of asthma in childhood. Journal of allergy and clinical immunology 2002; 110:65-7.

5. Kummeling I, Thijs C, Penders J, Snijders BE, Stelma F, Reimerink J, et al. Etiology of atopy in infancy: the KOALA Birth Cohort Study. Pediatr Allergy Immunol 2005; 16:679-84.

6. Williams HC, Burney PG, Hay RJ, Archer CB, Shipley MJ, Hunter J, et al. The U.K. Working Party's Diagnostic Criteria for Atopic Dermatitis. I. Derivation of a minimum set of discriminators for atopic dermatitis. Brit J Dermatol 1994; 131:383-96.

7. Stallman PJ, Aalberse RC. Estimation of basophil-bound IgE by quantitative immunofluorescence microscopy. Int Arch Allergy Appl Immunol 1977; 54:9-18.

8. Aalberse RC, Koshte V, Clemens JG. Immunoglobulin E antibodies that crossreact with vegetable foods, pollen, and Hymenoptera venom. J Allergy Clin Immunol 1981; 68:35664 .

9. Schuurman J, Perdok GJ, Lourens TE, Parren PW, Chapman MD, Aalberse RC. Production of a mouse/human chimeric IgE monoclonal antibody to the house dust mite allergen Der $\mathrm{p}$ 2 and its use for the absolute quantification of allergen-specific IgE. J Allergy Clin Immunol 1997; 99:545-50.

10. Kusel MM, Holt PG, de Klerk N, Sly PD. Support for 2 variants of eczema. J Allergy Clin Immunol 2005; 116:1067-72.

11. Williams $\mathrm{H}$, Flohr C. How epidemiology has challenged 3 prevailing concepts about atopic dermatitis. J Allergy Clin Immunol 2006; 118:209-13.

12. Wright AL, Holberg CJ, Martinez FD, Morgan WJ, Taussig LM. Breast feeding and lower respiratory tract illness in the first year of life. Group Health Medical Associates. BMJ 1989; 299:946-9.

13. Rusconi F, Galassi C, Corbo GM, Forastiere F, Biggeri A, Ciccone G, et al. Risk factors for early, persistent, and late-onset wheezing in young children. SIDRIA Collaborative Group. Am J Respir Crit Care Med 1999; 160:1617-22.

14. Henderson J, North K, Griffiths M, Harvey I, Golding J. Pertussis vaccination and wheezing illnesses in young children: prospective cohort study. The Longitudinal Study of Pregnancy and Childhood Team. BMJ 1999; 318:1173-6. 


\section{CHAPTER 3}

15. Lemanske RF, Jackson DJ, Gangnon RE, Evans MD, Li Z, Shult PA, et al. Rhinovirus illnesses during infancy predict subsequent childhood wheezing. J Allergy Clin Immunol 2005; 116:571-7.

16. Chantry CJ, Howard CR, Auinger P. Full breastfeeding duration and associated decrease in respiratory tract infection in US children. Pediatrics 2006; 117:425-32.

17. Wright AL, Holberg C), Taussig LM, Martinez FD. Factors influencing the relation of infant feeding to asthma and recurrent wheeze in childhood. Thorax 2001; 56:192-7.

18. Bottcher MF, Jenmalm MC, Garofalo RP, Bjorksten B. Cytokines in breast milk from allergic and nonallergic mothers. Pediatric Res 2000; 47:157-62.

19. Thijs C, Houwelingen A, Poorterman I, Mordant A, van den Brandt PA. Essential fatty acids in breast milk of atopic mothers: comparison with non-atopic mothers, and effect of borage oil supplementation. Eur J Clin Nutr 2000; 54:234-8.

20. Duchen K, Yu G, Bjorksten B. Atopic sensitization during the first year of life in relation to long chain polyunsaturated fatty acid levels in human milk. Pediatr Res 1998; 44:478-84. 
Age at first introduction of cow's milk products and other food products in relation to infant atopic manifestations in the first two years of life, The KOALA Birth Cohort Study

Bianca EP Snijders

Carel Thijs

Ronald van Ree

Piet A van den Brandt

Pediatrics (pending revisions) 


\begin{abstract}

\section{Background}

Scientific evidence is scarce about timing of solid food introduction and its association with the development of atopy. We aimed to evaluate any associations between the introduction of cow's milk products / other solid food products and infant atopic manifestations in the second year of life, taking into account reverse causation.
\end{abstract}

\title{
Methods
}

Data from 2558 infants of an ongoing prospective birth cohort study in the Netherlands were analyzed. Data on the main determinants (introduction of cow's milk products and other food products), outcomes (eczema, Atopic Dermatitis (UK Working Party Criteria), recurrent wheeze, any sensitization, sensitization against respectively: cow's milk, henn's egg, peanut and at least 1 inhalent allergen) and confounders were collected by repeated questionnaires on 34 weeks of gestation, 3, 7, 12 and 24 months postpartum. Information on sensitization was gathered by venous blood collections performed during home visits at age 2 . Analyses were done by multiple logistic regression analyses.

\section{Results}

More delay in introduction of cow's milk products was associated with a higher risk of eczema ( $p$ trend o.01). In addition, a delayed introduction of other food products was associated with an increased risk of atopy development at the age of two years (eczema ( $p$ trend 0.02), atopic dermatitis by UK-WP ( $p$ trend 0.00 ), recurrent wheeze ( $p$ trend 0.01 ), any sensitization ( $p$ trend 0.01 ) and sensitization against at least 1 inhalant allergen ( $p$ trend 0.00 )). Exclusion of infants with early symptoms of eczema and recurrent wheeze (in order to avoid reverse causation) did not essentially change our results.

\section{Discussion}

Delaying the introduction of cow's milk or other food products may not be favourable in preventing the development of atopy. 


\section{INTRODUCTION}

The prevalence of atopic manifestations has increased worldwide, especially in children (1). Symptoms are most common in Western countries i.e. about one third of the children in western societies show symptoms (2). Possible approaches to allergy prevention may include a wide variety of measures including: maternal dietary restriction during pregnancy, breastfeeding, dietary restrictions while breastfeeding, the use of hypoallergenic formulas, and delays in the introduction of certain foods into the infant's diet (3). Among these possible approaches, delaying the introduction of solid foods into the infant's diet is one of the most commonly recommended (4). The age when solid foods are introduced to infants has varied greatly during the last century (5). In 2001, the World Health Organization (WHO) issued a revised global recommendation that mothers should exclusively breastfeed until 6 months of age (6). The American Academy of Pediatrics suggest that solids should be delayed until 6 months of age, but cow's milk to 1 year, egg to 2 years, and peanuts, tree nuts and fish to 3 years (7). It is not surprising that these guidelines differ in emphasis as they are based on limited evidence (8).

Since most studies on dietary habits and atopy development have mainly focused on the duration of breastfeeding, scientific evidence about timing of solid food introduction is scarce and conflicting. Of interest is a study of Zutavern et al. showing an increased risk of eczema in relation to late introduction to egg and milk (9). This study challenges the widely held belief that delayed introduction of solids reduces the risk of allergy. Recently, Tarini et al. conducted a systematic review of the relationship between early introduction of solid foods to infants and the development of allergic disease (5). Thirteen studies that met the inclusion criteria were critically evaluated, concluding that the available evidence suggest that early solid feeding may increase the risk of eczema but there is only little data supporting an association between early solid feeding and other allergic conditions (5).

Previously we have reported on the relationship between breastfeeding duration and infant eczema in which we also explored the possible influence of reverse causation (10). In this large prospective Birth Cohort Study we had data available on the age of first introduction of cow's milk and other food products. Since only a 


\section{CHAPTER 4}

few studies have added new evidence in this conflicting research area, we aimed to establish any associations between the timing of the introduction of cow's milk products/other (solid) food products and infant atopic manifestations in first two years of life. 


\section{METHODS}

\section{Study population}

Study subjects are mother-infant pairs previously enrolled in the ongoing KOALA Birth Cohort Study, that was mainly set up to study the etiology of allergic diseases (11). At 34 weeks of gestation, we recruited participants with diverse lifestyles (conventional and alternative). Pregnant women with a conventional lifestyle ( $n=2343$ ) were recruited from an ongoing prospective cohort study on Pregnancyrelated Pelvic Girdle pain in the Netherlands. Additionally, pregnant women with an alternative lifestyle $(n=491)$ were recruited through several 'alternative' channels: organic food shops, anthroposophic doctors and midwifes, Steiner Schools, and magazines. The alternative group had more intention to breastfeed (93\%) and were less likely to smoke during pregnancy (11). The study was approved by the medical ethics committee of the Maastricht University.

\section{Data collection}

During pregnancy and during the first two years postpartum, information on infant feeding patterns (age of first introduction of cow's milk products or other food products and /or breastfeeding), other determinants and allergic outcome were collected for all members of the cohort by repeated questionnaires at 34 weeks of gestation and at 3, 7, 12 and 24 months. All infant's of participants $(n=2834)$ with a completed informed consent and the presence of the first questionnaire (34 weeks of gestation) were included. We excluded infants with Down's syndrome and those with missing information on the main determinants: the introduction of cow's milk products and/or other food products.

\section{Exposures}

The age of introduction of cow's milk products was defined as: artificial formulas (including hypoallergenic formulas), (raw / pasteurized) milk, porridge, dairy products, yoghurts and categorized as the age of first introduction: '0-3 months', '4-6 months', '7-9 months', 'after age 9 months'. The age of introduction other food products (like fruit mash) was categorized as the age of first introduction as follows: 'age 3 months', '4-6' months', 'after age 7 months'.

Adjustments were made for the following potential confounders: duration of breastfeeding (never, '0-3 months', '4-6 months', '7-9 months, > 9 months'), gender 
of infant (boys, girls), recruitment group (conventional, alternative lifestyle), maternal smoking during pregnancy (yes, no), infant's exposure to ETS (environmental tobacco smoke) (yes, no), maternal age at delivery (in years), maternal education (primary school, preparatory vocational or lower general secondary education (low), vocational education, higher general secondary or pre-university education (middle), higher vocational or academic education (high)), presence of parental allergic disease (both parents non-allergic, only father allergic, only mother allergic, both parents allergic), siblings atopic history i.e. parental reported doctor's diagnosed food allergy, eczema, hay fever, asthma, pet and/or house dust mite allergy (no siblings; $\geq 1$ siblings, all none-atopic; or $\geq 1$ siblings, at least 1 atopic).

\section{Infant's outcomes (atopic manifestations)}

'Eczema (by parental questionnaires)': In the 7, 12 and 24 months postpartum questionnaires, parents were asked; 'has your child ever had an itchy rash that was coming and going in the past months'? If this question was answered affirmatively, infants were defined as having developed eczema in the first two years of life. Cases of only diaper rash, rash around the eyes and/or scalp scaling were excluded.

'Atopic dermatitis by UK Working Party criteria': To specify eczema reported by parents as described above, we defined atopic dermatitis according to UK Working Party criteria (20) for all infants who were visited at home at age 2 years. The probability of the presence of atopic dermatitis was derived from the presence of four clinical symptoms: 1 ) presence of itchy rash (PIR, coded as $0=$ absent, $1=$ present), 2) history of flexural dermatitis (HFD, $o=$ absent, $1=$ present), 3) visible flexural dermatitis (VFD, $0=$ absent, $1=$ present), and 4 ) onset before age of 2 years $(\mathrm{OB} 2, \mathrm{o}=$ absent, $1=$ present). The UK-WP probability score of atopic dermatitis $(A D)$ is then computed as: probability $A D=$ odds $(A D) /[$ odds $(A D)+1]$; where odds $(\mathrm{AD})=\exp [-4.36+1.84(\mathrm{HFD})+3.46(\mathrm{OB} 2)+2.09(\mathrm{VFD})+1.71(\mathrm{PIR})](20)$. In this study, infants with a UK-WP probability score of atopic dermatitis $(A D)>0.9$ were regarded as infants with 'probable presence of atopic dermatitis'.

'Recurrent wheezing in the second year of life' was defined as reported presence of wheezing with at least 4 attacks between 0-7 months, mentioned in the 7 months 
postpartum questionnaire and/or between 7-12 months of life, mentioned in the 12 months postpartum questionnaire and/or between 13-24 months, mentioned in the 24 months postpartum questionnaire.

\section{Measurements and definitions of infant allergic sensitization}

Infant's venous blood samples were obtained during a home visit at 2 years post partum. All blood samples were analyzed for specific IgE against hen's eggs, cow's milk, peanuts, birch, grass pollen, cat, dog and house dust mite using Radio Allergen Sorbent Test as described earlier (12). The detection limit for specific IgE was $0.10 \mathrm{IU} / \mathrm{ml}$. Any sensitization was regarded as positive if specific serum IgElevels were $>0.3 \mathrm{IU} / \mathrm{ml}$ against one or more of the tested food or inhalant allergens. Sensitization against one of the food allergens (hen's egg, cow's milk or peanut) was positive if specific serum IgE-levels were $>0.3 \mathrm{IU} / \mathrm{ml}$ against the corresponding food allergens. Sensitization against inhalant allergens was regarded as positive if specific serum IgE-levels were $>0.3 \mathrm{IU} / \mathrm{ml}$ against at least one of the tested inhalant allergens (birch, grass pollen, cat, dog or house dust mite).

\section{Statistical analysis}

Relationships between the age of introduction of cow's milk products / other food products and (atopic) outcome measures (i.e. eczema, atopic dermatitis according UK Working Party criteria, recurrent wheeze, and (any) sensitization against cow's milk, henn's egg, peanut, at least 1 inhalent allergen) were analyzed. The relationships were analyzed using logistic regression, and results are presented as crude odds ratios ( $\mathrm{COR}$ ) and adjusted odds ratios (aOR) with corresponding $95 \%$ confidence intervals $(95 \% \mathrm{Cl})$. All potential confounders were put in the logistic regression model simultaneously. For all trend analysis we considered all categorical variables as a continuous variable to test linearity.

Reverse causation was addressed by means of a risk-period specific analysis as described earlier (10). Briefly, we excluded in the analyses infants with early symptoms of eczema or wheeze in order to disentangle the exposure from the onset of symptoms. In other words, no overlap occurs between exposure immediately after birth and onset of disease. This analysis has the advantage that it keeps track of infants with early symptoms.

Separate analyses of the conventional versus the alternative cohort showed that the key findings were similar between these groups. Hence, we have combined all infants in the final analyses, adjusting for 'recruitment group'. 


\section{RESULTS}

Of the 2834 infants enrolled at birth, we included 2558 infants in the present study (after excluding infant's with Down's syndrome $(n=3)$ and participants with missing information of the main determinants: the age of introduction of cow's milk products and/or other food products $(n=273)$. The response rate of the questionnaire at age two years was high $(n=2434 / 2558,95 \%)$. Mothers in the alternative cohort showed more delay in the age of introduction of cow's milk products (Table 1). Also, they had a higher rate and a longer duration of breastfeeding compared to the conventional cohort (Table 1). Other characteristics that differed between both groups were maternal age, maternal smoking during pregnancy, environmental tobacco smoking and maternal education (Table 1).

\section{Table 1}

Baseline characteristics in both recruitment groups

\begin{tabular}{|c|c|c|c|c|c|c|}
\hline & \multicolumn{2}{|c|}{$\begin{array}{l}\text { CONVENTIONAL } \\
(\mathrm{N}=\mathbf{2 1 1 0})\end{array}$} & \multicolumn{2}{|c|}{$\begin{array}{c}\text { ALTERNATIVE } \\
(\mathrm{N}=448)\end{array}$} & \multicolumn{2}{|c|}{$\begin{array}{c}\text { TOTAL } \\
(\mathrm{N}=\mathbf{2 5 5 8})\end{array}$} \\
\hline $0-3$ months & 946 & $(45 \%)$ & 49 & $(11 \%)$ & 995 & $(39 \%)$ \\
\hline 4-6 months & 687 & $(33 \%)$ & 138 & $(31 \%)$ & 825 & $(32 \%)$ \\
\hline 7-9 months & 434 & $(21 \%)$ & 234 & $(52 \%)$ & 668 & $(26 \%)$ \\
\hline After age 9 months & 43 & $(2 \%)$ & 27 & $(6 \%)$ & 70 & $(3 \%)$ \\
\hline \multicolumn{7}{|c|}{ Age of introduction other foods products, $n$ (\%) } \\
\hline Age 3 months & 183 & $(9 \%)$ & 22 & $(5 \%)$ & 205 & $(8 \%)$ \\
\hline 4-6 months & 1880 & $(90 \%)$ & 397 & $(89 \%)$ & 2277 & $(89 \%)$ \\
\hline After age 7 months & 47 & $(2 \%)$ & 29 & $(7 \%)$ & 76 & $(3 \%)$ \\
\hline \multicolumn{7}{|c|}{ Use of hypoallergenic formulas, $n$ (\%) } \\
\hline Yes & 150 & $(7 \%)$ & | 22 & $(5 \%)$ & I 172 & | (7\%) \\
\hline \multicolumn{7}{|l|}{ Breastfeeding, n (\%) } \\
\hline Never & 377 & $(18 \%)$ & 11 & $(3 \%)$ & 388 & $(15 \%)$ \\
\hline $0-3$ months & 797 & $(38 \%)$ & 56 & $(13 \%)$ & 853 & (33\%) \\
\hline 4-6 months & 357 & $(17 \%)$ & 70 & $(16 \%)$ & 427 & $(17 \%)$ \\
\hline 7-9 months & 280 & $(13 \%)$ & 111 & $(25 \%)$ & 391 & $(15 \%)$ \\
\hline$>9$ months & 250 & $(12 \%)$ & 196 & $(44 \%)$ & 446 & $(17 \%)$ \\
\hline Unknown & 49 & $(2 \%)$ & 4 & $(1 \%)$ & 53 & $(2 \%)$ \\
\hline
\end{tabular}




\begin{tabular}{|c|c|c|c|c|c|c|}
\hline \multirow[b]{2}{*}{ Gender of infants, no of boys (\%) } & \multicolumn{2}{|c|}{$\begin{array}{l}\text { CONVENTIONAL } \\
\qquad(\mathrm{N}=\mathbf{2 1 1 0})\end{array}$} & \multicolumn{2}{|c|}{$\begin{array}{l}\text { ALTERNATIVE } \\
\qquad(\mathrm{N}=448)\end{array}$} & \multicolumn{2}{|c|}{$\begin{array}{c}\text { TOTAL } \\
(\mathrm{N}=2558)\end{array}$} \\
\hline & 1083 & $(51 \%)$ & 230 & $(51 \%)$ & 1313 & $(51 \%)$ \\
\hline Maternal age in years, mean (sd) & \multicolumn{2}{|c|}{$32(4)$} & \multicolumn{2}{|c|}{$34(4)$} & \multicolumn{2}{|c|}{$32(4)$} \\
\hline Maternal smoking during pregnancy, $\mathrm{n}(\%)$ & 174 & $(8 \%)$ & 2 & $(<1 \%)$ & 176 & $(7 \%)$ \\
\hline Environmental tobacco smoking (ETS), $n$ (\%) & 107 & $(5 \%)$ & 2 & $(<1 \%)$ & 109 & $(4 \%)$ \\
\hline \multicolumn{7}{|l|}{ Maternal Education, $\mathrm{n}(\%)$} \\
\hline Low & 239 & $(11 \%)$ & 17 & $(4 \%)$ & 256 & $(10 \%)$ \\
\hline Middle & 814 & $(39 \%)$ & 79 & $(18 \%)$ & 79 & $(35 \%)$ \\
\hline High & 943 & $(45 \%)$ & 341 & $(76 \%)$ & 341 & $(50 \%)$ \\
\hline Unknown & 114 & $(5 \%)$ & 11 & $(3 \%)$ & 125 & $(5 \%)$ \\
\hline \multicolumn{7}{|l|}{ Parental allergic disease, $\mathrm{n}(\%)$} \\
\hline Both parents non-allergic & 842 & $(40 \%)$ & 173 & $(39 \%)$ & 1015 & $(40 \%)$ \\
\hline Only father allergic & 450 & $(21 \%)$ & 102 & $(23 \%)$ & 552 & $(22 \%)$ \\
\hline Only mother allergic & 468 & $(22 \%)$ & 102 & $(23 \%)$ & 570 & $(22 \%)$ \\
\hline Both parents allergic & 284 & $(14 \%)$ & 65 & $(15 \%)$ & 349 & $(14 \%)$ \\
\hline Unknown & 66 & $(3 \%)$ & 6 & $(1 \%)$ & 72 & $(3 \%)$ \\
\hline \multicolumn{7}{|l|}{ Sibling history of atopic manifestations, $n$ (\%) } \\
\hline No siblings & 1734 & $(82 \%)$ & 343 & $(77 \%)$ & 2077 & $(81 \%)$ \\
\hline$\geq 1$ sibling(s), all non-atopic & 235 & $(11 \%)$ & 69 & $(15 \%)$ & 304 & $(12 \%)$ \\
\hline$\geq 1$ sibling(s), at least 1 atopic & 83 & $(4 \%)$ & 33 & $(7 \%)$ & 116 & $(5 \%)$ \\
\hline Unknown & 58 & $(3 \%)$ & 3 & $(1 \%)$ & 61 & $(2 \%)$ \\
\hline \multicolumn{7}{|l|}{ Infants atopic outcome at age 2 years, $n$ (\%) } \\
\hline Eczema & 665 & $(31 \%)$ & 128 & $(29 \%)$ & 783 & $(31 \%)$ \\
\hline Atopic Dermatitis UK Working Party $(\mathrm{N}=822)^{\dagger}$ & 85 & $(14 \%)$ & 24 & $(11 \%)$ & 109 & $(13 \%)$ \\
\hline Recurrent wheeze & 230 & $(11 \%)$ & 29 & $(7 \%)$ & 259 & $(10 \%)$ \\
\hline Sensitization (overall) $(\mathrm{N}=782)^{+}$ & 164 & $(30 \%)$ & 56 & $(25 \%)$ & 220 & $(28 \%)$ \\
\hline Sensitization against cow's milk $(\mathrm{N}=789)^{\dagger}$ & 115 & $(20 \%)$ & 35 & $(16 \%)$ & 150 & $(19 \%)$ \\
\hline Sensitization against (hens) egg $(\mathrm{N}=789)^{\dagger}$ & 38 & $(7 \%)$ & 9 & $(4 \%)$ & 47 & $(6 \%)$ \\
\hline Sensitization against peanut $(\mathrm{N}=789)^{\dagger}$ & 36 & $(6 \%)$ & 6 & (3\%) & 42 & $(5 \%)$ \\
\hline $\begin{array}{l}\text { Sensitization against at least } 1 \text { inhalant } \\
\text { allergen }(N=756)^{\dagger}\end{array}$ & 55 & $(10 \%)$ & 29 & $(13 \%)$ & 84 & $(11 \%)$ \\
\hline
\end{tabular}

\footnotetext{
Numbers may not add up total because of missing values

$\dagger \quad$ Only available in those infants who had a home visit
} 


\section{CHAPTER 4}

More delay in introduction of both cow's milk products and other food products was associated with a higher risk of eczema ( $p$ trend 0.01 and 0.02 , respectively; Table 2). No associations were found between the introduction of cow's milk

\section{Table 2}

Associations between introduction of cow's milk/food products and the development of infant's eczema and atopic dermatitis by UK-WP at age 2

\begin{tabular}{|c|c|c|c|c|}
\hline & \multicolumn{4}{|c|}{ ECZEMA (QUESTIONNAIRES) } \\
\hline & $\mathbf{N}$ & n (\%) & $\operatorname{cOR}(95 \% \mathrm{Cl})$ & $\mathrm{aOR}(95 \% \mathrm{Cl})^{*}$ \\
\hline \multicolumn{5}{|c|}{ Age of introduction cow's milk products ${ }^{\dagger}$} \\
\hline $0-3$ months & 976 & $297(30 \%)$ & 1.0 & 1.0 \\
\hline 4-6 months & 800 & $239(30 \%)$ & $0.97(0.79-1.19)$ & $1.13(0.83-1.56)$ \\
\hline 7-9 months & 664 & $219(33 \%)$ & $1.13(0.91-1.39)$ & $1.55(1.03-2.33)$ \\
\hline After age 9 months & 70 & $28(40 \%)$ & $1.52(0.93-2.51)$ & $2.29(1.21-4.33)$ \\
\hline$P_{\text {trend }}$ & & & 0.12 & 0.01 \\
\hline \multicolumn{5}{|c|}{ Age of introduction other foods products ${ }^{\dagger}$} \\
\hline Age 3 months & 191 & $51(27 \%)$ & 1.0 & 1.0 \\
\hline 4-6 months & 2245 & $701(31 \%)$ & $1.25(0.90-1.74)$ & $1.28(0.91-1.81)$ \\
\hline After age 7 months & 74 & $31(42 \%)$ & $1.98(1.13-3.47)$ & $2.10(1.17-3.76)$ \\
\hline$P_{\text {trend }}$ & & & 0.03 & 0.02 \\
\hline \multicolumn{5}{|c|}{ Breastfeeding duration (confounder) } \\
\hline Never & 388 & $112(29 \%)$ & 1.0 & 1.0 \\
\hline $0-3$ months & 853 & $263(31 \%)$ & $1.09(0.83-1.42)$ & $1.00(0.75-1.33)$ \\
\hline 4-6 months & 427 & 135 (32\%) & $1.11(0.82-1.50)$ & $0.87(0.55-1.35)$ \\
\hline 7-9 months & 391 & $126(32 \%)$ & $1.12(0.82-1.52)$ & $0.74(0.46-1.20)$ \\
\hline$>9$ months & 446 & $133(30 \%)$ & $1.00(0.74-1.35)$ & $0.66(0.40-1.09)$ \\
\hline$P_{\text {trend }}$ & & & 0.95 & 0.06 \\
\hline
\end{tabular}

may not add up to total numbers because of missing values

COR crude Odds Ratio

aOR adjusted Odds Ratio

* Based on logistic regression analysis, adjusted for (duration of breastfeeding), gender of infant, recruitment group (conventional, alternative lifestyle), maternal smoking during pregnancy, infant's exposure to environmental tobacco smoke, maternal age at delivery (in years), maternal education, presence of parental allergic disease, (older) siblings atopic history. 
products and atopic dermatitis according to UK Working Party criteria. However, more delay in other food products was associated with a higher risk for atopic dermatitis by UK Working Party criteria ( $p$ trend 0.00 ; Table 2 ).

\begin{tabular}{|c|c|c|c|}
\hline \multicolumn{4}{|c|}{ ATOPIC DERMATITIS (UK WORKING PARTY) } \\
\hline $\mathbf{N}$ & n (\%) & COR $(95 \% \mathrm{Cl})$ & aOR $(95 \% \mathrm{Cl})^{*}$ \\
\hline 286 & $36(13 \%)$ & 1.0 & 1.0 \\
\hline 249 & $32(13 \%)$ & $1.02(0.62-1.71)$ & $0.65(0.25-1.67)$ \\
\hline 265 & $35(13 \%)$ & $1.06(0.64-1.74)$ & $0.64(0.22-1.90)$ \\
\hline \multirow[t]{2}{*}{22} & $6(27 \%)$ & $2.60(0.96-7.09)$ & $1.43(0.33-6.29)$ \\
\hline & & 0.35 & 0.93 \\
\hline 55 & $3(6 \%)$ & 1.0 & 1.0 \\
\hline 743 & $98(13 \%)$ & $2.63(0.81-8.60)$ & $2.67(0.80-8.97)$ \\
\hline \multirow[t]{2}{*}{24} & $8(33 \%)$ & $8.67(2.05-36.59)$ & $9.46(2.05-43.61)$ \\
\hline & & 0.00 & 0.00 \\
\hline 109 & $12(11 \%)$ & 1.0 & 1.0 \\
\hline 236 & $28(12 \%)$ & $1.09(0.53-2.23)$ & $1.11(0.51-2.41)$ \\
\hline 154 & $28(18 \%)$ & $1.80(0.87-3.71)$ & $2.58(0.77-8.67)$ \\
\hline 159 & $23(15 \%)$ & $1.37(0.65-2.88)$ & $1.58(0.44-5.66)$ \\
\hline \multirow[t]{2}{*}{158} & $18(11 \%)$ & $1.04(0.48-2.26)$ & $1.30(0.34-4.95)$ \\
\hline & & 0.75 & 0.60 \\
\hline
\end{tabular}

$\dagger \quad$ The age of introduction cow's milk products and the age of introduction other food products were simultaneously included in the logistic regression analysis, which means these variable were adjusted for each other. 


\section{CHAPTER 4}

A delayed introduction of other food products showed a higher risk for recurrent wheeze ( $p$ trend 0.01 ; Table 3) while this was not found for a delayed introduction of cow's milk products (after adjustment for confounding factors). The results for breastfeeding duration (confounder) between 7-9 months showed a reduced risk for recurrent wheeze (aOR 0.31, 95\% $\mathrm{Cl}$ 0.14-0.70).

\section{Table 3}

Associations between introduction of cow's milk/food products and the development of infant's recurrent wheeze and overall sensitization at age 2

\begin{tabular}{|c|c|c|c|c|}
\hline & \multicolumn{4}{|c|}{ RECURRENT WHEEZE } \\
\hline & $\mathbf{N}$ & n (\%) & $\operatorname{cOR}(95 \% \mathrm{Cl})$ & aOR $(95 \% \mathrm{Cl})^{\star}$ \\
\hline \multicolumn{5}{|c|}{ Age of introduction cow's milk products ${ }^{\dagger}$} \\
\hline 0-3 months & 730 & $127(17 \%)$ & 1.0 & 1.0 \\
\hline 4-6 months & 589 & $83(14 \%)$ & $0.78(0.58-1.05)$ & $1.07(0.66-1.75)$ \\
\hline 7-9 months & 519 & $44(9 \%)$ & $0.44(0.31-0.63)$ & $0.89(0.45-1.77)$ \\
\hline After age 9 months & 56 & $5(9 \%)$ & $0.47(0.18-1.19)$ & $0.96(0.30-3.07)$ \\
\hline$P_{\text {trend }}$ & & & 0.00 & 0.77 \\
\hline \multicolumn{5}{|c|}{ Age of introduction other foods products ${ }^{\dagger}$} \\
\hline Age 3 months & 153 & $17(11 \%)$ & 1.0 & 1.0 \\
\hline 4-6 months & 1685 & $232(14 \%)$ & $1.28(0.76-2.16)$ & $1.71(1.00-2.95)$ \\
\hline After age 7 months & 56 & $10(18 \%)$ & $1.74(0.74-4.07)$ & $3.52(1.42-8.73)$ \\
\hline$P_{\text {trend }}$ & & & 0.20 & 0.01 \\
\hline \multicolumn{5}{|c|}{ Breastfeeding duration (confounder) } \\
\hline Never & 388 & $53(14 \%)$ & 1.0 & 1.0 \\
\hline $0-3$ months & 853 & $101(12 \%)$ & $0.86(0.59-1.24)$ & $0.87(0.58-1.32)$ \\
\hline 4-6 months & 427 & $46(11 \%)$ & $0.73(0.47-1.12)$ & $0.74(0.38-1.45)$ \\
\hline 7-9 months & 391 & $21(5 \cdot 4 \%)$ & $0.31(0.18-0.53)$ & $0.31(0.14-0.70)$ \\
\hline$>9$ months & 446 & $33(7.4 \%)$ & $0.42(0.27-0.68)$ & $0.46(0.21-1.02)$ \\
\hline$P_{\text {trend }}$ & & & 0.00 & 0.02 \\
\hline
\end{tabular}

may not add up to total numbers because of missing values

COR crude Odds Ratio

aOR adjusted Odds Ratio

* Based on logistic regression analysis, adjusted for (duration of breastfeeding), gender of infant, recruitment group (conventional, alternative lifestyle), maternal smoking during pregnancy, infant's 
Delaying the introduction of cow's milk products tended to be associated with a lower risk of atopic sensitization, but did not reach statistical significance ( $p$ trend 0.26; Table 3). Unexpectedly, a delayed introduction of other food products was positively associated with atopic sensitization at 2 years ( $p$ trend 0.01 ; Table 3 ).

\begin{tabular}{|c|c|c|c|}
\hline \multicolumn{4}{|c|}{ ANY SENSITIZATION } \\
\hline $\mathbf{N}$ & n (\%) & $\operatorname{cOR}(95 \% \mathrm{Cl})$ & aOR $(95 \% \mathrm{Cl}) *$ \\
\hline 270 & $72(27 \%)$ & 1.0 & 1.0 \\
\hline 235 & $72(31 \%)$ & $1.22(0.83-1.79)$ & $0.73(0.36-1.46)$ \\
\hline 255 & $69(27 \%)$ & $1.02(0.69-1.50)$ & $0.57(0.25-1.29)$ \\
\hline \multirow[t]{2}{*}{22} & $7(32 \%)$ & $1.28(0.50-3.28)$ & $0.71(0.21-2.41)$ \\
\hline & & 0.80 & 0.26 \\
\hline 50 & $5(10 \%)$ & 1.0 & 1.0 \\
\hline 709 & $208(29 \%)$ & $3.74(1.46-9.55)$ & $3.69(1.42-9.62)$ \\
\hline \multirow[t]{2}{*}{23} & $7(30 \%)$ & $3.94(1.09-14.19)$ & $4.31(1.14-16.22)$ \\
\hline & & 0.01 & 0.01 \\
\hline 102 & $24(24 \%)$ & 1.0 & 1.0 \\
\hline 220 & $59(27 \%)$ & $1.19(0.69-2.06)$ & $1.33(0.74-2.40)$ \\
\hline 148 & $49(33 \%)$ & $1.61(0.91-2.85)$ & $2.42(0.97-6.03)$ \\
\hline 153 & $47(31 \%)$ & $1.44(0.81-2.55)$ & $2.22(0.85-5.76)$ \\
\hline \multirow[t]{2}{*}{153} & $39(26 \%)$ & $1.11(0.62-2.00)$ & $1.89(0.70-5.12)$ \\
\hline & & 0.63 & 0.57 \\
\hline
\end{tabular}

exposure to environmental tobacco smoke, maternal age at delivery (in years), maternal education, presence of parental allergic disease, (older) siblings atopic history.

$\dagger \quad$ The age of introduction cow's milk products and the age of introduction other food products were simultaneously included in the logistic regression analysis, which means these variable were adjusted for each other. 


\section{CHAPTER 4}

In addition, besides 'any sensitization', we assessed whether the introduction of cow's milk or other food products was associated with sensitization against the introduction of separate food allergens (cow's milk, hen's egg, peanut). A delay in introduction of cow's milk products tended to be associated with a lower risk for sensitization against cow's milk, but this trend was not statistically significant

\section{Table 4}

Associations between introduction of cow's milk/food products and the development of infant's sensitization against egg, milk, peanut and sensitization against at least 1 inhalant allergen, at age 2

\begin{tabular}{|c|c|c|c|c|}
\hline & \multicolumn{4}{|c|}{ SENSITIZATION AGAINST COW'S MILK } \\
\hline & $\mathbf{N}$ & n (\%) & $\operatorname{cOR}(95 \% \mathrm{Cl})$ & $\mathrm{aOR}(95 \% \mathrm{Cl})^{*}$ \\
\hline \multicolumn{5}{|c|}{ Age of introduction cow's milk products } \\
\hline $0-3$ months & 270 & $50(19 \%)$ & 1.0 & 1.0 \\
\hline 4-6 months & 235 & $54(23 \%)$ & $1.31(0.85-2.02)$ & $0.87(0.40-1.87)$ \\
\hline 7-9 months & 255 & $44(17 \%)$ & $0.92(0.59-1.44)$ & $0.60(0.24-1.50)$ \\
\hline After age 9 months & 22 & $2(9 \%)$ & $0.44(0.10-1.94)$ & $0.33(0.06-1.82)$ \\
\hline$P_{\text {trend }}$ & & & 0.44 & 0.10 \\
\hline \multicolumn{5}{|c|}{ Age of introduction other foods productst } \\
\hline Age 3 months & 50 & $4(8 \%)$ & 1.0 & 1.0 \\
\hline 4-6 months & 709 & $143(20 \%)$ & $2.91(1.03-8.20)$ & $2.64(0.92-7.59)$ \\
\hline After age 7 months & 23 & $3(13 \%)$ & $1.73(0.35-8.43)$ & $1.82(0.35-9.37)$ \\
\hline$P_{\text {trend }}$ & & & 0.21 & 0.23 \\
\hline \multicolumn{5}{|c|}{ Breastfeeding duration (confounder) } \\
\hline Never & 104 & $18(17 \%)$ & 1.0 & 1.0 \\
\hline $0-3$ months & 223 & $41(18 \%)$ & $1.07(0.58-1.97)$ & $1.17(0.61-2.26)$ \\
\hline 4-6 months & 148 & $33(22 \%)$ & $1.34(0.71-2.54)$ & $1.78(0.65-4.89)$ \\
\hline 7-9 months & 153 & $37(24 \%)$ & $1.49(0.79-2.79)$ & $2.32(0.81-6.66)$ \\
\hline$>9$ months & 155 & $19(12 \%)$ & $0.66(0.33-1.33)$ & $1.19(0.38-3.67)$ \\
\hline$P_{\text {trend }}$ & & & 0.55 & 0.97 \\
\hline
\end{tabular}

may not add up to total numbers because of missing values

COR crude Odds Ratio

aOR adjusted Odds Ratio

* Based on logistic regression analysis, adjusted for (duration of breastfeeding), gender of infant, recruitment group (conventional, alternative lifestyle), maternal smoking during pregnancy, infant's 
( $\mathrm{p}$ trend 0.10 ; Table 4). Also, we studied the associations for sensitization against one or more inhalant allergens (birch, grass pollen, cat, dog or house dust mite), showing that delayed introduction of other food products lead to a higher risk for inhalant allergen sensitization ( $p$ trend 0.00 ; Table 4).

\begin{tabular}{|c|c|c|c|}
\hline \multicolumn{4}{|c|}{ SENSITIZATION AGAINST HENN`S EGG } \\
\hline $\mathbf{N}$ & n (\%) & $\operatorname{cOR}(95 \% \mathrm{Cl})$ & aOR $(95 \% \mathrm{Cl})^{*}$ \\
\hline 270 & $16(6 \%)$ & 1.0 & 1.0 \\
\hline 235 & $15(6 \%)$ & $1.08(0.52-2.24)$ & $1.10(0.35-3.51)$ \\
\hline 255 & $12(5 \%)$ & $0.78(0.36-1.69)$ & $0.66(0.16-2.81)$ \\
\hline \multirow[t]{2}{*}{22} & $4(18 \%)$ & $3.53(1.07-11.66)$ & $3.35(0.56-20.15)$ \\
\hline & & 0.70 & 0.86 \\
\hline 50 & $1(2 \%)$ & 1.0 & 1.0 \\
\hline 709 & $44(6 \%)$ & $3.24(0.44-24.03)$ & $3.10(0.40-24.05)$ \\
\hline \multirow[t]{2}{*}{23} & $2(9 \%)$ & $4.67(0.40-54.31)$ & $5.88(0.45-76.85)$ \\
\hline & & 0.19 & 0.15 \\
\hline 104 & $4(4 \%)$ & 1.0 & 1.0 \\
\hline 223 & $16(7 \%)$ & $1.92(0.63-5.90)$ & $2.08(0.63-6.93)$ \\
\hline 148 & $7(5 \%)$ & $1.22(0.35-4.26)$ & $1.56(0.27-8.90)$ \\
\hline 153 & $13(9 \%)$ & $2.28(0.72-7.19)$ & $2.76(0.47-16.11)$ \\
\hline \multirow[t]{2}{*}{155} & $7(5 \%)$ & $1.18(0.34-4.12)$ & $1.89(0.28-12.68)$ \\
\hline & & 0.92 & 0.54 \\
\hline
\end{tabular}

exposure to environmental tobacco smoke, maternal age at delivery (in years), maternal education, presence of parental allergic disease, (older) siblings atopic history.

$\dagger \quad$ The age of introduction cow's milk products and the age of introduction other food products were simultaneously included in the logistic regression analysis, which means these variable were adjusted for each other. 


\begin{tabular}{|c|c|c|c|c|}
\hline & \multicolumn{4}{|c|}{ SENSITIZATION AGAINST PEANUT } \\
\hline & $\mathbf{N}$ & n (\%) & $\operatorname{cOR}(95 \% \mathrm{Cl})$ & aOR $(95 \% \mathrm{Cl})^{*}$ \\
\hline \multicolumn{5}{|c|}{ Age of introduction cow's milk products ${ }^{\dagger}$} \\
\hline 0-3 months & 271 & $18(7 \%)$ & 1.0 & 1.0 \\
\hline 4-6 months & 235 & $13(6 \%)$ & $0.82(0.39-1.72)$ & $0.86(0.24-3.08)$ \\
\hline 7-9 months & 256 & $10(4 \%)$ & $0.57(0.26-1.26)$ & $0.56(0.12-2.68)$ \\
\hline After age 9 months & 22 & $1(5 \%)$ & $0.67(0.09-5.26)$ & $0.53(0.40-7.05)$ \\
\hline$P_{\text {trend }}$ & & & 0.18 & 0.42 \\
\hline \multicolumn{5}{|c|}{ Age of introduction other foods products ${ }^{\dagger}$} \\
\hline Age 3 months & 50 & $1(2 \%)$ & 1.0 & 1.0 \\
\hline 4-6 months & 711 & $39(6 \%)$ & $2.84(0.38-21.14)$ & $2.55(0.32-20.12)$ \\
\hline After age 7 months & 23 & $2(9 \%)$ & $4.67(0.40-54.31)$ & $7.85(0.58-106.55)$ \\
\hline$P_{\text {trend }}$ & & & 0.19 & 0.11 \\
\hline \multicolumn{5}{|c|}{ Breastfeeding duration (confounder) } \\
\hline Never & 104 & $5(5 \%)$ & 1.0 & 1.0 \\
\hline $0-3$ months & 223 & $16(7 \%)$ & $1.51(0.54-4.25)$ & $1.68(0.54-5.30)$ \\
\hline 4-6 months & 148 & $7(5 \%)$ & $0.96(0.30-3.12)$ & $1.42(0.24-8.47)$ \\
\hline 7-9 months & 153 & $10(7 \%)$ & $1.36(0.45-4.09)$ & $2.29(0.37-14.33)$ \\
\hline$>9$ months & 155 & $4(3 \%)$ & $0.52(0.14-1.97)$ & $1.15(0.15-9.03)$ \\
\hline$P_{\text {trend }}$ & & & 0.24 & 0.84 \\
\hline
\end{tabular}

may not add up to total numbers because of missing values

COR crude Odds Ratio

aOR adjusted Odds Ratio

* Based on logistic regression analysis, adjusted for duration of breastfeeding, gender of infant, recruitment group (conventional, alternative lifestyle), maternal smoking during pregnancy, infant's exposure to environmental tobacco smoke, maternal age at delivery (in years), maternal education, presence of parental allergic disease, (older) siblings atopic history.

$\dagger \quad$ The age of introduction cow's milk products and the age of introduction other food products were simultaneously included in the logistic regression analysis, which means these variable were adjusted for each other. 
INTRODUCTION OF COW'S MILK / OTHER FOOD PRODUCTS

\begin{tabular}{|c|c|c|c|}
\hline \multicolumn{4}{|c|}{ SENSITIZATION AGAINST AT LEAST 1 INHALANT ALLERGEN } \\
\hline $\mathbf{N}$ & n (\%) & $\operatorname{cOR}(95 \% \mathrm{Cl})$ & $\mathrm{aOR}(95 \% \mathrm{Cl}) *$ \\
\hline 261 & $21(8 \%)$ & 1.0 & 1.0 \\
\hline 228 & $28(12 \%)$ & $1.60(0.88-2.90)$ & $1.06(0.34-3.29)$ \\
\hline 247 & $31(13 \%)$ & $1.64(0.92-2.94)$ & $0.81(0.23-2.85)$ \\
\hline \multirow[t]{2}{*}{20} & $4(20 \%)$ & $2.86(0.88-9.33)$ & $1.07(0.19-5.91)$ \\
\hline & & 0.05 & 0.67 \\
\hline 50 & $1(2 \%)$ & 1.0 & 1.0 \\
\hline 683 & $77(11 \%)$ & $6.23(0.85-45 \cdot 73)$ & $6.55(0.87-49.32)$ \\
\hline \multirow[t]{2}{*}{23} & $6(26 \%)$ & $17.29(1.94-154.17)$ & $20.86(2.17-200.75)$ \\
\hline & & 0.00 & 0.00 \\
\hline 100 & $9(9 \%)$ & 1.0 & 1.0 \\
\hline 210 & $15(7 \%)$ & $0.79(0.33-1.84)$ & $0.68(0.27-1.74)$ \\
\hline 143 & $21(15 \%)$ & $1.74(0.76-3.97)$ & $1.55(0.37-6.44)$ \\
\hline 147 & $16(11 \%)$ & $1.24(0.52-2.92)$ & $0.92(0.21-4.06)$ \\
\hline \multirow[t]{2}{*}{150} & $23(15 \%)$ & $1.83(0.81-4.14)$ & $1.60(0.36-7.17)$ \\
\hline & & 0.03 & 0.61 \\
\hline
\end{tabular}


To control for reverse causation (early symptoms urging the parents to delay the introduction of foods in the hope of diminishing the symptoms), we excluded infants with early symptoms in several so called risk-period specific analyses:

\section{Exclusion of early symptoms of eczema}

First, we excluded infants with early symptoms of eczema i.e. between 0-7 months. In this respect only the introduction of cow's milk between 4-6 months (in comparison with 0-3 months) can be studied since no overlap occurs with the onset of symptoms after 7 months. The magnitude of the association for introducing cow's milk products between 4-6 months slightly changed (adjusted $O R$ 1.21). The odds ratio for introducing other food products between 4-6 months turned away from 1 and reached statistical significance (adjusted OR 1.72; 95\% $\mathrm{Cl}$ 1.00-2.96). Second, we excluded infants with symptoms of eczema in the first year of life (i.e. between 0-12 months). The results of introducing cow's milk products between 4-6 months (adjusted OR 1.20) and 7-9 months (adjusted OR 1.85) tended towards the same direction (compared with the results presented in Table 2) but both $95 \%$ confidence intervals of these risk-period specific analyses became wider.

\section{Exclusion of early symptoms of recurrent wheeze}

In the same manner as described above, we first excluded infants with symptoms of recurrent wheeze between 0-7 months. The odds ratio for introducing cow's milk products between 4-6 months (versus 0-3 months) changed (adjusted OR 0.85 ) and the confidence intervals became wider. The odds ratio for introducing other food products between 4-6 months attenuated (adjusted OR 1.35) and was no more statistically significant. After excluding infants who developed symptoms of wheeze in the first year of life, the odds ratios for introducing cow's milk between 4-6 months and between 7-9 months were 1.19 and 1.48 , respectively (the corresponding confidence intervals became clearly wider). The odds ratio for introducing other food products between 4-6 months and the risk of recurrent wheeze was comparable with the overall results presented in Table 3 (adjusted $O R 1.71$ versus 1.50 in the risk-period specific analysis).

\section{Exclusion of hypoallergenic formulas}

We found that infants receiving hypoallergenic formulas between birth and 3 months $(n=127)$, showed a higher risk of eczema versus infants given non-hypo- 
allergenic formula feeding (crude OR: 1.78; $95 \% \mathrm{Cl}: 1.28-2.47$ ) even after adjusting for potential confounders (adjusted OR: 1.62; 95\% Cl: 1.08-2.43). In addition, hypoallergenic formulas were associated with a higher risk for recurrent wheeze (crude OR: $3.86 ; 95 \% \mathrm{Cl} 2.45-6.09$ ), also after adjusting for other confounders (adjusted OR 2.42; $95 \% \mathrm{Cl}: 1.33-4.43$ ). Since, these results may imply the presence of reverse causation (i.e. hypoallergenic formulas were introduced after the development of eczema or recurrent wheeze), we repeated all analyses in which we excluded participants who introduced hypoallergenic formulas (0-3 months). The odds ratios that are presented in Table 2, 3 and 4, did only slightly change and the magnitude of the $p$ values for trend analyses remained the same. Therefore we do not present the results after exclusion of hypoallergenic formulas.

\section{DISCUSSION}

In this study, a delayed introduction of cow's milk products was associated with an increased risk of eczema and recurrent wheeze. Also, our data demonstrated that a delayed introduction of other food products was associated with an increased risk of eczema, similar to our findings with atopic dermatitis by UK-WP. Furthermore, a delayed introduction of other food products was associated with an increased risk of recurrent wheeze, atopic sensitization and in particular, inhalant allergen sensitization. We have also demonstrated that longer breastfeeding duration (7-9 months) showed a reduced risk for recurrent wheeze. The risk of recurrent wheeze for breastfeeding longer than 9 months tended in the same direction. Overall, we found a statistical significant trend towards a reduced risk of recurrent wheeze with a longer duration of breastfeeding. Previously, we have speculated that these results may be explained by a protection of breastfeeding against respiratory infections (13).

It has been suggested that a early introduction of solid foods may result in allergic sensitization against (food) allergens since the infant's gut-mucosal barrier is immature and early exposure to (food) allergens may trigger an allergic response of the immune system (14). In a study of children with an immature gastrointestinal tract or immune response no increased risk for the development of food allergies was found (15). However, there is only scarce scientific evidence to support this hypothesis. Most studies have focussed on the duration of breastfeeding as a 
preventive measure to avoid the development of asthma and allergy. In 1999, Oddy et al that found that it was the later age at which cow's milk was introduced rather than the duration of breastfeeding that was more closely associated with lower risk of asthma or atopy at age 6 years. They found that the introduction of milk other than breast milk was a significant risk factor for asthma, wheeze and a positive skin prick test reaction against at least one common aeroallergen. These results favor 'exclusion mechanisms' (16). However, it was noted that studies attempting to separate the effects of breastfeeding duration and the age of introduction of cow's milk or food products face problems of high correlation between these those variables. Therefore, the possibility that it may be breastfeeding itself that may confer protection cannot be rejected (16).

Several other studies have previously focussed on the introduction of first exposure of milk or food products. The results of our study tended towards the same direction as several previous studies. Zutavern et al showed an increased risk of eczema, in relation to late introduction of egg and milk in a prospective birth cohort study in the UK. Late introduction of egg was furthermore associated with a non-significantly increased risk of preschool wheezing (9). Our results confirm that also wheeze may be implicated as an atopic outcome, since we found that age of introduction of food products other than cow's milk products was associated not only with higher risk of eczema, but also wheeze and sensitization for inhalant allergens. Mihrshahi et al. showed that breastfeeding for 6 months or more (yes versus no) and introduction of solid foods after 3 months (yes versus no) were both associated with an increased risk of atopy (defined as the presence of any allergen weal $\geq 2 \mathrm{~mm}$ and larger than the negative control) at age 5 years (17). Interestingly, Poole at al. showed that children who were first exposed to cereals after 6 months of age had an increased risk of wheat allergy compared with children first exposed to cereals before age 6 months (18). In contrast with these above mentioned studies, Morgan et al. showed that the introduction of four or more solids before 17 weeks post-term (compared with less than four foods at 17 weeks post-term) was associated with a higher risk of eczema in infants with and without a family history of allergy suggesting that a delay of the introduction of solids reduced the development of eczema $(8,19)$. However it should be noted that this study was done in preterm infants which may possibly confound (8) their results since prematurity has been shown to reduce the long-term risk of atopy (20). Andreasyan et al. showed recently that there was no association between 
introduction of non-milk fluids in infancy and childhood atopic disease (21). The results of a follow up analysis of a double blind, placebo controlled, randomised feeding intervention trial showed that brief neonatal exposure to cows' milk (quantity was regarded sufficient to induce sensitization) in breast fed children was not associated with atopic disease or allergic symptoms up to age $5(22,23)$.

Most studies addressing the relationship between timing of solid introduction and atopy development were prospective birth cohort studies instead of randomized controlled trials. A major disadvantage of cohort studies has been the phenomenon of reverse causation when interpreting the results $(8,9)$. Recently, Zutavern et al investigated whether a delayed introduction of solids (after 4 or 6 months) is protective against the development of atopic dermatitis and atopic sensitization when taking into account reverse causation in a German prospective birth cohort study (24). Their results provided evidence (i.e. their results changed) for reverse causation between the introduction of solids and early skin or allergic symptoms. In the present study, we have indeed thought of the idea that parents of infants with early symptoms of eczema or wheeze may delay the introduction of cow's milk products or other food products, which would make our results susceptible to reverse causation. We have attempted to avoid reverse causation in our analysis as follows; first, we excluded all infants with reported symptoms of eczema between 0-7 months resulting in cases that were 'at risk' for developing eczema between 7-24 months. Second, in the same way we excluded all infants with reported symptoms in the first year of life (0-12 months), resulting in cases that were 'at risk' in the second year of life (12-24 months). The same was done for the outcome 'recurrent wheeze'. We have noted that the results (odds ratios and $95 \%$ confidence intervals) of our so called risk-period specific analysis did slightly change which implies the presence of reverse causation as a potential bias cannot be fully excluded. However, to our opinion, the interpretation of our main findings were minimally affected by reverse causation. Unfortunately, we were not able to assess whether our results of atopic dermatitis by UK-WP and allergic sensitization were prone to reverse causation since the data were only available at the age of 2 years. Hence, we could not exclude those infants who developed early symptoms.

Another explanation that has been put forward to explain the results of an increased risk of atopy by a delayed introduction of cow's milk or food allergens 
may be the induction of 'oral tolerance', i.e. the induction of systemic immunologic hyporesponsiveness, a usual response to soluble dietary proteins. Although the biologic mechanism of this, is largely unexplained, the induction of oral tolerance affects a broad spectrum of immunological functions, locally and systemically, to a varying degree (25). Previously, it has also been put forward that late introduction of food products is associated with allergy, since introducing food products to older infants tends to be in greater amounts (26). Hence, it has been speculated that a larger antigen dose may result in T-cell activation instead of anergy or tolerance (18). Indeed, it may be anticipated that our results can be explained by the induction of oral tolerance that will be induced by larger amounts of cow's milk and other food products, leading to an increased exposure to (food) antigens in older infants ( $>7$ months versus 0-3 months) participating in this study.

In conclusion, we have shown that a delayed introduction of cow's milk products is associated with a higher risk of eczema. In addition, a delayed introduction of other food products is associated with an increased risk of atopy development in the first two years of life (eczema, atopic dermatitis by UK-WP, recurrent wheeze, any sensitization and inhalant allergen sensitization). Although breastfeeding remains definitely favourable for the infant's health (i.e. protection against infections), it may be questioned whether delaying the introduction of cow's milk or other food products may have a substantial additional advantage as a possible preventive measure to avoid the development of atopic manifestations. Based on the current knowledge, it may be too early to change the current guidelines on the introduction of cow's milk (like WHO), although these guidelines may be discussed in the light of the 'induction' of oral tolerance. Future research may focus on separating formula products from 'other cow's milk products' since the current guidelines imply that introduction of cow's milk products should wait, but are not meant to imply that milk-based formulas cannot be used. 


\section{REFERENCES}

1. Magnus P, Jaakkola JJ. Secular trend in the occurrence of asthma among children and young adults: critical appraisal of repeated cross sectional surveys. Bmj 1997;314(7097):1795-9.

2. Worldwide variation in prevalence of symptoms of asthma, allergic rhinoconjunctivitis, and atopic eczema: ISAAC. The International Study of Asthma and Allergies in Childhood (ISAAC) Steering Committee. Lancet 1998;351(9111):1225-32.

3. Arshad SH. Primary prevention of asthma and allergy. J Allergy Clin Immunol 2005;116(1):314; quiz 15 .

4. Wood RA. Prospects for the Prevention of Allergy: A Losing Battle or a Battle Still Worth Fighting? Arch Pediatr Adolesc Med 2006;160(5):552-554.

5. Tarini BA, Carroll AE, Sox CM, Christakis DA. Systematic review of the relationship between early introduction of solid foods to infants and the development of allergic disease. Arch Pediatr Adolesc Med 2006;160(5):502-7.

6. WHO. Fifty-fourt World Health Assemby. WHA54.2. Agenda item 13.1. Infant and young children nutrition.

7. Zeiger RS. Food allergen avoidance in the prevention of food allergy in infants and children. Pediatrics 2003;111(6 Pt 3):1662-71.

8. Khakoo GA, Lack G. Introduction of solids to the infant diet. Arch Dis Child 2004; $89(4): 295$.

9. Zutavern A, von Mutius E, Harris J, Mills P, Moffatt S, White C, et al. The introduction of solids in relation to asthma and eczema. Arch Dis Child 2004;89(4):303-8.

10. Snijders BE, Thijs C, Kummeling I, Penders J, van den Brandt PA. Breastfeeding and infant eczema in the first year of life in the KOALA birth cohort study: a risk-period specific analysis. Pediatrics 2007;119(1):e137-41.

11. Kummeling I, Thijs C, Penders J, Snijders BE, Stelma F, Reimerink J, et al. Etiology of atopy in infancy: the KOALA Birth Cohort Study. Pediatr Allergy Immunol 2005;16(8):679-84.

12. Aalberse RC, Koshte V, Clemens JG. Immunoglobulin E antibodies that crossreact with vegetable foods, pollen, and Hymenoptera venom. J Allergy Clin Immunol 1981;68(5):35664 .

13. Snijders BE, Thijs C, Dagnelie PC, Stelma FF, Mommers M, Kummeling I, et al. Breastfeeding duration and infant atopic manifestations, by maternal allergic status, in the first 2 years of life (KOALA study). J Pediatr 2007;151(4):347-51, 351 e1-2.

14. Illi S, von Mutius E, Lau S, Nickel R, Niggemann B, Sommerfeld C, et al. The pattern of atopic sensitization is associated with the development of asthma in childhood. J Allergy Clin Immunol 2001;108(5):709-14. 


\section{CHAPTER 4}

15. Liem JJ, Kozyrskyj AL, Huq SI, Becker AB. The risk of developing food allergy in premature or low-birth-weight children. J Allergy Clin Immunol 2007;119(5):1203-9.

16. Oddy WH, Holt PG, Sly PD, Read AW, Landau LI, Stanley FJ, et al. Association between breast feeding and asthma in 6 year old children: findings of a prospective birth cohort study. BMJ Clinical research ed 1999;319(7213):815-9.

17. Mihrshahi S, Ampon R, Webb K, Almqvist C, Kemp AS, Hector D, et al. The association between infant feeding practices and subsequent atopy among children with a family history of asthma. Clin Exp Allergy 2007;37(5):671-9.

18. Poole JA, Barriga K, Leung DY, Hoffman M, Eisenbarth GS, Rewers M, et al. Timing of initial exposure to cereal grains and the risk of wheat allergy. Pediatrics 2006;117(6):2175-82.

19. Morgan J, Williams P, Norris F, Williams CM, Larkin M, Hampton S. Eczema and early solid feeding in preterm infants. Arch Dis Child 2004;89(4):309-14.

20. Siltanen M, Kajosaari M, Pohjavuori M, Savilahti E. Prematurity at birth reduces the longterm risk of atopy. J Allergy Clin Immunol 2001;107(2):229-34.

21. Andreasyan K, Ponsonby AL, Dwyer T, Dear K, Cochrane J. Infant feeding and childhood atopy: does early introduction of non-milk fluids matter? Pediatr Allergy Immunol 2007;18(3):250-7.

22. de Jong MH, Scharp-van der Linden VT, Aalberse RC, Oosting J, Tijssen JG, de Groot CJ. Randomised controlled trial of brief neonatal exposure to cows' milk on the development of atopy. Arch Dis Child 1998;79(2):126-30.

23. de Jong MH, Scharp-Van Der Linden VT, Aalberse R, Heymans HS, Brunekreef B. The effect of brief neonatal exposure to cows' milk on atopic symptoms up to age 5. Arch Dis Child 2002;86(5):365-9.

24. Zutavern A, Brockow I, Schaaf B, Bolte G, von Berg A, Diez U, et al. Timing of Solid Food Introduction in Relation to Atopic Dermatitis and Atopic Sensitization: Results From a Prospective Birth Cohort Study. Pediatrics 2006;117(2):401-411.

25. van Wijk F, Knippels L. Initiating mechanisms of food allergy: Oral tolerance versus allergic sensitization. Biomed Pharmacother 2007;61(1):8-20.

26. Ivarsson A, Hernell O, Stenlund H, Persson LA. Breast-feeding protects against celiac disease. Am J Clin Nutr 2002;75(5):914-21. 
Cytokines and soluble CD14 in breast milk in relation with atopic manifestations in mother and infant (KOALA Study)

Bianca EP Snijders

Jan GMC Damoiseaux

John Penders

Ischa Kummeling

Foekje F Stelma

Ronald van Ree

Piet A van den Brandt

Carel Thijs

Clin Exp Allergy 2006;36:1609-15 


\begin{abstract}

\section{Background}

Conflicting evidence exists concerning the protective role of breastfeeding in allergy and atopic disease etiology. Breast milk contains biologically active molecules influencing the innate immune system of newborns.
\end{abstract}

\title{
Objective
}

We aim to assess whether cytokines (TGF- $\beta 1$, IL-10 and IL-12) and soluble CD14 ( $\mathrm{sCD}_{14}$ ) in breast milk are influenced by maternal atopic constitution and modify the development of atopic manifestations in infants.

\section{Methods}

Milk samples were collected at one month postpartum of 315 lactating mothers participating in the ongoing KOALA Birth Cohort Study. The cytokines and SCD14 were analyzed by ELISA in the aqueous fraction. We compared concentrations of cytokines and sCD14 in breast milk between mothers with and without an allergic history and also with and without allergic sensitization (specific lgE). Associations of cytokines and sCD14 with the development of eczema, wheezing in the first two years of life and allergic sensitization of infants at the age of 2 years, were analyzed by multivariate logistic regression analyses to correct for confounders.

\section{Results}

We found higher $\mathrm{SCD} 14$ levels in mothers with a positive versus negative allergic history (7.6 vs $7.0 \mu \mathrm{g} / \mathrm{mL} ; \mathrm{p}=0.04)$ and in mothers who were sensitized versus non-sensitized ( $7.8 \mathrm{vs} 7.1 \mu \mathrm{g} / \mathrm{mL} ; \mathrm{p}=0.03$ ). None of the studied immune factors were associated with infant's atopic outcomes. IL-10 was not detected above the detection limit of $0.2 \mathrm{pg} / \mathrm{ml}$.

\section{Conclusion}

Taken together the results of the present and previous studies, we conclude that there is no convincing evidence for a relation between TGF- $\beta 1, \mathrm{SCD} 14$, IL-10 or IL12 in breast milk and atopic manifestations in infants. 


\section{INTRODUCTION}

Atopic diseases such as atopic eczema, allergic rhinitis and allergic asthma have increased in the developed world during recent decades (1). Breastfeeding has been considered to afford protection against atopic disorders. Protection may be conveyed by biologically active molecules that are present in human milk such as: cytokines, chemokines, hormones, growth factors, secretory antibodies and essential fatty acids $(2,3)$. Via several mechanisms immune-modulating factors in human milk can actively stimulate the newborn's immune system, which is rapidly maturing during the first years of life (4). In the current study we focus on four immune factors (Transforming growth factor- $\beta 1$ (TGF- $\beta 1$ ), interleukin-10 (IL10), interleukin-12 (IL-12) and soluble CD14 (sCD14)) that may influence the innate immune system.

TGF- $\beta 1$ and IL-10 are anti-inflammatory cytokines produced by several cell types, including regulatory $T$ cells which are currently in the focus of allergy and asthma research (5). Regulatory T cells suppress both Th1 and Th2-mediated immune responses (6) and are thought to play a role in the development of allergic disease (7). Especially TGF- $\beta 1$ is an abundant cytokine in human milk (8). Oddy et al demonstrated a positive association between low concentrations of TGF- $\beta 1$ in human milk and infant wheezing (9).

Human milk also contains IL-12 and the soluble form of CD14 (sCD14). Both are lipopolysaccharide (LPS)(10) associated immune factors that promote Th1 development, thereby preventing excessive IgE production and allergic inflammation (11). CD14 is an innate immune receptor for LPS, a component of gram-negative bacterial cell walls (12). The complex interplay between $C D 14$, toll like receptor (TLR) 4 and MD-2 is responsible for recognition of LPS (13). Subsequently, intracellular signalling results in secretion of IL-12. An association was found between reduced $\mathrm{SCD} 14$ levels in breast milk and a diagnosis of eczema in children aged 6 months (14). Recently, increased levels of SCD14 were found to be associated with a lower incidence of doctor's diagnosed asthma at the age of two years, especially in children of mothers without a history of atopic diseases (15). Also, a deficit of IL-12 production was proposed to occur in atopic individuals (11). 


\section{CHAPTER 5}

There are two possible explanations for the relation between levels of immune factors in breast milk and the development of atopy in the infant: first, maternal atopic constitution (genetic or acquired) determines levels of cytokines in breast milk and infant's atopy by separate mechanisms; second, immune factors have a direct effect on mucosal immunity in the child.

This study had two objectives. First, we aimed to investigate whether the mother's atopic constitution influences milk levels of TGF- $\beta 1$, IL-10, IL-12 and SCD14. Second, we examined whether these immune factors are associated with the development of infant's atopy (eczema, wheezing) in the first two years of life and allergic sensitization at age two. 


\section{METHODS}

\section{Design}

This study is part of the KOALA Birth Cohort Study $(\mathrm{N}=2834)$, an ongoing prospective birth cohort study in the Netherlands. The design of the study has been described, in detail, elsewhere (16). Briefly, we recruited participants with diverse lifestyles (conventional and alternative) at 34 weeks of gestation. Pregnant women with a conventional lifestyle $(n=2343)$ were recruited from an ongoing prospective cohort study on Pregnancy-related Pelvic Girdle pain in the Netherlands. Additionally, pregnant women with an alternative lifestyle $(n=491)$ were recruited through several 'alternative' channels: organic food shops, anthroposophic doctors and midwifes, Steiner Schools, and magazines. During the first two years postpartum, information on breastfeeding, atopic outcomes and their determinants were collected for all members of the cohort by repeated questionnaires at 3, 7, 12 and 24 months. During home visits at 34-36 weeks of gestation maternal venous blood was collected. From October 2002 we started recruiting participants for breast milk sampling by asking pregnant mothers who intended to start breastfeeding to consent for breast milk collection. This resulted in breast milk being sampled in 315 breastfeeding mothers between December 2002 and September 2003, including a short questionnaire at the time of breast milk collection ( 1 month postpartum). The study (including biosampling) was approved by the medical ethics committee of the Maastricht University.

\section{Collection and processing of breast milk}

Mothers received a sterile $50 \mathrm{ml}$ tube (Cellstar PP-test tubes, Greiner bio-one, Austria) and were instructed to collect the milk sample in the morning, before breastfeeding their child, from the contra-lateral breast (since the last feeding) and to keep the tube in the refrigerator $\left( \pm 4^{\circ} \mathrm{C}\right)$ until it was collected by one of the researchers. If the mother was not able to collect the milk sample by herself (with or without a pumping regimen), an electric breast pump (Medela, Switzerland) was used with the help of one of the researchers (within the same day). During transport the milk samples were stored in a cooler (Coleman Company, Inc.) on packed ice $\left( \pm 4^{\circ} \mathrm{C}\right)$ until processing on the same day. The sample was centrifuged ( $400 \mathrm{~g}, 12$ minutes, no brake, $4^{\circ} \mathrm{C}$ ) to separate the lipid- and aqueous fraction. The lipid layer was trimmed off with a pipette and released in plastic storage vials (Sarstedt, Nümbrecht, Germany). The aqueous fraction was poured in other vials 
with another pipet. The remaining debris was not used to avoid contamination with cell fragments. All fractions were stored at $-80^{\circ} \mathrm{C}$ in the European Biobank Maastricht.

\section{ELISA assays in breast milk}

Quantitative colorimetric cytokine ELISA kits were used to assess the concentrations of TGF- $\beta 1, \mathrm{sCD} 14$ (R\&D Systems Europe Ltd, Abingdon, UK), IL-10 and IL-12 (Biosource Int. Camarillo (CA) USA) in human aqueous milk fractions according to the manufacturers instructions. The aqueous milk fractions were assayed at dilution factors of 1.4 for TGF- $\beta 1$ and 2000 for $\mathrm{SCD} 14$. The minimum detectable dose of TGF- $\beta 1$ and SCD14 was $7 \mathrm{pg} / \mathrm{ml}$ and $125 \mathrm{pg} / \mathrm{ml}$, respectively. For the activation of latent TGF- $\beta 1$ to the active form, a standard activation procedure was used. Briefly, $0.1 \mathrm{ml} 1 \mathrm{M} \mathrm{HCl}$ was added to $0.5 \mathrm{ml}$ aqueous milk fraction and subsequently mixed to incubate for 10 minutes at room temperature. Neutralization of the acidified milk sample was done by adding $0.1 \mathrm{ml} 1.2 \mathrm{M}$ $\mathrm{NaOH} / 0.5 \mathrm{M}$ HEPES. Undiluted aqueous milk fractions were used to determine the IL-10 and IL-12 concentrations. The minimum detectable dose was $0.2 \mathrm{pg} / \mathrm{ml}$ for IL-10 and $0.8 \mathrm{pg} / \mathrm{ml}$ for IL-12. All ELISA assays were performed in duplicate. We conducted a pilot study for all parameters. We could not detect IL-10 concentrations in our pilot study $(n=16)$.

\section{Determination of maternal and infant's total and specific IgE}

Maternal venous blood samples were obtained during a home visit at 34-36 weeks of gestation. Serum samples were analyzed for total IgE levels as described earlier $(17,18)$. For values $<150 \mathrm{IU} / \mathrm{ml}$ a sandwich RIA was used $(17)$, for values $>150 \mathrm{IU} / \mathrm{ml}$ a competitive RIA (18). Maternal venous blood samples were analyzed for specific IgE against 13 common respiratory and food allergens. Calculation was performed by means of a standard curve that was obtained by RAST with a dilution series of a chimeric monoclonal IgE antibody against the major allergen Der p 2 and Sepharose-coupled recombinant Der p 2 (19)

In order to collect venous blood of the infants, home visits were made at 2 years postpartum. Infant's venous blood samples were analyzed for specific IgE against hen's eggs, cow's milk, peanuts, birch, grass pollen, cat, dog and mite using RAST as described earlier (18). The detection limit for total and specific IgE was $0.50 \mathrm{IU} / \mathrm{ml}$ and $0.10 \mathrm{IU} / \mathrm{ml}$, respectively. 


\section{Definition of maternal allergic history and maternal sensitization}

A positive maternal allergic history was defined if in her self reported questionnaire the mother positively confirmed that a physician had at least once diagnosed asthma, eczema, allergy for house dust mite/pets, or allergic rhinoconjunctivitis (such as hayfever).

Maternal sensitization was considered as present if serum specific IgE against one or more of the tested inhalant or food allergens was positive $(>0.3 \mathrm{IU} / \mathrm{ml})$. High total IgE for mothers was arbitrarily defined as total IgE level $>100 \mathrm{IU} / \mathrm{ml}$.

\section{Definition of infant's atopic manifestations and infant's allergic sensitization}

Information on the development of eczema (based on ISAAC questions) was obtained in the 3, 7 and 12 months questionnaires. Parents were asked; 'has your child ever had an itchy rash that was coming and going in the past months'? If this question was answered affirmatively, infants were defined as having developed eczema in the first two years of life. Cases of only diaper rash, rash around the eyes and/or scalp scaling were excluded. 'Ever wheezing' was defined as parentally reported presence of wheezing, with at least one attack, in the 7, 12 or 24 month postpartum questionnaires. Infant's were considered to be sensitized if specific serum IgE-levels were $>0.3 \mathrm{IU} / \mathrm{ml}$ against one or more of the tested food or inhalant allergens. High total IgE for infants was arbitrarily defined as total IgE level > $10 \mathrm{IU} / \mathrm{ml}$.

\section{Atopic dermatitis by UK Working Party criteria}

To specify eczema reported by parents as described above, we defined atopic dermatitis according to UK Working Party criteria (20) for all infants who were visited at home at age 2 years. The probability of the presence of atopic dermatitis was derived from the presence of four clinical symptoms: 1) presence of itchy rash (PIR, coded as $0=$ absent, $1=$ present), 2 ) history of flexural dermatitis (HFD, $0=$ absent, 1 = present), 3 ) visible flexural dermatitis (VFD, $0=$ absent, $1=$ present), and 4 ) onset before age of 2 years (OB2, $0=$ absent, $1=$ present). The UK-WP probability score of atopic dermatitis $(A D)$ is then computed as: probability $A D=$ odds $(A D) /[$ odds $(A D)+1]$; where odds $(A D)=\exp [-4.36+1.84(\mathrm{HFD})+3.46(\mathrm{OB} 2)+$ 2.09 (VFD) +1.71(PIR)] (20). In this study, infants with a UK-WP probability score of atopic dermatitis $(A D)>0.9$ were regarded as infants with 'probable presence of atopic dermatitis'. 


\section{Statistical analysis}

Extreme values of concentrations of cytokines and $\mathrm{SCD}_{14}$ were not excluded since these did not influence our results. Mean values of concentrations of cytokines and $\mathrm{SCD}_{14}$ were compared between groups using analysis of variance (ANOVA). To assess the association between cytokines and infant's atopic manifestations we conducted a multivariate logistic regression analysis in order to adjust for possible confounders ('recruitment group' (conventional versus alternative), maternal age (years), maternal allergic history (yes/no), number of older siblings (no siblings, one, two or more), season of breast milk collection (winter 20022003, spring 2003, summer 2003), use of probiotics in capsules or yogurts at 1 months postpartum (yes/no), maternal infection in week of breast milk collection (yes; that is, vomiting, diarrhoea, having a cold, sore throat, mastitis, fever or urinary tract infection), time-interval between birth and breast milk collection (in days) and total storage time in freezer until analysis (in days)). Based on sample sizes of previous studies $(9,14)$ we estimated that 300 breast milk samples were sufficient to detect differences of interest. We consider $p$-values $\leq 0.05$ as statistically significant. All analyses are presented for both recruitment groups (conventional and alternative cohort) together, because stratified analyses showed similar results for both groups.

\section{RESULTS}

A total of 315 mothers donated a breast milk sample at one month postpartum. This sub cohort consisted of $60 \%$ of breastfeeding mothers from the KOALA study who were visited for venous blood collection at 34-36 weeks of gestation (from October 2002 onwards). The main reasons for not donating breast milk were unsuccessful breastfeeding or logistic reasons. The characteristics of these mothers and their infants are summarized in Table 1 . We could determine TGF- $\beta 1$ and $\mathrm{SCD}_{14}$ in 307 (98\%) breast milk samples whereas IL-12 was determined in 293 (93\%) samples. No data of IL-10 in breast milk is presented since we did not detect IL-10 above the detection limit of $0.2 \mathrm{pg} / \mathrm{ml}$. 


\section{Table 1}

Characteristics of participants (with conventional versus alternative lifestyle) with breast milk sample $(\mathrm{N}=315)$

\begin{tabular}{|c|c|c|}
\hline & $\begin{array}{l}\text { Conventional } \\
\mathrm{N}=146\end{array}$ & $\begin{array}{l}\text { Alternative } \\
\mathrm{N}=169\end{array}$ \\
\hline Maternal age in years (mean \pm SD) & $32.4 \pm 3.3$ & $34.0 \pm 4.2$ \\
\hline Breastfeeding duration in months (mean \pm SD) * & $4.2 \pm 3.0$ & $6.5 \pm 3.1$ \\
\hline Sex of infant (no. of boys, percentage) & $71(48.6 \%)$ & $83(49.1 \%)$ \\
\hline \multicolumn{3}{|l|}{ Infant's atopic outcome, at age 2 years } \\
\hline Eczema by questionnaire (yes, percentage) & $42(28.8 \%)$ & $51(30.2 \%)$ \\
\hline Atopic dermatitis by UK-WP (yes, percentage) & $16(11.0 \%)$ & $15(8.9 \%)$ \\
\hline Wheeze (yes, percentage) & $41(28.1 \%)$ & $42(24.9 \%)$ \\
\hline Both eczema + wheeze (yes, percentage) & $11(7.5 \%)$ & $12(7.1 \%)$ \\
\hline \multicolumn{3}{|l|}{ Cytokines and sCD14 in breast milk } \\
\hline $\mathrm{TGF}-\beta 1$ in $\mathrm{pg} / \mathrm{ml}($ mean $\pm \mathrm{SD}) \mathrm{N}=307^{\dagger}$ & $225.6 \pm 178.3$ & $212.5 \pm 117.8$ \\
\hline Range TGF- $\beta 1$ in $\mathrm{pg} / \mathrm{ml}$ & $12.0-1536.8$ & $2.0-647.9$ \\
\hline $\mathrm{IL}-10$ in $\mathrm{pg} / \mathrm{ml}$ & $N D^{\ddagger}$ & \\
\hline $\mathrm{sCD} 14$ in $\mu \mathrm{g} / \mathrm{ml}($ mean $\pm \mathrm{SD}) \mathrm{N}=307^{\dagger}$ & $7.7 \pm 2.9$ & $7.1 \pm 2.2$ \\
\hline Range $\mathrm{sCD}_{14}$ in $\mu \mathrm{g} / \mathrm{ml}$ & $1.7-23.8$ & $2.3-20.1$ \\
\hline $\mathrm{IL}-12$ in $\mathrm{pg} / \mathrm{ml}($ mean $\pm \mathrm{SD}) \mathrm{N}=293^{\dagger}$ & $10.6 \pm 6.5$ & $10.8 \pm 6.0$ \\
\hline Range IL-12 in $\mathrm{pg} / \mathrm{ml}$ & $0.7-52.8$ & $1.5-51.6$ \\
\hline
\end{tabular}

* $\quad$ Exclusive and non-exclusive breastfeeding.

$\dagger \quad$ Missings due to insufficient aqueous fraction available.

$\ddagger \quad$ Not detectable i.e. under the detection limit of $0.2 \mathrm{pg} / \mathrm{ml}$.

We found no difference in mean concentrations of TGF- $\beta 1$ in breast milk between mothers with or without an allergic history (Table 2). Also, mean concentrations of TGF- $\beta 1$ in breast milk were not different between mothers with and without allergic sensitization $(p=0.15)$ (Table 2 ) or between mothers with or without high levels of total IgE (not shown). For SCD14, we found a somewhat higher concentration in breast milk in mothers with an allergic history compared to mothers without (7.6 vs $7.0 \mu \mathrm{g} / \mathrm{ml} ; \mathrm{p}=0.04$ ) (Table 2 ). Also, we found a higher concentration of sCD14 in mothers who were sensitized compared to non sensitized mothers ( 7.8 vs 7.1 


\section{CHAPTER 5}

$\mu \mathrm{g} / \mathrm{ml}, \mathrm{p}=0.03$ ) (Table 2 ). The levels of $\mathrm{sCD} 14$ were similar in mothers with high versus low total IgE levels ( $7.3 \mathrm{vs} 7.2 \mu \mathrm{g} / \mathrm{ml} ; \mathrm{p}=0.84$; results not shown in table). Finally, we did not detect differences in mean concentrations of IL-12 in breast milk between mothers with and without an allergic history or between sensitized and non sensitized mothers (Table 2), nor between mothers with and without high levels of total IgE (not shown).

\section{Table 2}

Mean concentrations of TGF- $\beta 1, \mathrm{SCD} 14$ and IL-12 in breast milk related with maternal allergic history and specific serum IgE

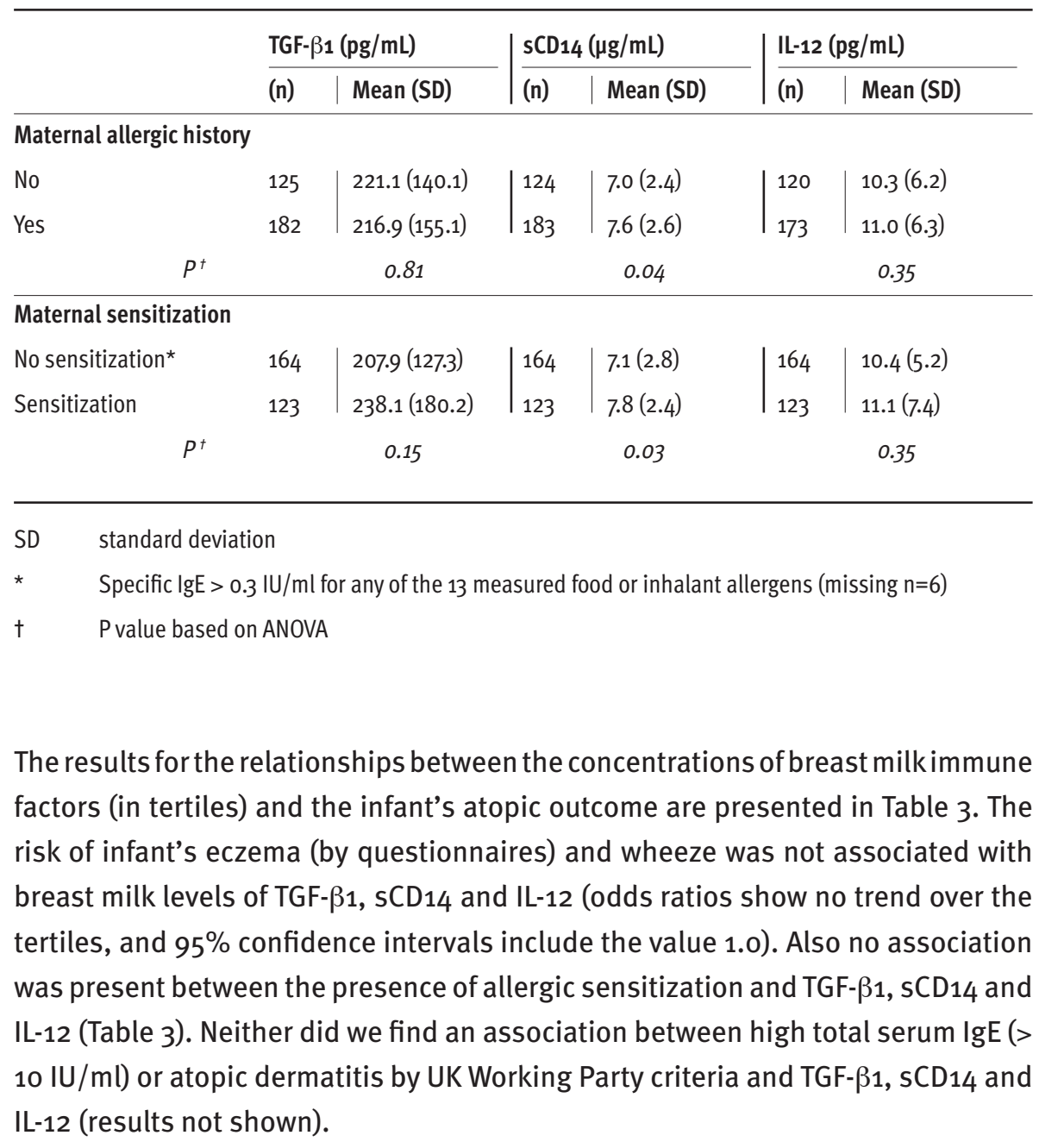




\section{Table 3}

Adjusted odds ratios for the presence of eczema and wheezing in the first two years of life and allergic sensitization at age 2 years, depending on the concentrations of TGF- $\beta 1, s C D 14$ and IL-12 (in tertiles) in breast milk

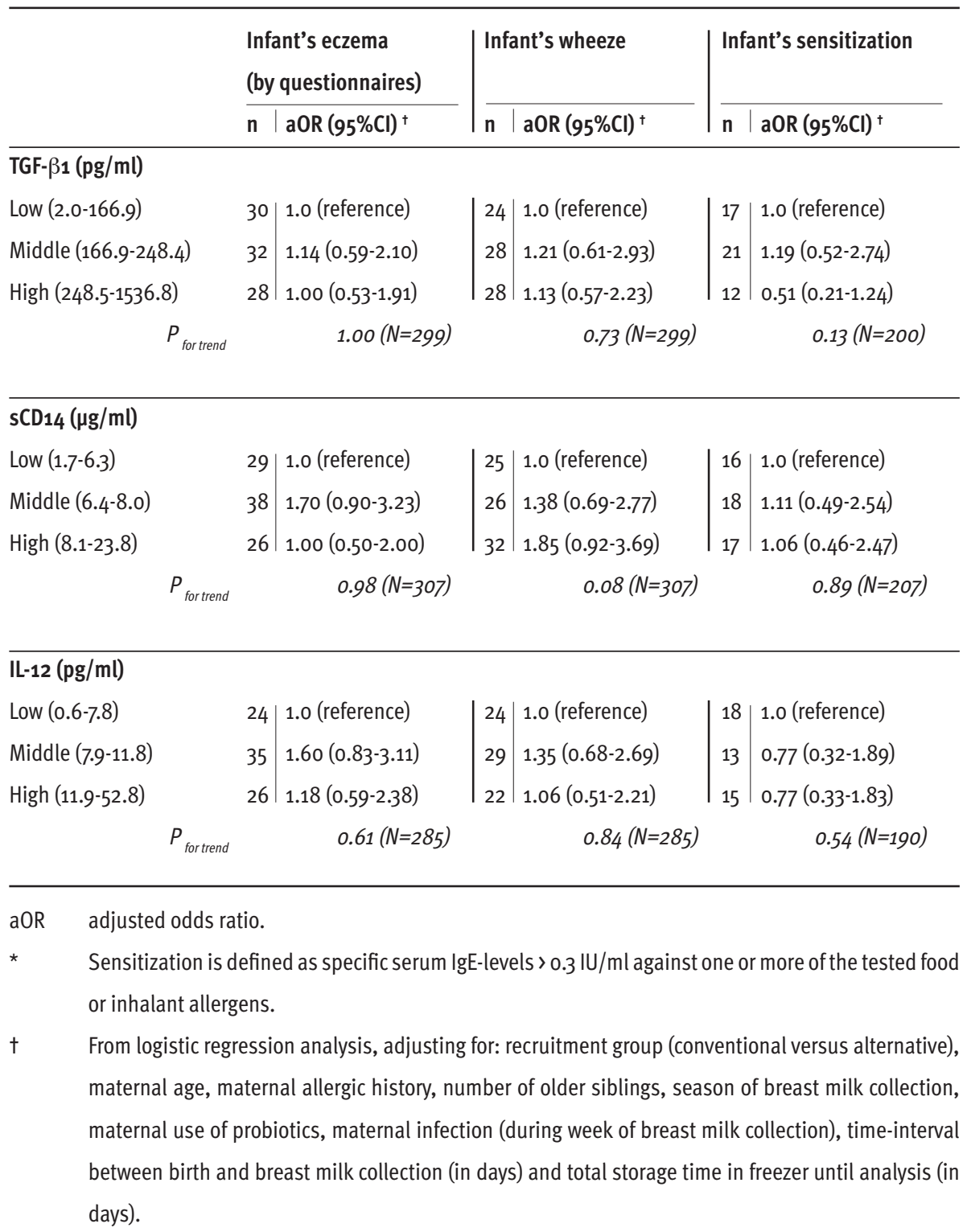




\section{DISCUSSION}

In the present study we found higher levels of $\mathrm{SCD}_{14}$ in mothers with a maternal allergic history and sensitization. No such associations between TGF- $\beta 1$ and IL12 in breast milk and maternal allergic status were found. None of the studied immune factors (TGF- $\beta 1, \mathrm{sCD}_{14}$ and IL-12) in breast milk were associated with infant's atopic outcomes.

Our first aim was to assess whether milk levels of TGF- $\beta 1, \mathrm{IL}-10, \mathrm{IL}-12$ and SCD14 reflect the mother's allergic history. A few studies have compared concentrations of immune factors in breast milk between atopic and non atopic mothers. In a small study, Rigotti et al found that TGF- $\beta 1$ was significantly less in the mature milk of allergic mothers (21). In agreement with the present study, Böttcher et al reported no differences for TGF- $\beta$ (22). In agreement with our findings, a small study found no associations between IL-12 in breast milk and a maternal atopic status (23). Our findings of higher levels of $\mathrm{sCD}_{14}$ in mothers with a maternal allergic history $(p=0.04)$ or mothers with sensitization $(p=0.03)$ have not been reported earlier. However, the results of a German study presenting a slightly higher prevalence of maternal atopic history in the upper quartile of breast milk $s C D 14$, directed towards borderline statistical significance $(p=0.07)(15)$. Savilahti et al found lower levels of $\mathrm{SCD} 14$ in colostrum of atopic versus nonatopic mothers when the definition of atopy was based on a single symptom but when a more rigid definition was used, the difference disappeared (24). For sCD14 levels in breast milk, our results tend towards a relation with both a maternal allergic history and maternal sensitization but not with high total IgE in the mother. We speculate that disease activity (at moment of breast milk sampling) in atopic mothers may be reflected in higher SCD14 levels. Higher levels of serum SCD14 are seen in subjects with disease activity for instance after exacerbation of asthma in children $(25,26)$. However, we did not assess the asthmatic status or the presence of rhinoconjuctivitis at the moment of breast milk sampling. Alternatively, atopic versus non-atopic mothers could differ in genetic constitution leading to different SCD14 levels. Guerra et al found that SCD14 levels in milk differed significantly by CD14/-1619 and CD14/-550 genotypes and haplotypes (27). The biologic relevance for the infant of such small differences in $\mathrm{SCD}_{14}$ concentrations between atopic and non atopic mothers can be argued. 
Our second aim was to assess whether TGF- $\beta 1, \mathrm{IL}-10, \mathrm{IL}-12$ and $\mathrm{SCD} 14$ levels in breast milk were associated with the development of infant's atopic manifestations. We consider infant's eczema (by questionnaire, adapted from ISAAC) and sensitization as separate outcome parameters instead of atopic eczema because sensitized infants do not necessarily show symptoms of eczema or vice versa (28). Consequently we use the term eczema instead of atopic eczema. However we use the term 'atopic dermatitis' for infants fulfilling the UK-WP criteria according to the criteria of Williams et al (20). If we used more stringent criteria for wheeze such as proposed by others (29), the number of cases was too small for a multivariate analysis.

We found no associations between TGF- $\beta 1, \mathrm{sCD} 14$ and IL-12 and infant's atopic outcomes.

The Infant Immune Study (Tucson, Arizona) found a statistically significant association between low levels of TGF- $\beta 1$ and wheeze at the age of 1 year (9). Furthermore, the British study of Jones et al found that low levels of breast milk sCD14 were associated with a diagnosis of eczema in 6-months-old infants, irrespective of skin prick testing, in a high risk cohort (14). More recently, Rothenbacher et al found a lower risk for atopic eczema for breastfed infants ( $\geq 6$ months, SCD14 in highest quartile) versus less than 3 months breastfeeding. They suggested that the beneficial effects of breastfeeding are supported by high levels of $\mathrm{SCD}_{14}$ (15). By contrast, Laitinen et al found that $\mathrm{SCD}_{14}$ tended to be higher in mature breast milk received by infants with versus without atopic eczema with positive skin prick test. Previous studies have investigated IL-10 (9, 22, 30-32), IL$12(23,33,34)$ or TGF- $\beta 1(8,9,22,24,32,35,36)$ concentrations in breast milk with inconsistent results with respect to the mothers and/or infant's atopic outcomes. We speculate that three explanations may clarify these inconsistencies. First, differences in methodologies could be an explanation, e.g. the moment of breast milk sampling. It can be anticipated that cytokine concentrations are higher in colostrum than mature milk. This is not supported by a study with longitudinal human milk collection, reporting a little change in the mean concentration of both TGF- $\beta 1$ and TGF- $\beta 2$ during the first 12 weeks of lactation, including colostrum (36). However, this may not necessarily apply for SCD14 and IL-12. Second, effects caused by colostral factors may no longer be valid at the infant's age of one month because the permeability of the gut is diminishing and the efficiency of proteolysis is enhanced (37). 
In addition, Blais et al found that SCD14 in breast milk is more susceptible to the infant's pancreatin digestion versus pepsin digestion by in vitro experiments, suggesting decreased activity of $\mathrm{S} C \mathrm{C} 14$ in the LPS-rich environment of the distal bowel (38).

Third, the use of different ELISA kits may explain inconsistent results between studies (23). It was noted in two studies that the use of ELISA assays of R\&D Systems did not detect IL-12 in breast milk $(33,34)$. We were also unable to detect IL-12 in breast milk with that same ELISA. However, using a high sensitivity kit (Biosource Int.) we detected IL-12 in our breast milk samples. Previously, IL-12 was also found in breast milk samples in a study using ELISA assays of Pharmingen (San Diego, CA) (23).

A limitation of our study was a restriction of complete standardization of breast milk collection. Different modes of pumping and individual variation in pumping techniques could have led to variation of the measured immune factors. The strength of this study was the number of breast milk samples available as only a few studies measured SCD14 or cytokines in a large amount of breast milk samples.

In summary, we found higher concentrations of $\mathrm{SCD}_{14}$ in breast milk in mothers with a positive allergic history and mothers with allergic sensitization but not for high total IgE. Taken together the results of the present study and other studies, we conclude that there may be no consistent effect on inter-individual differences of TGF- $\beta 1, \mathrm{sCD}_{14}$ and IL-12 in breast milk and the infant's atopic outcomes. Therefore the search for modifying effects of factors present in breast milk on the development of atopic manifestations should continue.

\section{ACKOWLEDGEMENTS}

We thank Nicole Custers (assistance in breast milk collection), Chantal Delnoy/ Brigitte Winants/Karen Groot (blood collection), Cobie Martens/Willeke Hendrikx (assistance data collection questionnaires), Astrid van Leeuwen (Sanquin, IgE determination), Mia Vaessen (assistance in ELISA) and all mothers and their infants, participating in the KOALA study. 


\section{REFERENCES}

1. Worldwide variation in prevalence of symptoms of asthma, allergic rhinoconjunctivitis, and atopic eczema: ISAAC. The International Study of Asthma and Allergies in Childhood (ISAAC) Steering Committee. Lancet 1998;351(9111):1225-32.

2. Hanson LA, Korotkova M, Haversen L, Mattsby-Baltzer I, Hahn-Zoric M, Silfverdal SA, et al. Breast-feeding, a complex support system for the offspring. Pediatr Int 2002;44(4):34752.

3. Wijga AH, van Houwelingen AC, Kerkhof M, Tabak C, de Jongste JC, Gerritsen J, et al. Breast milk fatty acids and allergic disease in preschool children: the Prevention and Incidence of Asthma and Mite Allergy birth cohort study. J Allergy Clin Immunol 2006;117(2):440-7.

4. Newburg DS. Innate immunity and human milk. J Nutr 2005;135(5):1308-12.

5. Akbari O, Stock P, DeKruyff RH, Umetsu DT. Role of regulatory T cells in allergy and asthma. Curr Opin Immunol 2003;15(6):627-33.

6. Damoiseaux J. Regulatory T cells: back to the future. Neth J Med 2006;64(1):4-9.

7. Romagnani S. Immunologic influences on allergy and the $\mathrm{TH}_{1} / \mathrm{TH}_{2}$ balance. J Allergy Clin Immunol 2004;113(3):395-400.

8. Saito S, Yoshida M, Ichijo M, Ishizaka S, Tsujii T. Transforming growth factor-beta (TGFbeta) in human milk. Clin Exp Immunol 1993;94(1):220-4.

9. Oddy WH, Halonen M, Martinez FD, Lohman IC, Stern DA, Kurzius-Spencer M, et al. TGF-beta in human milk is associated with wheeze in infancy. J Allergy Clin Immunol 2003;112(4):7238.

10. Frey EA, Miller DS, Jahr TG, Sundan A, Bazil V, Espevik T, et al. Soluble CD14 participates in the response of cells to lipopolysaccharide. J Exp Med 1992;176(6):1665-71.

11. Camporota L. Interleukin-12 and the development of atopy. Clin ExpAllergy2001;31(10):14814 .

12. Wright SD, Ramos RA, Tobias PS, Ulevitch RJ, Mathison JC. CD14, a receptor for complexes of lipopolysaccharide (LPS) and LPS binding protein. Science 1990;249(4975):1431-3.

13. Miyake K. Innate recognition of lipopolysaccharide by CD14 and toll-like receptor 4-MD-2: unique roles for MD-2. Int Immunopharmacol 2003;3(1):119-28.

14. Jones CA, Holloway JA, Popplewell EJ, Diaper ND, Holloway JW, Vance GHs, et al. Reduced soluble CD14 levels in amniotic fluid and breast milk are associated with the subsequent development of atopy, eczema, or both. J Allergy Clin Immunol 2002;109(5):858-66.

15. Rothenbacher D, Weyermann M, Beermann C, Brenner H. Breastfeeding, soluble CD14 concentration in breast milk and risk of atopic dermatitis and asthma in early childhood: birth cohort study. Clin Exp Allergy 2005;35(8):1014-21. 


\section{CHAPTER 5}

16. Kummeling I, Thijs C, Penders J, Snijders BE, Stelma F, Reimerink J, et al. Etiology of atopy in infancy: the KOALA Birth Cohort Study. Pediatr Allergy Immunol 2005;16(8):679-84.

17. Stallman PJ, Aalberse RC. Estimation of basophil-bound IgE by quantitative immunofluorescence microscopy. Int Arch Allergy Appl Immunol 1977;54(1):9-18.

18. Akkerdaas JH, Wensing M, Asero R, Rivas MF, Knulst AC, Bolhaar S, et al. IgE binding to pepsin-digested food extracts. Int Arch Allergy Immunol 2005;138(3):203-8.

19. Schuurman J, Perdok GJ, Lourens TE, Parren PW, Chapman MD, Aalberse RC. Production of a mouse/human chimeric IgE monoclonal antibody to the house dust mite allergen Der $p$ 2 and its use for the absolute quantification of allergen-specific IgE. J Allergy Clin Immunol 1997;99(4):545-50.

20. Williams HC, Burney PG, Hay RJ, Archer CB, Shipley MJ, Hunter JJ, et al. The U.K. Working Party's Diagnostic Criteria for Atopic Dermatitis. I. Derivation of a minimum set of discriminators for atopic dermatitis. Br J Dermatol 1994;131(3):383-96.

21. Rigotti E, Piacentini GL, Ress M, Pigozzi R, Boner AL, Peroni DG. Transforming growth factorbeta and interleukin-10 in breast milk and development of atopic diseases in infants. Clin Exp Allergy 2006;36(5):614-8.

22. Bottcher MF, Jenmalm MC, Garofalo RP, Bjorksten B. Cytokines in breast milk from allergic and nonallergic mothers. Pediatr Res 2000;47(1):157-62.

23. Bryan DL, Hawkes JS, Gibson RA. Interleukin-12 in human milk. Pediatr Res 1999;45(6):8589.

24. Savilahti E, Siltanen M, Kajosaari M, Vaarala O, Saarinen KM. IgA antibodies, TGF-beta1 and -beta2, and soluble CD14 in the colostrum and development of atopy by age 4. Pediatr Res 2005;58(6):1300-5.

25. Garty BZ, Monselise Y, Nitzan M. Soluble CD14 in children with status asthmaticus. Isr Med Assoc J 2000;2(2):104-7.

26. Kusunoki T, Nakahata T, Miyanomae T, Inoue Y. Possible dual effect of CD14 molecule on atopy. Am J Respir Crit Care Med 2002;165(4):551-2; author reply 552.

27. Guerra S, Carla Lohman I, LeVan TD, Wright AL, Martinez FD, Halonen M. The Differential Effect of Genetic Variation on Soluble CD14 Levels in Human Plasma and Milk. Am J Reprod Immunol 2004;52(3):204-11.

28. Kusel MM, Holt PG, de Klerk N, Sly PD. Support for 2 variants of eczema. J Allergy Clinical Immunol 2005;116(5):1067-72.

29. Martinez FD. Development of wheezing disorders and asthma in preschool children. Pediatrics 2002;109(2 Suppl):362-7.

30. Rudloff S, Niehues T, Rutsch M, Kunz C, Schroten H. Inflammation markers and cytokines in breast milk of atopic and nonatopic women. Allergy 1999;54(3):206-11. 
31. Garofalo R, Chheda S, Mei F, Palkowetz KH, Rudloff HE, Schmalstieg FC, et al. Interleukin10 in human milk. Pediatr Res 1995;37(4 Pt 1):444-9.

32. Ogawa J, Sasahara A, Yoshida T, Sira MM, Futatani T, Kanegane H, et al. Role of transforming growth factor-beta in breast milk for initiation of IgA production in newborn infants. Early Hum Dev 2004:77(1-2):67-75.

33. Srivastava MD, Srivastava A, Brouhard B, Saneto R, Groh-Wargo S, Kubit J. Cytokines in human milk. Res Commun Mol Pathol Pharmacol 1996;93(3):263-87.

34. Sone S, Tsutsumi H, Takeuchi R, Matsuda K, Imai S, Ogra PL, et al. Enhanced cytokine production by milk macrophages following infection with respiratory syncytial virus. J Leukoc Biol 1997;61(5):630-6.

35. Kalliomaki M, Ouwehand A, Arvilommi H, Kero P, Isolauri E. Transforming growth factorbeta in breast milk: a potential regulator of atopic disease at an early age. J Allergy Clin Immunol 1999;104(6):1251-7.

36. Hawkes JS, Bryan DL, James MJ, Gibson RA. Cytokines (IL-1beta, IL-6, TNF-alpha, TGFbeta1, and TGF-beta2) and prostaglandin E2 in human milk during the first three months postpartum. Pediatr Res 1999;46(2):194-9.

37. Goldman AS, Chheda S, Garofalo R. Evolution of immunologic functions of the mammary gland and the postnatal development of immunity. Pediatr Res 1998;43(2):155-62.

38. Blais DR, Harrold J, Altosaar I. Killing the messenger in the nick of time: persistence of breast milk SCD14 in the neonatal gastrointestinal tract. Pediatr Res 2006;59(3):371-6. 

6

\section{$C D 14$ polymorphisms in mother and infant, soluble CD14 in breast milk and atopy development in the infant (KOALA Birth Cohort Study)}

Bianca EP Snijders

Foekje F Stelma

Naomi E Reijmerink

Carel Thijs

Gerrit van der Steege

Jan GMC Damoiseaux

Piet A van den Brandt

Ronald van Ree

Dirkje S Postma

Gerard H Koppelman

Submitted for publication 


\begin{abstract}
Background

Different $C D_{14}$ polymorphisms have been associated with atopic phenotypes in infants. In addition, $C D_{14}$ genotypes of breastfeeding mothers have been associated with soluble $\mathrm{CD}_{14}$ ( $\left(\mathrm{SCD}_{14}\right.$ ) levels in breast milk. The role of $C_{14}$ genotype of infant and mother and their interaction with $\mathrm{SCD}_{14}$ levels in breast milk in atopy development remains to be established.
\end{abstract}

\title{
Objective
}

We aimed to study the associations of $C D_{14}$ single nucleotide polymorphisms (SNPs), and their interaction with breast milk sCD14, with atopy development at age two. In addition, we assessed whether levels of sCD14 in breast milk associated with SNPs in CD14.

\section{Methods}

Four SNPs in CD14 gene were investigated in 698 infants and 188 mothers. Associations between these SNPs, sCD14 and atopy development were analyzed in multiple logistic or linear regression models.

\section{Results}

SNP CD14/-1619 was associated with eczema. The CC homozygotes showed a lower risk of eczema versus $\Pi$ homozygotes (adjusted odds ratio $=0.56,95 \%$ confidence interval 0.33-0.96) in a co-dominant model. Breast milk sCD14 levels did not significantly modify the effect of the child's $C D 14$ genotype on atopy development ( $p$ interaction $\geq 0.10$ ). Maternal $C D_{14}$ SNPs were not significantly associated with $\mathrm{sCD} 14$ levels in breast milk (ANOVA, $\mathrm{p} \geq 0.48$ ).

\section{Conclusions}

We found an association between CC homogyzotes of SNP CD14/-1619 and eczema. Our data did not support a modifying role of breast milk sCD14 levels on the relationship between $C D_{14}$ genotype and atopy development at age 2 years. 


\section{INTRODUCTION}

Both genetic and environmental factors are known to contribute to the development of atopy, such as eczema, total IgE, allergen sensitization and asthma. ${ }^{1}$ The gene encoding $C D_{14}$ is a candidate gene for atopy on chromosome 5931.1, a region that has been linked with asthma and atopic responses. ${ }^{2}$ The protein CD14 is a cell-surface receptor that in conjunction with Toll-like receptor- (TLR) 4 binds to bacterial lipopolysaccharide (LPS), thereby playing a role in the innate host defence.3, 4 In addition, the soluble form of this protein receptor (sCD14) may act as a receptor through $\mathrm{CD}_{14}$-negative cells, such as intestinal epithelial and dendritic cells, enabling these cells to respond to endotoxin stimuli and to affect the immune system in postnatal maturation. ${ }^{5,6}$

Most studies investigating the association between $C D 14$ and atopic phenotypes have focussed on SNP CD14/-159 (i.e. rs2569190, also called CD14/-260). Baldini et al reported an association between $\mathrm{CD}_{14} /-159 \mathrm{C}$ allele and serum IgE levels in skin test positive children. ${ }^{2}$ Later reports also found an association of the $\mathrm{C}$ allele with total serum IgE levels and other atopic phenotypes ${ }^{7-9}$, but other studies did not confirm this ${ }^{10-14}$ or found an association with the T allele. ${ }^{15-17}$ These discrepancies have been explained by interaction of the $C D 14$ genotype with different levels of environmental microbial exposures, such as lipopolysaccharide (LPS).$^{18}$ Alternatively, populations may differ by other genetic polymorphisms that could be in linkage disequilibrium (LD) with $\mathrm{CD}_{14} /-159 .{ }^{19}$

The CD14/-159 promoter SNP may alter gene transcription ${ }^{20}$ and thus affect soluble CD14 levels. Indeed, Baldini et al reported an association of $C_{14} /-159$ with serum sCD14 levels at age 11 years. ${ }^{2}$ More recently, they found an association between $C D_{14}$ genotypes (CD14/-4089, CD14/-1619, CD14/-159) and plasma SCD14 at three months of age, but not at birth, providing further support that genetic variation in the $C D_{14}$ gene affects serum sCD14 levels. ${ }^{20}$ Also, Kabesch et al showed lower levels of serum SCD14 in CC versus TT homozygotes of the CD14/-159. ${ }^{13}$ However, this association was not confirmed by others. ${ }^{21,22}$

Few studies have investigated whether maternal $C D_{14}$ polymorphisms could influence the levels of sCD14 in breast milk. In one study, CD14/-550 (rs5744455) and $C_{14} /-1619$ (rs2915863) genotypes and haplotypes in mothers were 


\section{CHAPTER 6}

associated with $\mathrm{SCD} 14$ levels in breast milk collected at day 11 postpartum. ${ }^{23}$ Breastfed infants are exposed to $\mathrm{SCD}_{14}$ in breast milk which may act as an additional exogenous source of CD14. Interestingly, reduced levels of SCD14 in breast milk were associated with the development of eczema at the age of 6 months in a high risk cohort (i.e. positive skin prick test response from firstdegree relatives). ${ }^{24}$ Similarly, lower SCD14 levels in breast milk were associated with the development of atopy in 4 year old children. ${ }^{6}$ However, we could not confirm such an association in the first two years of life. ${ }^{25}$ Thus, both the infant's $C D_{14}$ genotype and the concentration of $\mathrm{sCD}_{14}$ in breast milk may affect atopy development in the child. It is unknown if these two factors interact. It is possible that for example, exogenous CD14 in breast milk may increase the receptor surface in the gut of $\mathrm{sCD}_{14}$ and therefore compensate lower $\mathrm{CD}_{14}$ availability in the child due to a specific $C D_{14}$ promoter genotype.

In this study we investigate the associations of maternal $C D_{14}$ SNPs on SCD14 levels in breast milk. Second, we investigate the association between $C D 14$ SNPs and atopy development in the first two years of life. Finally, we assess whether the relation between infant $C D_{14}$ genotypes and atopy development may be modified by $\mathrm{SCD} 14$ levels in breast milk. 


\section{METHODS}

\section{Design}

This study is part of the KOALA Birth Cohort Study, the Netherlands. The design of the study has been described in detail previously. ${ }^{26}$ Briefly, participants with diverse lifestyles (conventional and alternative) were recruited at 34 weeks of gestation through different channels. Pregnant women with a conventional lifestyle ( $n=2343$ ) were recruited from an ongoing prospective cohort study on Pregnancy-related Pelvic Girdle pain in the Netherlands. Additionally, pregnant women with an alternative lifestyle $(n=491)$ were recruited through organic food shops, anthrophosophic doctors and midwifes, Steiner Schools, and magazines. During the first two years postpartum, information on breastfeeding, atopic outcomes and their determinants were collected for all members of the cohort by repeated questionnaires at ages 3, 7, 12 and 24 months. The study was approved by the medical ethics committee of the Maastricht University. Written informed parental consent was obtained from all participants.

\section{Recruitment of the subcohort}

In this study we started with a subcohort of 864 of a total of 2834 KOALA participants. This is the number of infants that was available for vena puncture at age 2 based on informed parental consent. All participants were considered for home visits at age 2 years in the period in which we had the financial means for those visits. Only for logistic reasons (e.g. geographic distance), some infants were not included, eventually leading to 864 infants. Table I B shows the baseline characteristics of the confounders of both the subcohort $(n=864)$ versus the total cohort $(n=2834)$. The selection of infants of whom buccal swabs for DNA extraction was available was based on the criterion: presence of venous blood at age 2. This resulted in a total of 698 (of the subcohort of 864 ) of whom the parents gave informed consent for obtaining DNA via buccal swabs.

For the assessment of gene-environment interactions we had the availability of 315 mothers in whom breast milk was sampled. This number was based on the number of mothers that intended to breastfeed (asked during pregnancy) and consent for sampling breast milk 1 month postpartum in the period between December 2002 and September 2003. Eventually, a total of 307 samples were suitable for sCD14 determination. Of those 307 mothers in whom we sampled breast milk, a total of 188 mothers gave consent to collect DNA via buccal swabs. 


\section{Measurement of infant's total and specific IgE}

In order to collect venous blood of the infants, home visits were made at 2 years postpartum. Infants' venous blood samples were analyzed for specific IgE against hen's eggs, cow's milk, peanuts, birch, grass pollen, cat, dog and house dust mite using Radio Allergo Sorbent Test (RAST) as described earlier. ${ }^{27}$ Total serum IgE levels were determined as described earlier. ${ }^{27,28}$ For values $<150 \mathrm{IU} / \mathrm{ml}$ a sandwich Radio Immuno Assay (RIA) was used ${ }^{28}$, for values $>150 \mathrm{IU} / \mathrm{ml}$ a competitive RIA ${ }^{29}$. The detection limit for total and specific IgE was $0.50 \mathrm{IU} / \mathrm{ml}$ and $0.10 \mathrm{IU} / \mathrm{ml}$, respectively.

\section{Definitions of atopy and IgE sensitization}

Infants were defined as having developed eczema in the first two years of life if their parents reported an itchy rash that was coming and going in the past months based on the 7,12 and 24 month postpartum questionnaires, based on ISAAC questions. Cases of only diaper rash, rash around the eyes and/or scalp scaling were excluded.

As a stricter phenotype of the eczema we defined atopic dermatitis according to UK Working Party criteria ${ }^{30.32}$ for all infants who were visited at home at age 2 years. The probability of the presence of atopic dermatitis was derived from the presence of four clinical symptoms: 1 ) presence of itchy rash (PIR, coded as $0=$ absent, 1 = present), 2) history of flexural dermatitis (HFD, $0=$ absent, $1=$ present), 3) visible flexural dermatitis (VFD, $0=$ absent, $1=$ present), and 4 ) onset before age of 2 years $(\mathrm{OB} 2,0=$ absent, $1=$ present). The UK-WP probability score of atopic dermatitis $(A D)$ is then computed as: probability $A D=$ odds $(A D) /[$ odds $(A D)+1]$; where odds $(A D)=\exp [-4.36+1.84(\mathrm{HFD})+3.46(\mathrm{OB} 2)+2.09(\mathrm{VFD})+1.71(\mathrm{PIR})] . .^{\circ} \mathrm{In}$ this study, infants with a UK-WP probability score of atopic dermatitis $(A D)>90 \%$ were regarded as infants with 'probable presence of atopic dermatitis'. Infants were considered to be sensitized if specific serum IgE-levels were $>0.3 \mathrm{IU} / \mathrm{ml}$ against one or more of the tested food or inhalant allergens.

\section{Soluble CD14 in breast milk}

The collection and processing of breast milk has been described in detail elsewhere. ${ }^{25}$ Briefly, breast milk was sampled in 315 breastfeeding mothers between December 2002 and September 2003, including a short questionnaire at the time of breast milk collection ( 1 month postpartum). In order to assess $\mathrm{SCD} 14$ concentrations in the aqueous fraction of breast milk, we used quantitative 
colorimetric cytokine ELISA kits (R\&D Systems Europe Ltd, Abingdon, UK) according to the manufacturer's instruction.

\section{DNA collection, processing and genotyping}

Genomic DNA was extracted from buccal swabs from mothers and infants by performing chloroform-2-propanol extraction. ${ }^{33}$ Subsequently, DNA was amplified by using REPLI-g UltraFast technology (Qiagen ${ }^{\mathrm{TM}}$ ). Haplotype tagging SNPs with a minimal allele frequency of $10 \%$ were retrieved from the Innate Immunity PGA, NHLBI Program in Genomic Applications. URL: http://innateimmunity.net (october 2005) Additional SNPs were selected from biomedical literature available until October 2005 for SNPs within $C D_{14}$ known to have functional impact or to be associated with asthma or atopy.

\section{Genotyping of $C D_{14}$ SNPS}

Five single nucleotide polymorphisms (SNP) of the $C D_{14}$ gene (i.e. CD14/-159 (rs2569190), CD14/-1145 (rs2569191), CD14/-1619 (rs2915863), CD14/-550 (rs5744455) and CD14/-1359 (rs3138078)) were genotyped in 698 KOALA infants (i.e. those infants who had a home visit at age 2 (for (specific) IgE determination and assessment of AD UK-WP) and whose parents later gave also informed consent for DNA collection). The same polymorphisms were determined in 188 KOALA mothers (i.e. those mothers who had collected a breast milk sample at one month postpartum and who later gave informed consent for DNA collection).

The innate immunity data are based on genotype information of 23 subjects of European American ancestry from the Coriell Institute. Minimal sets of haplotype tagging SNPs were obtained using PHASE software package which uses a Bayesian partition/ligation method (PHASE (v.2) http://www.stats.ox.ac.uk/mathgen/ software.html.)

We aimed to obtain information on $>80 \%$ of the variation within a gene by selecting tagSNPs of those haplotypes that represent haplotype frequencies of $>80 \%$ of all haplotypes observed in the population. Figure 1 shows the linkage disequilibrium between the markers.

Genotyping was performed by Competitive Allele-Specific PCR using KASParTM genotyping chemistry, performed under contract by K-Biosciences (http://www. kbiosciences.co.uk/). Quality of genotype data was guaranteed by standards of K-Biosciences. We verified the genotyping quality by another three steps: 1) 16 

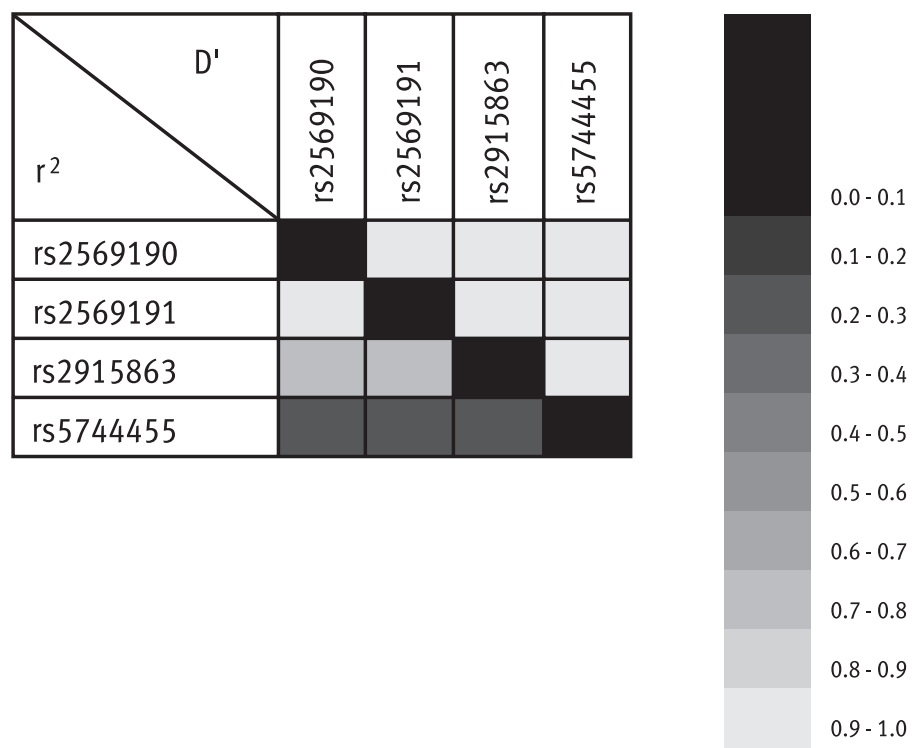

Figure 1

Linkage disequilibrum between markers

samples were genotyped in both genomic and amplified DNA; 2) in the same genotyping process, trios were added to check inheritance of alleles between parents and children was checked using FBAT (http://www.biostat.harvard.edu); 3) genotype data were analyzed for deviations from Hardy-Weinberg equilibrium.

Genotyping of the same polymorphisms in 188 KOALA mothers was done as follows:

Three SNPs were analysed using TaqMan probes and primers on an ABl79ooHT apparatus using SDS 2.2 software (Applied Biosystems). The assay for the SNP at nucleotide position -159 (rs2569190) was ordered as an Assay-onDemand assay ( $\mathrm{hCV}$ 16043997), and TaqMan assays for the -550 (rs5744455) and -1619 (rs2915863) were ordered through the Assay-by-Design service (Applied Biosystems). Primers and MGB-probes for the latter two assays were: rs5744455, forward primer 5'-AAGAAAGTATTACTTAATCAAAGGAGCAAGGA, reversed primer 5'- AACCTCATCTGTTGGCACCAA, VIC-probe 5'- AAGAAAAGGAAGTTAGTCTAAA and FAM-probe 5'-AAAAGGAAGTTGGTCTAAA ; rs2915863, forward primer 5'GGCGAGAGCCACCACA, reversed primer 5'- CAACAAGAACAAAACTCCGTCTCAA, VIC- 
probe 5'-CTGAAAGTCTIITIACTITAT, andFAM-probe 5'-TGAAAGTCTIITATIITAT. The fourth SNP, rs2569191 at -1145, was analysed by allele specific, quantitative PCR. Using one reversed and three different forward primers, one for each allele and a third primer amplifying both alleles, 3 separate real time PCR reactions were carried out using a standard PCR protocol with a SYBR Green containing reaction mixture (Quantitect, Qiagen Benelux BV, The Netherlands) on an ABI790oHT machine. Ct values of all three reactions were determined with the aid of SDS 2.2 software. The delta-Ct between the respective allele specific reactions and the both-allele reaction were calculated allowing the genotypes to be determined. The sequence of the reversed primer was 5'-GGTCTAGGGATGTGGACCTG, the sequences of the three forward primers were: -1145Both 5'-GAGGATTAATTAGTA ACTCACCAGT, -1145C-allele 5'-GGATTAATTAGTAACTCACCAGTcTC, -1145T-allele 5'GGATTAATTAGTAACTCACCAGTCTT. The lower case " $c$ " nucleotide at the third to last position is a deliberately introduced mismatch with respect to the target sequence to improve amplification specificity.

\section{Statistical analyses}

Genotype distribution was tested for deviations from Hardy-Weinberg Equilibrium using $\chi^{2}$ analyses. The associations between sCD14 levels in breast milk and maternal $C_{14}$ polymorphisms were determined using analysis of variance (ANOVA). We tested all the genetic models in a co-dominant model, by analyzing the three genotypes separately.

Relationship between infant CD14 polymorphisms and the development of atopy until age 2 years: Association analyses were performed in infants who received a house visit at age 2 years $(n=867)$. The logistic regression analysis was adjusted for recruitment group (conventional versus alternative), maternal age, siblings atopic history i.e. parental reported doctor's diagnosed food allergy, eczema, hay fever, asthma, pet and/or house dust mite allergy (no siblings; $\geq 1$ siblings, all none-atopic; or $\geq 1$ siblings, at least 1 atopic), maternal smoking during pregnancy/lactation (yes versus no), presence of pets i.e. cats and/or dogs (yes versus no), gender of the infant (boy, girl). All potential confounders were simultaneously included in the logistic regression model. With regard to Total IgE as an outcome, the corresponding geometric means were determined by means of ANOVA (adjusted for the same confounders). 
Gene Environment Interactions between infant $C D 14$ polymorphisms and SCD14 levels in breast milk: When assessing the gene environment interactions between $C D_{14}$ and SCD14, we used the subgroup of breastfed infants of whose mothers information on breast milk SCD14 concentration was available $(n=307)$. The potential confounders included in the logistic regression model were similar as described above. In addition, the level of $\mathrm{SCD}_{14}(\mu \mathrm{g} / \mathrm{mL})$ in breast milk was added as co-variable since we aimed to address the gene-environment interaction between sCD14 (high (i.e. upper tertile) versus low (i.e. middle and lower tertile)) in breast milk and infant $C D_{14}$ polymorphisms, comparing logistic regression models with and without interaction terms using the Likelihood Ratio test.

\section{RESULTS}

Baseline characteristics of the study population are summarized in Table $1 \mathrm{~A}$. Infants of mothers in the alternative lifestyle cohort were less likely to be exposed to smoking during pregnancy or lactation than infants of mothers in the conventional cohort ( $2 \%$ versus $8 \%$, respectively). Also, more infants of mothers with alternative lifestyle were breastfed than infants of mothers in the conventional cohort (97\% versus $83 \%$ ). 1 SNP failed because of designing problems (CD14/1359 (rs3138078), however this SNP was not a haplotype tagging SNP (i.e. in strong LD with CD14/-550 (rs5744455)), but a SNP previously associated with atopy. Therefore this SNP was not replaced by another SNP. 


\section{Table 1 A}

Baseline characteristics of infants in both recruitment groups and total of the subcohort

\begin{tabular}{|c|c|c|c|c|c|c|}
\hline & \multicolumn{2}{|c|}{$\begin{array}{l}\text { CONVENTIONAL } \\
(\mathrm{N}=622)^{\star}\end{array}$} & \multicolumn{2}{|c|}{$\begin{array}{l}\text { ALTERNATIVE } \\
(\mathrm{N}=242)^{*}\end{array}$} & \multicolumn{2}{|c|}{$\begin{array}{c}\text { TOTAL } \\
(\mathrm{N}=864)^{*}\end{array}$} \\
\hline & $\mathrm{n}$ & (\%) & n & (\%) & $\mathrm{n}$ & (\%) \\
\hline \multicolumn{7}{|l|}{ CD14 polymorphisms tested $n(\%)$} \\
\hline CD14/-159 ${ }^{\dagger}($ rs2569190) & 489 & $(79 \%)$ & 203 & $(84 \%)$ & 692 & $(80 \%)$ \\
\hline $\mathrm{CD}_{14} /-1145^{\dagger}(\mathrm{rs} 2569191)$ & 491 & $(79 \%)$ & 207 & $(86 \%)$ & 698 & $(81 \%)$ \\
\hline $\mathrm{CD}_{14} /-1619^{\dagger}(\mathrm{rs} 2915863)$ & 477 & $(77 \%)$ & 204 & $(84 \%)$ & 681 & $(79 \%)$ \\
\hline $\mathrm{CD}_{14} /-550^{\dagger}(\mathrm{rs} 5744455)$ & 477 & $(77 \%)$ & 201 & $(83 \%)$ & 678 & $(78 \%)$ \\
\hline Gender boys (yes) n (\%) & 322 & $(52 \%)$ & 126 & $(52 \%)$ & 448 & $(52 \%)$ \\
\hline \multicolumn{7}{|l|}{ Sibling history of atopy development } \\
\hline No siblings & 523 & $(84 \%)$ & 191 & $(79 \%)$ & 714 & $(83 \%)$ \\
\hline$\geq 1$ sibling, all non-atopic & 65 & $(11 \%)$ & 31 & $(13 \%)$ & 96 & $(11 \%)$ \\
\hline$\geq 1$ sibling, at least one atopic & 34 & $(6 \%)$ & 20 & $(8 \%)$ & 54 & $(6 \%)$ \\
\hline Maternal age in years, mean (sd) & & $32(4)$ & & $34(4)$ & & $33(4)$ \\
\hline Maternal smoking during pregn/lact (yes) & 48 & $(8 \%)$ & 4 & $(2 \%)$ & 52 & $(6 \%)$ \\
\hline Presence of pets (yes) & 254 & $(41 \%)$ & 94 & $(39 \%)$ & 348 & $(40 \%)$ \\
\hline \multicolumn{7}{|l|}{ Infants' atopic outcomes until age 2 years } \\
\hline Atopic Dermatitis UK-WP & 88 & $(14 \%)$ & 28 & $(12 \%)$ & 116 & $(13 \%)$ \\
\hline Eczema & 199 & $(32 \%)$ & 69 & $(29 \%)$ & 268 & $(31 \%)$ \\
\hline Sensitization & 168 & $(29 \%)$ & 57 & $(24 \%)$ & 225 & $(27 \%)$ \\
\hline Total serum IgE (IU/mL), median (range) & \multicolumn{2}{|c|}{$11(\leq 0.5-5300)$} & \multicolumn{2}{|c|}{$16(\leq 0.5-3700)$} & \multicolumn{2}{|c|}{$12(\leq 0.5-5300)$} \\
\hline
\end{tabular}

* $\quad$ overall numbers may not add up to total because of missing values

$\dagger$ relative from the transcription start site 
CHAPTER 6

\section{Table 1 B}

Distribution of confounders: subcohort versus total cohort

\begin{tabular}{|c|c|c|c|c|}
\hline \multirow[b]{2}{*}{ Alternative participants (yes) n (\%) } & \multicolumn{2}{|c|}{$\begin{array}{l}\text { SUBCOHORT } \\
(\mathrm{N}=864)^{*}\end{array}$} & \multicolumn{2}{|c|}{$\begin{array}{l}\text { TOTAL } \\
(\mathrm{N}=\mathbf{2 8 3 4})^{*}\end{array}$} \\
\hline & 242 & $(28 \%)$ & 491 & $(17 \%)$ \\
\hline Gender boys (yes) n (\%) & 448 & $(52 \%)$ & 1450 & $(51 \%)$ \\
\hline \multicolumn{5}{|l|}{ Sibling history of atopy development } \\
\hline No siblings & 714 & $(83 \%)$ & 2250 & $(79 \%)$ \\
\hline$\geq 1$ sibling, all non-atopic & 96 & $(11 \%)$ & 329 & $(12 \%)$ \\
\hline$\geq 1$ sibling, at least one atopic & 54 & $(6 \%)$ & 127 & $(5 \%)$ \\
\hline Maternal age in years, mean (sd) & & $33(4)$ & & $32(4)$ \\
\hline Maternal smoking during pregn/lact (yes) & 52 & $(6 \%)$ & 243 & $(9 \%)$ \\
\hline Presence of pets (yes) & 348 & $(40 \%)$ & 1194 & $(42 \%)$ \\
\hline
\end{tabular}

* overall numbers may not add up to total because of missing values

\section{Table 2}

Allele Frequencies for mother and infant

\begin{tabular}{lccc}
\hline & & Mother $(\mathrm{N}=\mathbf{1 8 8})^{\star}$ & Infant $(\mathrm{N}=\mathbf{6 9 8})^{\star}$ \\
\hline CD14/-159 & $\Pi$ & $27.0 \%$ & $24.3 \%$ \\
& $\mathrm{CT}$ & $51.4 \%$ & $48.7 \%$ \\
& $\mathrm{CC}$ & $21.6 \%$ & $27.0 \%$ \\
\hline $\mathrm{CD} 14 /-1145$ & $\mathrm{CC}$ & $27.7 \%$ & $25.2 \%$ \\
& $\mathrm{CT}$ & $52.7 \%$ & $47.3 \%$ \\
& $\Pi$ & $19.7 \%$ & $27.5 \%$ \\
\hline $\mathrm{CD} 14 /-1619$ & $\mathrm{CC}$ & $21.4 \%$ & $17.0 \%$ \\
& $\mathrm{CT}$ & $51.9 \%$ & $48.5 \%$ \\
& $\Pi$ & $26.7 \%$ & $34.5 \%$ \\
\hline $\mathrm{CD} 14 /-550$ & $\mathrm{CC}$ & $61.2 \%$ & $69.1 \%$ \\
& $\mathrm{CT}$ & $36.2 \%$ & $35.0 \%$ \\
& $\Pi$ & $2.7 \%$ & $5.9 \%$ \\
& & & \\
\hline
\end{tabular}

Overall numbers (not shown) did not always add up to total of 188 for mothers and 698 for infants because of missing values 
The distributions of maternal and infant genotypes for the four different SNPs are presented in Table 2. Genotype frequencies of all four SNPs in mother and infant were found to be in Hardy-Weinberg Equilibrium ( $p$ values from $\chi^{2}$-tests always larger than 0.51).

\section{Relationship between SCD14 in breast milk and maternal CD14 polymorphisms}

Concentrations of sCD14 in breast milk $(\mathrm{N}=307)$ were normally distributed (mean $7.4 \mu \mathrm{g} / \mathrm{mL}$, standard deviation $2.6 \mu \mathrm{g} / \mathrm{mL}$ ). Table 3 shows that mean $\mathrm{sCD} 14$ concentrations in breast milk did not differ across the genotypes of the four tested maternal $C D_{14}$ polymorphisms.

\section{Table 3}

Values of $\mathrm{SCD}_{14}$ in breast milk by $\mathrm{CD}_{14}$ genotypes of the mother

\begin{tabular}{|c|c|c|c|}
\hline & & $\mathbf{N}$ & $\begin{array}{l}\mathrm{sCD} 14 \text { in breast milk } \\
\text { (in } \mu \mathrm{g} / \mathrm{mL} \text { ), mean (sd) }\end{array}$ \\
\hline \multirow[t]{4}{*}{ CD14/-159 } & $\pi$ & 50 & $7.6(2.0)$ \\
\hline & CT & 95 & $7.2(2.6)$ \\
\hline & $C \mathrm{C}$ & 40 & $7.4(3.3)$ \\
\hline & & & ANOVA $(p$ value $)=0.70$ \\
\hline \multirow[t]{4}{*}{$\mathrm{CD}_{14 /-1145}$} & $\mathrm{CC}$ & 52 & $7.6(2.1)$ \\
\hline & СT & 99 & $7.2(2.6)$ \\
\hline & $\Pi$ & 37 & $7.6(3.5)$ \\
\hline & & & ANOVA $(p$ value $)=0.58$ \\
\hline \multirow[t]{4}{*}{ CD14/-1619 } & $\mathrm{CC}$ & 40 & $7.6(2.0)$ \\
\hline & CT & 97 & $7.2(2.6)$ \\
\hline & $\Pi$ & 50 & $7.4(3.1)$ \\
\hline & & & ANOVA $(p$ value $)=0.57$ \\
\hline \multirow[t]{4}{*}{$\mathrm{CD} 14 /-550$} & $\mathrm{CC}$ & 115 & $7.3(2.5)$ \\
\hline & СT & 68 & $7.4(2.9)$ \\
\hline & $\Pi$ & 5 & $8.8(2.4)$ \\
\hline & & & ANOVA $(p$ value $)=0.48$ \\
\hline
\end{tabular}




\section{Relationship between infant $\mathrm{CD}_{14}$ polymorphisms and the development of atopy until age 2 years}

One $C D 14$ polymorphism was significantly associated with eczema. CC homozygotes of CD14/-1619 showed a statistically significantly lower risk of eczema compared with $\Pi$ homozygotes (adjusted $\mathrm{OR}=0.56,95 \% \mathrm{Cl}$ 0.33-0.96, Table 4 ) in the co-dominant model, an effect not observed in the heterozygotes (CT heterozygotes: adjusted $\mathrm{OR}=1.28,95 \% \mathrm{Cl} 0.89-1.84$, Table 4). When combining

\section{Table 4}

Adjusted odds ratios for CD14 polymorphisms and atopy development until age 2 years $(\mathrm{N}=864)$

\begin{tabular}{|c|c|c|c|c|}
\hline & & $\begin{array}{l}\text { AD UK-WP } \\
\text { aOR }(95 \% \mathrm{Cl})^{*}\end{array}$ & $\begin{array}{l}\text { ECZEMA } \\
\text { aOR }(95 \% \mathrm{Cl})^{*}\end{array}$ & $\begin{array}{l}\text { ALLERGIC SENSITIZATION } \\
\text { aOR }(95 \% \mathrm{Cl})^{\star}\end{array}$ \\
\hline \multirow{3}{*}{ CD14/-159 } & $\mathrm{CC}$ & 1.00 (reference) & 1.00 (reference) & 1.00 (reference) \\
\hline & $\mathrm{CT}$ & $1.59(0.92-2.75)$ & $1.32(0.89-1.96)$ & $1.13(0.75-1.72)$ \\
\hline & $\Pi$ & $0.86(0.43-1.17)$ & $0.77(0.47-1.24)$ & $0.91(0.55-1.49)$ \\
\hline
\end{tabular}

\begin{tabular}{ll|l|l|l}
\hline $\mathrm{CD} 14 /-1145$ & $\Pi 1.00$ (reference) & 1.00 (reference) & 1.00 (reference) \\
& $\mathrm{CT}$ & $1.44(0.84-2.45)$ & $1.32(0.89-1.96)$ & $1.03(0.68-1.56)$ \\
& $\mathrm{CC}$ & $0.74(0.38-1.46)$ & $0.78(0.48-1.24)$ & $0.86(0.53-1.40)$
\end{tabular}

\begin{tabular}{ll|l|l|l}
\hline CD14/-1619 & $\Pi 1.00$ (reference) & 1.00 (reference) & 1.00 (reference) \\
& CT & $1.35(0.82-2.21)$ & $1.28(0.89-1.84)$ & $1.02(0.69-1.50)$ \\
& CC & $0.55(0.25-1.21)$ & $0.56(0.33-0.96)$ & $0.90(0.54-1.51)$
\end{tabular}

\begin{tabular}{ll|l|l|l}
\hline CD14/-550 & CC & 1.00 (reference) & 1.00 (reference) & 1.00 (reference) \\
CT & $1.43(0.90-2.27)$ & $1.22(0.86-1.74)$ & $1.19(0.82-1.73)$ \\
$\Pi$ & $0.59(0.17-2.01)$ & $0.83(0.40-1.79)$ & $1.39(0.65-2.96)$
\end{tabular}

\footnotetext{
* Adjusted odds ratios (aOR) with $95 \%$ confidence intervals ( $95 \%-\mathrm{Cl})$ from logistic regression analysis, adjusted for: recruitment group (conventional versus alternative), maternal age, siblings atopic history i.e. parental reported doctor's diagnosis of food allergy, eczema, hay fever, asthma, pet and/or house dust mite allergy (no siblings; $\geq 1$ siblings, all none-atopic; or $\geq 1$ siblings, at least 1 atopic), maternal smoking during pregnancy/lactation (yes versus no), presence of pets i.e. cats and/or dogs (yes versus no), gender of the infant (boy, girl)
} 
the $\Pi$ homozygotes and $\mathrm{CT}$ heterozygotes into a recessive model, again the $\mathrm{CC}$ homozygotes showed a lower risk of eczema $(\mathrm{OR}=0.4895 \% \mathrm{Cl} 0.30-0.79$, not shown in Table 4). The same adjusted OR was observed for AD UK-WP (Table 4). None of the other SNPs were found to be statistically significantly associated with the outcomes (AD UK-WP, eczema, or allergic sensitization at age 2 (Table 4)). Also, there were no statistically significant associations between any of the tested $C D_{14}$ polymorphisms and crude geometric means of total IgE levels at age 2 (Figure 2). These results for total IgE levels did not change after adjusting for all potential confounders (results not shown).
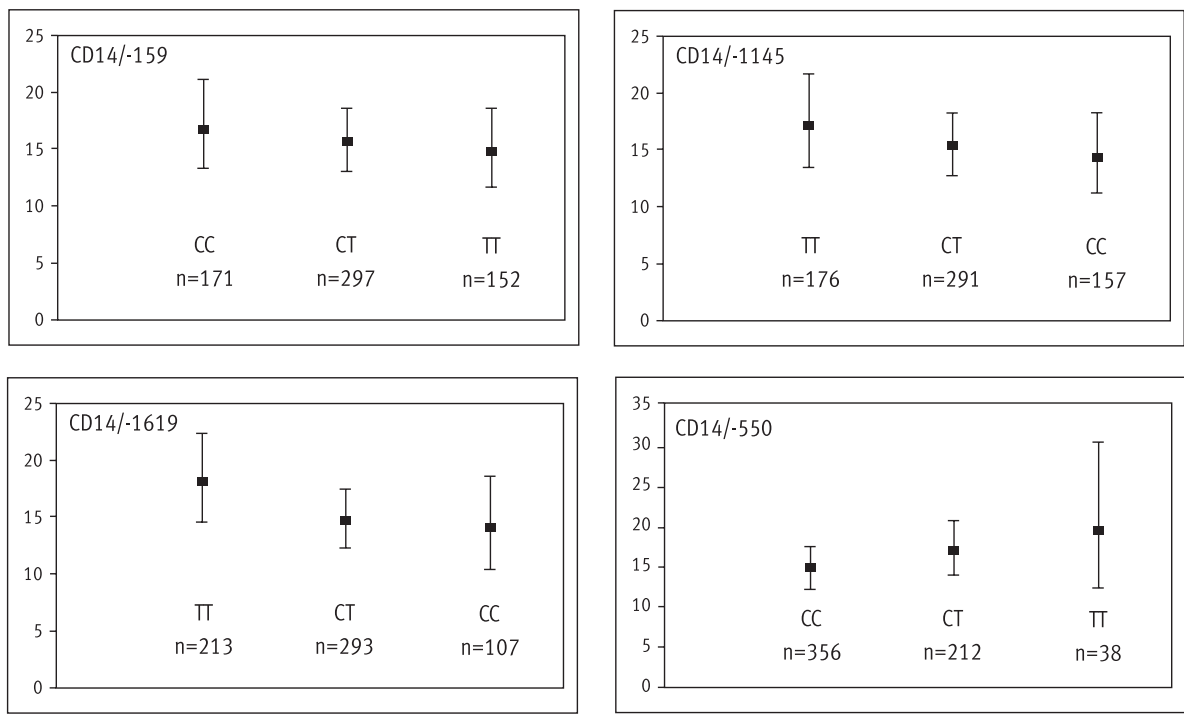

y-axis: concentration total $\lg E($ in $\mathrm{IU} / \mathrm{mL}$ ) at 2 years

Figure 2

Geometric Means ( $95 \% \mathrm{Cl}$ ) for total IgE levels at age 2 years by Infant CD14 polymorphisms*.

Gene Environment Interactions between infant CD14 polymorphisms and sCD14 levels in breast milk

Breast milk sCD14 levels did not modify the effect of infant's CD14 genotype on atopy development at age 2 years. All multiplicative interaction terms that were assessed in order to test our initial hypothesis (i.e. the effect of infant CD14 polymorphism may be modified by $\mathrm{SCD}_{14}$ levels in breast milk), were statistically non-significant ( $p$-values for interactions always larger than $0.10, \mathrm{~N}=307$ ). 


\section{DISCUSSION}

This study shows a protective association for CC homozygotes of $C D 14$ gene (SNP CD14/-1619) on eczema until the age of 2 years both in a co-dominant and a recessive model for the $C$ allele. To our knowledge, we are the first to report such an association between SNP CD14/-1619 and infant eczema. Our results on eczema were confirmed when taking a more strict phenotype, i.e. atopic dermatitis by UKWP, although this result was not statistically significant probably due to a smaller sample size.

Earlier, an association has been found between two other CD14 SNPs (CD14/2738 (=rs2569193) and CD14/-159) and eczema. ${ }^{34}$ Our results can not be regarded as a confirmation of the results on SNP rs2569193, given the low level of Linkage Disequilibrium ( $r^{2}$ of 0.2 ) between this SNP and CD14/-1619 (www.innateimmunity. net). For SNP CD14/-159, we were not able to confirm this association. The discrepant finding may be explained by differences in phenotype definition. In the study of Litonjua et al34, parental reported eczema at 2 years was used, which was validated against both clinical examination and clinical chart-recorded diagnosis. Finally, these differences may be caused by other population specific SNPs, which could be in Linkage Disequilibrium with $\mathrm{CD}_{14} /$-159 in one population but not in another. Also, interactions between $C D_{14}$ and environmental exposures may vary between populations and geographical areas. ${ }^{19}$ We did not correct for multiple testing given the specific hypothesis we formulated. The consistence of our finding for both eczema and atopic dermatitis by UK-WP implies that these findings are not likely due to chance. However, we acknowledge the multiplicity of our tests which implicates that these results need to be interpreted with caution.

Previously, we hypothesized that atopic versus non atopic-mothers may have a different genetic constitution, possibly leading to different $s C D 14$ levels in breast milk. ${ }^{25}$ We found that atopic mothers had slightly higher levels of sCD14 in breast milk versus non-atopic mothers. ${ }^{25}$ However, in the present study we found no significant associations between maternal CD14 polymorphisms and the concentration of $\mathrm{sCD}_{14}$ in breast milk, determined at 1 month postpartum. Therefore, the effect of maternal atopic predisposition on $\mathrm{sCD}_{14}$ in breast milk could not be related to the $\mathrm{CD}_{14}$ polymorphisms in the present study. In contrast with our findings, Guerra et al found that $\mathrm{SCD}_{14}$ levels in milk differed significantly 
by $C D 14 /-550$ and $C D 14 /-1619$ genotypes and haplotypes at day $11 .{ }^{23}$ Several reasons might explain these different findings. First, subjects from the study by Guerra et al in Tucson (USA) may not be comparable to our Dutch population due to different genetic make-up. Indeed, $24 \%$ of the studied population in the Tucson study were of Hispanic origin (other $76 \%$ non-Hispanic Caucasians). ${ }^{23}$ However, when comparing the $\mathrm{CD} 14$ allele frequencies between the two studies, no important differences were observed. Second, mean concentrations of SCD14 in breast milk found in the Tucson study ${ }^{23}$ were approximately 2 -fold the concentrations of $\mathrm{sCD} 14$ detected in our samples. As already hypothesized by Vercelli et al ${ }^{18,35}$, the effect of $C_{14}$ may be dose-dependent. Possibly this is also the case for $\mathrm{SCD}_{14}$. The differences in $\mathrm{SCD}_{14}$ concentration could also be due to a difference in timing of breast milk sampling (i.e. 11 days (Tucson) versus 1 month (KOALA) postpartum).

Since asthma and atopy are complex disorders, it has been thought that geneenvironment or gene-gene interactions are likely to contribute to inconsistent study results. Earlier, SNP CD14/-159 has been shown to alter the transcriptional activity of $C D 14 .{ }^{20}$ Therefore it can be postulated that interactions of this SNP with other genes and environmental exposures could further modulate gene expressions and lead to different effects on IgE production and expression of atopic disorders. ${ }^{35}$ In the present study, we found no evidence that breast milk sCD14 levels could modify the effect of the child's $C D 14$ genotype on atopy development. It has been proposed that statistical significance can only be reached when the combination of two effects exceeds the multiplicative value of both effects assessed separately. ${ }^{36}$ However, this definition of interaction may be conservative and is hardly observed in genetic studies of complex diseases, since large study populations or very strong interactions are needed to reach statistical significance for multiple interaction. ${ }^{37}$ Our negative results may indeed be explained by a lack of power, since we were dependent on the number of breast milk samples $(\mathrm{N}=307)$. We are aware that our sample size is limited to detect gene environment interactions. However, we were able to exclude a strong interacting effect of breastfeeding and CD14 genotype. Also, we did not find strong evidence for substantial selection bias as a result of using a subcohort (Table 1B). The number of alternative participants was higher but we believe that we have correctly adjusted for this confounder. We conclude from our data that a strong interacting effect of breast milk $\mathrm{SCD}_{14}$ with $C \mathrm{CD}_{14}$ genotype on atopy 
development was not present. Another explanation for these results may be a dose-dependent relationship between environmental exposures to bacterial products and the outcome of the immune response..$^{18}$ Interestingly, Simpson et al showed in children with the CC genotype of SNP CD14/-159 that an increasing endotoxin load was associated with a significant reduction in the risk of allergic sensitization and eczema but with an increased risk of nonatopic wheeze. ${ }^{38}$ However, their results showed no effect on atopic wheeze, suggesting that the same genotype may confer an increase, a decrease, or no effect on sensitization, dependent on the population endotoxin exposure. ${ }^{38}$

In conclusion, we found a protective association between the $C D 14$ gene (SNP CD14/-1619) and infant eczema at the age of 2 years. Second, we found no significant associations between maternal $C D_{14}$ polymorphisms and the concentration of $\mathrm{SCD}_{14}$ in breast milk collected at one month postpartum. We conclude that breast milk sCD14 levels do not modify the effect of the child's CD14 genotype on the development of atopic manifestations at age 2 years.

\section{ACKNOWLEDGEMENTS}

From the University Medical Center Groningen (The Netherlands), we thank Renske Bottema (DNA collection), Marcel Mulder (genotyping of KOALA mothers), Marjan Kerkhof (scientific discussion). Last but not least, we thank all mothers and infants participating in this study. 


\section{REFERENCES}

1. Martinez FD. Gene-environment interactions in asthma: with apologies to William of Ockham. Proc Am Thorac Soc 2007; 4:26-31.

2. Baldini M, Lohman IC, Halonen M, Erickson RP, Holt PG, Martinez FD. A Polymorphism* in the 5 ' flanking region of the CD14 gene is associated with circulating soluble CD14 levels and with total serum immunoglobulin E. American journal of respiratory cell and molecular biology 1999; 20:976-83.

3. Wright SD, Ramos RA, Tobias PS, Ulevitch RJ, Mathison JC. CD14, a receptor for complexes of lipopolysaccharide (LPS) and LPS binding protein. Science 1990; 249:1431-3.

4. Miyake K. Innate recognition of lipopolysaccharide by CD14 and toll-like receptor 4-MD-2: unique roles for MD-2. Int Immunopharmacol 2003; 3:119-28.

5. Martinez FD. Maturation of immune responses at the beginning of asthma. J Allergy Clin Immunol 1999; 103:355-61.

6. Savilahti E, Siltanen M, Kajosaari M, Vaarala O, Saarinen KM. IgA antibodies, TGF-beta1 and -beta2, and soluble CD14 in the colostrum and development of atopy by age 4. Pediatr Res 2005; 58:1300-5.

7. Koppelman GH, Reijmerink NE, Colin Stine O, Howard TD, Whittaker PA, Meyers DA, et al. Association of a promoter polymorphism of the CD14 gene and atopy. American journal of respiratory and critical care medicine 2001; 163:965-9.

8. Buckova D, Holla LI, Schuller M, Znojil V, Vacha J. Two CD14 promoter polymorphisms and atopic phenotypes in Czech patients with IgE-mediated allergy. Allergy 2003; 58:10236.

9. Leung TF, Tang NL, Sung YM, Li AM, Wong GW, Chan IH, et al. The C-159T polymorphism in the CD14 promoter is associated with serum total IgE concentration in atopic Chinese children. Pediatr Allergy Immunol 2003; 14:255-60.

10. Heinzmann A, Dietrich H, Jerkic SP, Kurz T, Deichmann KA. Promoter polymorphisms of the CD14 gene are not associated with bronchial asthma in Caucasian children. Eur J Immunogenet 2003; 30:345-8.

11. Sengler C, Haider A, Sommerfeld C, Lau S, Baldini M, Martinez F, et al. Evaluation of the CD14 C-159 T polymorphism in the German Multicenter Allergy Study cohort. Clin Exp Allergy 2003; 33:166-9.

12. Hui Liang X, Cheung W, Kiat Heng C, Jun Liu J, Wei Li C, Lim B, et al. CD14 promoter polymorphisms have no functional significance and are not associated with atopic phenotypes. Pharmacogenet Genomics 2006; 16:229-36.

13. Kabesch M, Hasemann K, Schickinger V, Tzotcheva I, Bohnert A, Carr D, et al. A promoter 


\section{CHAPTER 6}

polymorphism in the CD14 gene is associated with elevated levels of soluble CD14 but not with IgE or atopic diseases. Allergy 2004; 59:520-5.

14. Kedda MA, Lose F, Duffy D, Bell E, Thompson PJ, Upham J. The CD14 C-159T polymorphism is not associated with asthma or asthma severity in an Australian adult population. Thorax 2005; 60:211-4.

15. Gao PS, Mao XQ, Baldini M, Roberts MH, Adra CN, Shirakawa T, et al. Serum total IgE levels and CD14 on chromosome 5931. Clin Genet 1999; 56:164-5.

16. Ober C, Tsalenko A, Parry R, Cox NJ. A second-generation genomewide screen for asthmasusceptibility alleles in a founder population. Am J Hum Genet 2000; 67:1154-62.

17. Sackesen C, Karaaslan C, Keskin O, Tokol N, Tahan F, Civelek E, et al. The effect of polymorphisms at the CD14 promoter and the TLR4 gene on asthma phenotypes in Turkish children with asthma. Allergy 2005; 60:1485-92.

18. Vercelli D. Learning from discrepancies: CD14 polymorphisms, atopy and the endotoxin switch. Clin Exp Allergy 2003; 33:153-5.

19. Kusunoki T, Nakahata T, Miyanomae T, Inoue Y. Possible dual effect of CD14 molecule on atopy. Am J Respir Crit Care Med 2002; 165:551-2; author reply 2.

20. LeVan TD, Guerra S, Klimecki W, Vasquez MM, Lohman IC, Martinez FD, et al. The impact of CD14 polymorphisms on the development of soluble CD14 levels during infancy. Genes Immun 2006; 7:77-80.

21. Heesen M, Blomeke B, Schluter B, Heussen N, Rossaint R, Kunz D. Lack of association between the -260 C-->T promoter polymorphism of the endotoxin receptor $\mathrm{CD}_{14}$ gene and the CD14 density of unstimulated human monocytes and soluble CD14 plasma levels. Intensive Care Med 2001; 27:1770-5.

22. Rahman SH, Salter G, Holmfield JH, Larvin M, McMahon MJ. Soluble CD14 receptor expression and monocyte heterogeneity but not the C-260T CD14 genotype are associated with severe acute pancreatitis. Crit Care Med 2004; 32:2457-63.

23. Guerra S, Carla Lohman I, LeVan TD, Wright AL, Martinez FD, Halonen M. The Differential Effect of Genetic Variation on Soluble CD14 Levels in Human Plasma and Milk. Am J Reprod Immunol 2004; 52:204-11.

24. Jones CA, Holloway JA, Popplewell EJ, Diaper ND, Holloway JW, Vance GHs, et al. Reduced soluble CD14 levels in amniotic fluid and breast milk are associated with the subsequent development of atopy, eczema, or both. Journal of allergy and clinical immunology 2002; 109:858-66.

25. Snijders BE, Damoiseaux JG, Penders J, Kummeling I, Stelma FF, van Ree R, et al. Cytokines and soluble $\mathrm{CD}_{14}$ in breast milk in relation with atopic manifestations in mother and infant (KOALA Study). Clin Exp Allergy 2006; 36:1609-15. 
26. Kummeling I, Thijs C, Penders J, Snijders BE, Stelma F, Reimerink J, et al. Etiology of atopy in infancy: the KOALA Birth Cohort Study. Pediatr Allergy Immunol 2005; 16:679-84.

27. Aalberse RC, Koshte V, Clemens JG. Immunoglobulin E antibodies that crossreact with vegetable foods, pollen, and Hymenoptera venom. J Allergy Clin Immunol 1981; 68:35664 .

28. Schuurman J, Perdok GJ, Lourens TE, Parren PW, Chapman MD, Aalberse RC. Production of a mouse/human chimeric IgE monoclonal antibody to the house dust mite allergen Der $\mathrm{p}$ 2 and its use for the absolute quantification of allergen-specific IgE. J Allergy Clin Immunol 1997; 99:545-50.

29. Stallman PJ, Aalberse RC. Estimation of basophil-bound IgE by quantitative immunofluorescence microscopy. Int Arch Allergy Appl Immunol 1977; 54:9-18.

30. Williams HC, Burney PG, Hay RJ, Archer CB, Shipley MJ, Hunter JJ, et al. The U.K. Working Party's Diagnostic Criteria for Atopic Dermatitis. I. Derivation of a minimum set of discriminators for atopic dermatitis. British journal of dermatology 1994; 131:383-96.

31. Williams HC, Burney PG, Pembroke AC, Hay RJ. The U.K. Working Party's Diagnostic Criteria for Atopic Dermatitis. III. Independent hospital validation. British journal of dermatology 1994; 131:406-16.

32. Williams HC, Burney PG, Strachan D, Hay RJ. The U.K. Working Party‘s Diagnostic Criteria for Atopic Dermatitis. II. Observer variation of clinical diagnosis and signs of atopic dermatitis. British journal of dermatology 1994; 131:397-405.

33. Sambrook J, Russell D. Molecular Cloning. 2001; 3rd Edition.

34. Litonjua AA, Belanger K, Celedon JC, Milton DK, Bracken MB, Kraft P, et al. Polymorphisms in the $5^{\prime}$ region of the $\mathrm{CD}_{14}$ gene are associated with eczema in young children. J Allergy Clin Immunol 2005; 115:1056-62.

35. Vercelli D. Genetics, epigenetics, and the environment: Switching, buffering, releasing. J Allergy Clin Immunol 2004; 113:381-6.

36. Botto LD, Khoury MJ. Commentary: facing the challenge of gene-environment interaction: the two-by-four table and beyond. Am J Epidemiol 2001; 153:1016-20.

37. Kabesch $M$. Gene by environment interactions and the development of asthma and allergy. Toxicol Lett 2006; 162:43-8.

38. Simpson A, John SL, Jury F, Niven R, Woodcock A, Ollier WE, et al. Endotoxin Exposure, CD14 and Allergic Disease: An Interaction between Genes and the Environment. Am J Respir Crit Care Med 2006. 

General Discussion 


\section{INTRODUCTION}

In the current thesis we have investigated the role of breastfeeding from several perspectives in an attempt to shed light on the controversy concerning the role of breastfeeding with respect to atopic disease development. In this chapter, the main findings are summarised, methodological considerations are discussed to facilitate a proper interpretation of the results and finally, the perspectives for future research are presented.

\section{MAIN FINDINGS}

In our KOALA study, in the first year of life, no association was observed between breastfeeding and the development of eczema. There was only a tendency towards a lower risk of eczema from age 4 months and onwards. Surprisingly, breastfeeding was associated with a tendency for a higher risk of eczema before 4 months of age (chapter 2).

Longer duration of breastfeeding in the first year was associated with a decreased risk of eczema for infants of mothers without allergy or asthma in the second year of life (chapter 3). Considering recurrent wheeze in the first two years of life, it appeared that longer breastfeeding duration was associated with a decreased risk (chapter 3).

Many studies have focussed on the perspective of breastfeeding duration assuming that the longer the child is (exclusively) breastfed, the healthier the infant's outcome will be. More recently, several studies have focussed on the perspective of the timing of introducing cow's milk or other food products. A delayed introduction of cow's milk or other food products has been proposed for the prevention of atopic disease. However, scientific evidence to support this has been scarce.(1) When we tested this in the KOALA study, we unexpectedly found a delayed introduction of cow's milk products associated with an increased risk of eczema and recurrent wheeze. Also, a delayed introduction of other food products was associated with an increased risk of eczema and this was confirmed by our findings with atopic dermatitis by UK-WP. In addition, a delayed introduction of other food products was associated with an increased risk of recurrent wheeze, atopic sensitization and in particular, inhalant allergen sensitization (chapter 4). Furthermore, we have focussed on a selection of immune factors in breast milk. 
First, we considered soluble $\mathrm{CD}_{14}$ (sCD14), the soluble form of the $\mathrm{CD}_{14}$ receptor which plays an important role in the recognition of gram negative bacteria in innate immunity. $(2,3)$ Second, we have taken into account both TGF- $\beta 1$ and IL-10 both secreted by regulatory T cells.(4) Finally, we focussed on IL-10 and IL-12. Of note, we were not able to detect the concentration of IL-10 above the detection limit in our breast milk samples.

Initially, we were interested whether the selected immune factors could be a reflection of the allergic status of the mother. Indeed higher levels of SCD14 were seen in mothers with a maternal allergic history and sensitization. No such associations between TGF- $\beta 1$ and IL-12 in breast milk and maternal allergic status were found. None of the immune factors (TGF- $\beta 1, \mathrm{sCD} 14$ and IL-12) in breast milk were associated with infant's wheeze and atopic outcomes (chapter 5).

We were able to study the interaction between the $C D_{14}$ genotype and soluble CD14 present in breast milk. The results suggest that breast milk sCD14 levels do not modify the effect of the $C D 14$ genotype on the development of atopic manifestations at age 2 years. In other words, we did not find evidence of geneenvironment interactions for any of the studied outcomes. However, our results showed a protective association for CC homozygocity (SNP CD14/-1619) on eczema until the age of 2 years (chapter 6).

\section{METHODOLOGICAL CONSIDERATIONS}

\section{Study design}

Ideally, the best design to investigate the relationship between breastfeeding and the development of atopy would be a randomised controlled trial. However, most studies performed are prospective birth cohort studies. Also, the KOALA Birth Cohort Study has a prospective design that is the most desirable design to investigate causal relationships between risk factors and disease outcomes.

An advantage of our study is the relatively short time intervals between subsequent follow-up questionnaires, which makes the influence of recall bias less likely. Follow-up rates were high which limits the possibility of differential bias regarding baseline characteristics or outcomes. Although we did not promote the KOALA study as a study focussing on atopic diseases, it is generally known that families with allergic complaints tend to be over-represented in studies on etiology of atopy. There was a difference between the KOALA participants and 
non-participants with respect to atopic predisposition, and this may be explained by self selection, because people with a positive family history of allergic disease tend to be more interested in participating in a study on health related topics. Also, participants in the KOALA study more often demonstrated an intention to breastfeed before birth than did non-participants.(5) In an etiological study, contrast in exposure is important, because analyses are focussed on risk comparisons and relative risks, rather than the absolute risk of the total cohort. Relative risk associations are however not biased to our opinion, since relative risks are based upon proportions and not on absolute numbers.(6)

\section{Validity of measurements}

\section{Measurement of breastfeeding}

The duration of breastfeeding can be measured in numerous ways. First, as the duration of exclusive breastfeeding defined by the age that (cow's) milk products is introduced; second as the duration of any breastfeeding (also referred to as breastfeeding 'per se').(7) In the present thesis we have chosen to address breastfeeding and the introduction of cow's milk products and other food products, separately. Hence we were able to study the independent effects of both breastfeeding duration and the introduction of cow's milk and other food products. A disadvantage may be a lack of assessment in duration of exclusive breastfeeding. Breastfeeding as an exposure may be subject to potential misclassification. One could argue whether in the studies presented in the current thesis, this misclassification will be either non-differential or differential. It may be possible that mothers of infants who have developed for example symptoms of eczema may be more interested in breastfeeding (as a preventive measure) and this will result in more precise and detailed information on the duration of breastfeeding. This will probably lead to an overestimation of the effect measure. In the KOALA study, differential bias seems unlikely because of relatively small intervals between the questionnaires so that the information was recorded before symptoms occurred.

With respect to the methods of breast milk collection it should be noted that a limitation was the lack of complete standardization of breast milk collection by mothers at home. Different modes of pumping and individual variation in 
pumping techniques may have led to variation of the measured immune factors. Unfortunately, further conditions affecting the concentrations of most immune factors in milk have been little studied. There are several conditions that influence the concentrations of immune factors in milk which may eventually relate to infants health. First, striking changes in the concentrations of immune factors in milk are dependent on the time post partum. Most milk components are at their highest concentrations in colostrum, decline rapidly during the first few days postpartum an then undergo slow decreases throughout the rest of lactation.(8) In the current thesis we have attempted to collect breast milk samples as much as possible within the same time postpartum (i.e. 4 weeks pp). Certainly, it would also have been interesting to have more samples over time e.g. monthly from shortly after birth until 4 months postpartum. However, this was not feasible in the current study. We postulated that the concentrations of TGF- $\beta 1, \mathrm{sCD} 14$ and IL12 may decrease over time due to storage at $-800 \mathrm{C}$ of more than 1 year. We found that differences in total storage time at $-800 \mathrm{C}$ for our samples did not influence the concentrations of TGF- $\beta 1, \mathrm{sCD} 14$ and IL-12 after considering this as a determinant in a linear regression analysis. Second, intercurrent infections like mastitis may also affect the concentration of immune factors in milk.(8) In chapter 5, we have adjusted our analysis for maternal infection, which also included mastitis.

\section{Measurement of introduction of cow's milk and other food products}

The relationship between breastfeeding and infant atopic manifestations may be confounded by the early introduction of cow's milk or other food products. The introduction of cow's milk and to a lesser extent other food products is highly correlated with the duration of breastfeeding. The introduction of solids may influence the development of infant's immune system and hence allergic disorders. It is therefore important to consider formula introduction in the analysis if one aims to know the independent effects of breastfeeding duration and the age of introduction of other foods, even if a mother continues to predominantly breastfeed.(7) In the present thesis, we have specifically addressed the introduction of cow's milk products and other food products when taking into account breastfeeding as a confounder (chapter 4).

\section{Measurement of the outcomes}

In this thesis, the definition of eczema in the KOALA Study was based on questions adapted from ISAAC questionnaires $(9,10)$ and included generally accepted 
characteristics, like a chronically relapsing course and an itchy rash. Also, the definition of recurrent wheeze was based on the ISAAC questionnaires. $(9,10)$ Outcomes like infant eczema and wheeze can be fairly unspecific for infants aged 2 years, and hence, may be subject to misclassification, especially when parentally reported. Notably, the measurement of wheeze may reflect respiratory infections at the age of two years.

In Chapters 3, 4, 5 and 6 we used the U.K. Working Party criteria for the definition of 'atopic dermatitis', along with the questionnaire-based diagnosis of eczema. We have chosen to use the term 'atopic dermatitis (AD)' for infants fulfilling the UK-WP criteria according to the criteria of Williams et al.(11) An advantage of the UK-WP criteria is that these include specific predilection sites of atopic dermatitis (flexural involvement).(11) A drawback of these criteria is, however, that infants who have outgrown their disease or who are in remission may not get diagnosed, because of the absence of flexural dermatitis at the time of the clinical examination (lower sensitivity). Both the higher specificity and lower sensitivity of the U.K. criteria are responsible for the lower prevalence of $A D$ compared to eczema as reported by parents (Figure 1).

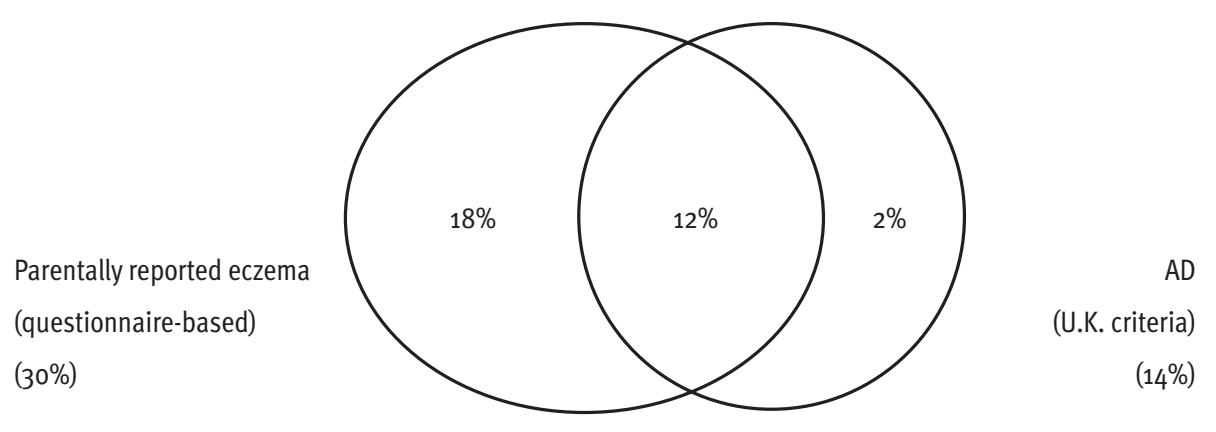

\section{Figure 1}

Venn diagram showing the proportion of infants with eczema (parentally reported in questionnaires), AD (according to U.K. criteria) or both in the KOALA study.

Subset areas presented above are not proportional to the actual relative subset size. 
However, eczema based on questionnaire data was based on the presence of an itchy rash anywhere (except diaper rash, rash around eyes and scalp scaling), and thus may include non-atopic eczema. Hence, this questionnaire-based definition of eczema has probably resulted in an overestimation of cases, whereas the U.K. criteria might have underestimated the number of cases of infants' eczema in the first two years of life.

In the current thesis we have chosen to use the U.K. criteria separately as this definition is the only validated classification which is solely based on clinical signs and symptoms. Other classifications are based on a mixture of clinical phenomenon's and tests (based on IgE determinations or skin prick testing) or on a family history. As a result, the U.K. criteria by Williams are more useful for research in the field of genetic risks such as association studies and studies addressing gene-environment interactions.

In chapter 3, 4, 5 and 6 we have considered infants' eczema and sensitization as separate outcome parameters instead of the term atopic eczema because sensitized infants do not necessarily show symptoms of eczema or vice versa.(12) In this thesis we therefore use the term eczema instead of atopic eczema.

\section{THE CONTROVERSIAL ROLE OF BREASTFEEDING IN ALLERGIC DISEASE}

In the current thesis we have investigated the role between breastfeeding and atopic manifestations by taking into account different methodological viewpoints, which are discussed in this paragraph:

\section{Confounding by indication:}

It is possible that allergic mothers are more likely to decide to breastfeed their infant than non-allergic mothers. This could be the case if allergic mothers are informed that breastfeeding would be better for their children. This may result in being exposed to non-breastfeeding and may correlate with a better outcome. Thus, behaviour may be confounder since it can be associated with both exposure and outcome.(13) In the present thesis we have adjusted all analysis for potential confounding-by-indication due to a family history of atopic manifestations. Previously, we have shown that atopy in parents and children should be viewed as separate confounders.(14) In all analyses we performed, we made a comparison between crude and adjusted odds ratios. Although in all analyses, a positive 
family history appeared as a significant risk factor for infant's allergic disease we did not notice substantial differences between crude and adjusted analyses. This may be reassuring, but we cannot completely rule out the possibility of residual confounding.

\section{Reverse causation:}

Reverse causation can be regarded as a feature of information bias and will occur if symptoms of disease will appear during exposure and this will inadvertently influence the exposure. In this particular case, the presence of eczema symptoms while breastfeeding may affect the mother in her decision to change the feeding habits of her infant. It is a relatively new problem because in older studies the public awareness of health promoting effects of breastfeeding was smaller.(15) Reverse causation has been put forward as an explanation for the inconsistent results between different studies.(15-18) Also, reverse causation may be more likely to be evident in the relationship between exclusive breastfeeding and risk of developing eczema. In chapter 2 we have discussed two solutions that have been proposed in the literature to avoid reverse causation. First, survival analysis (Cox regression) is a suitable method to consider only breastfeeding before the appearance of eczema.(19) However, survival analysis requires the data on the exact onset of eczema in small time intervals, which many studies lack. Second, it can be avoided by excluding infants with onset of disease during lactation. $(15,17,20)$ It should be noted that the proposed method by Kull et al (17) to exclude cases with onset during lactation has the danger of excluding too many cases (possibly leading to selection bias) and hence this method is not guaranteeing an unbiased result. The most logical method is to restrict the analysis to those subjects who are still 'at risk'. Such an analysis has the additional advantage that it keeps track of infants with early symptoms (such as the infants with early eczema in our study). However, this analysis does not add up risk-periods leading to an overall effect which can be regarded as an disadvantage. In the present thesis we have shown that controlling for reverse causation can be accomplished by risk-period specific analyses in which only exposure before the risk-period is taken into account.

\section{Effect modification:}

There are several reasons why effect modification by maternal allergic status is important to address. First, it is possible that the association between breast- 
feeding and asthma and atopy will vary at different levels of a third key variable, such as the underlying genetic risk of atopy. In the current thesis we have shown that maternal asthma and allergic predisposition in the child may modify the relationship between breastfeeding and atopic manifestations. Second, the milk composition between allergic and non-allergic mothers may differ in such a way that it affects atopic manifestation in the child.(21) In chapter 5 of this theses we showed that only $\mathrm{SCD}_{14}$ of the studied immune factors appeared to be dependent on the allergic status of the mother. Of note, not only cytokines, but also differences in long chain polyunsaturated fatty acids levels may differ between atopic and non-atopic mothers. $(22,23)$

Finally, different gene-environment or gene-gene interactions between studies may also contribute to the inconsistent study results. Gene-environment interaction in childhood asthma and allergy has focused on both environmental and exposure (e.g. infection or contacts with microbial products such as endotoxin) as well as genes involved in the immunological response to those stimulants (like CD14 gene, Toll-like receptors). However, one should take into account that multiple genetic and environmental effects overlap and these effects may or may not be independent from each other. Thus a certain phenotype or disease may be caused by a genetic factor, by an environmental condition, or alternatively by an interaction of both genetic and environmental condition. We were interested in the interaction between soluble $C D_{14}$ levels in breast milk and $C D_{14}$ gene because it seemed plausible that there may be biological interaction between both factors, as certain genotypes have been shown to correlate with the levels of sCD14.(24)

\section{INTERPRETATIONS OF THE FINDINGS}

There was no strong evidence for a protective effect of breastfeeding and eczema in the first year of life (chapter 2). This finding was confirmed by another recent study in which breastfeeding has no significant effect on the prevalence of eczema in the first year of life.(25) After examining whether our results could possible be biased by the influence of reverse causation the conclusion did not essentially change that breastfeeding 'per se' does not protect against eczema.

Longer duration of breastfeeding was associated with a decreased risk of infant eczema (by questionnaire) in the second year of life, but only in infants of mothers 
without allergy or asthma. Since we did not find such an association with eczema for neither allergic, nor for asthmatic mothers, the overall relationship between breastfeeding and infant eczema in the first two years of life is modified by maternal allergic status. Initially, the idea of effect modification by maternal asthmatic status was pointed out by investigators of the Tucson birth cohort in which it was demonstrated that breastfeeding increased the risk of atopy and asthma primarily among atopic children of mothers with asthma.(21) In a recent study by Mandane, it has been shown that for boys, breastfeeding and maternal atopy were each associated with an increased risk of atopy at age 13 years. For girls, breastfeeding and maternal atopy were no independent risk factors for atopy at age of 13 years. However, breastfeeding increased the risk for atopy in girls with maternal atopy compared with non-breast-fed girls with maternal atopy. Results for the outcome of asthma followed a similar pattern.(26) From the results of those studies which were performed to elucidate the role of maternal and or parental allergic status it appears that it may be important to stratify by maternal (and / or paternal) status of a family history. From the study of Mandane et al (26), it can also be concluded that this is further complicated by effect modification by the sex of the child. In this thesis, we did only adjust for gender. The protective effect of breastfeeding against recurrent wheeze was irrespective of maternal allergic status and we speculate that these results may reflect protection against respiratory infection rather than atopic respiratory illness. This can be explained by the fact that breast milk contains antibodies against viral infections to which the mother has been exposed. A breastfed infant is therefore better protected against respiratory infections caused by viruses and will subsequently have less symptoms of wheeze.

In chapter 4 we have shown that a delayed introduction of cow's milk products is associated with a higher risk of eczema. In addition, a delayed introduction of other food products is associated with an increased risk of atopy development in the first two years of life (eczema, atopic dermatitis by UK-WP, recurrent wheeze, any sensitization and inhalant allergen sensitization). Our results were recently supported by a study that found an increased risk of doctors-diagnosed eczema for the avoidance of egg in the first year.(27) Those and our results contradict with the previous thoughts that early introduction of cow's milk or other food products may be harmful for the infant and longer breastfeeding may be more favourable to avoid atopic manifestations. In chapter 3 and 4 together, we separated the 
effects of delayed introduction of foods from breastfeeding duration (chapter 4) and we showed that the risk of eczema and wheeze was lower with increasing breastfeeding duration, while atopic sensitization was not associated with breastfeeding duration (chapter 3). Therefore, we suggest that early introduction of foods in combination with continuing breastfeeding helps in the induction of oral tolerance.

In chapter 5 and 6 , the aim of this thesis shifted towards hypotheses that were more focussed on biological mechanisms i.e. the immunology of breast milk (chapter 5) and gene-environment interactions (chapter 6).

In particular, we were interested in several immune factors as will be discussed below: First we have assessed TGF- $\beta 1$ since this cytokine is known to be a potential regulator of early atopic sensitization.(28) For example, in the gut, TGF- $\beta 1$ as a $T$ regulatory cytokine is able to down-regulate both Th1 and Th2 responses.(29) TGF- $\beta$ plays a role on two crucial parts of the mucosal immune system, namely IgA production and it plays an important role in the induction of oral tolerance through activation of antigen-specific TGF- $\beta$-producing T cells.(30) Concentrations of TGF- $\beta 1$ vary from mother to mother.(31) It was suggested that these variations in concentrations of TGF- $\beta 1$ could possibly explain the controversial effect of breastfeeding on the development of atopic disease.(32) The concentration of TGF- $\beta 1$ did not vary with the atopic status of the mother (chapter 5 ) which is in agreement with a previous study that also did not find differences between allergic and non-allergic mothers for TGF- $\beta$.(33) Taking into account the relationship with infant atopic manifestations, Oddy et al (34) previously reported a significant association with low levels of TGF- $\beta 1$ in breast milk and wheeze in infancy at the age of 1 year.(34) Our results (chapter 5 ) were not in line with this previous finding. We defined wheezing in the first year of life as reported presence of wheezing ever that was mentioned in the 7 or 12 months postpartum questionnaire. The percentage of infants, defined as ever wheezers in our cohort was 19.7\% (62/315) However, this percentage is lower compared with the percentage of ever wheezers reported in the study of Oddy, that was found to be $39.9 \%$ (97/243).(34) Perhaps wheezing symptoms are more frequently reported by participants of the Infant Immune Study (Tucson, Arizona) compared with participants of our study.

The second cytokine which was addressed by the KOALA study was IL-10. In the study of Oddy et al also IL-10 in breast milk was measured. The authors stated 
that IL-10 is produced in lower amounts compared to TGF- $\beta 1$. However, they found a slight (non-linear) relationship for IL-10 with wheeze.(34) We concluded that the concentrations of IL-10 in our breast milk samples were too low and therefore not detectable using 2 different high sensitivity kits of different manufacturers. Test samples from 10 women (not participating in our cohort) to exclude diminishing of IL-10 due to storage at $-800 \mathrm{C}$ for a duration of $>1$ year were negatively tested for IL10. Two other studies were also unable to detect IL-10 in breast milk samples.(32, 35) However, Garofalo et al.(36) were able to detect IL-10 in both the aqueous and lipid fraction of breast milk, obtained within 80 hours of lactation, stored at -600 C, ranging from 66 to $9301 \mathrm{pg} / \mathrm{mL}$.(36) Therefore we postulated that differences in collection time after birth could explain these discrepancies in IL-10 concentration range.(35)

An increased IL-10/IL-12 ratio was found in serum of wheezing infants (37) which triggered our interest for IL-12. It was already known that IL-12 was detected in breast milk in an Australian study found in 24 of 39 samples using ELISA assay of Pharmingen (San Diego, CA).(38) These authors highlighted the importance of using similar ELISA kits since the use of antibodies of differing specificity for the antigen of interest may hamper a proper comparison between studies.(38) We did not detect IL-12 in breast milk using a high sensitivity kit of R\&D Systems. However, using another high sensitivity kit (Biosource International) we detected IL-12 in our breast milk samples in low concentrations. Comparing Il-12 concentrations for allergic and non-allergic mothers and for allergic and non-allergic infants did not lead to any significant difference. Since we did not detect IL-10, we could not determine the IL-10/II-12 ratio in breast milk.

Of special interest was soluble CD14 which is present in breast milk in high levels.(39) Previously it has been postulated that $\mathrm{SCD}_{14}$ may have a sentinel role enabling LPS induced activation of membrane CD14 negative-cells such as intestinal epithelial cells, in the neonatal gut.(3) From the results of chapter 5 we may conclude that there is no effect of inter-individual differences in levels of SCD14 in breast milk on the infant's atopic outcomes. In contrast with our findings, Jones et al (39) found that soluble CD14 levels in breast milk collected 3 months postpartum were significantly lower in children with eczema at 6 months of age. The difference in the timing of breast milk collection and outcome measurement may explain the discrepant findings. Of note, we found higher concentrations of SCD14 in breast milk in mothers with a positive allergic history and mothers with 
allergic sensitization but not for high total IgE (chapter 5).

In chapter 6 we have explored whether a different genetic constitution between mothers with and without a positive allergic history might be an explanation for different sCD14 levels in breast milk. However, in chapter 6 no significant associations between maternal $C D_{14}$ polymorphisms and the concentration of sCD14 in breast milk, determined at 1 month postpartum were found. Therefore, the effect of maternal atopic predisposition on $\mathrm{SCD} 14$ in breast milk (chapter 5) could not be explained by the $C D 14$ polymorphisms studied in chapter 6 . In contrast with our findings, Guerra et al (24) found that SCD14 levels in milk at day 11 differed significantly by $\mathrm{CD} 14 /-550$ and $\mathrm{CD}_{14} /-1619$ genotypes and haplotypes.(24) The discrepancy with our findings may not only be explained by a different genetic make-up but also a difference between the mean concentrations of sCD14 in breast milk found in both studies.(24) The effect of $C D_{14}$ may be dose-dependent $(40,41)$ and we postulate this may also apply for SCD14. The differences in SCD14 concentration could also be due to a difference in timing of breast milk sampling (i.e. 11 days (Tucson) versus 1 month (KOALA) postpartum).

In conclusion, as a result of the current public awareness of feeding habits, reverse causation can be regarded as a new kind of bias that should be addressed in future studies. Also, we could confirm that effect modification by a maternal allergic status plays in role in elucidating the controversial role of breastfeeding. Since a long time, the early introduction of solid food is considered as a risk factor for infants of developing allergic disease but from our data we conclude that a combination of breastfeeding with introducing cow's milk or other food products at a young age may not be that harmful for the child as it may induce oral tolerance.

Not only the duration of breastfeeding and the timing of introduction of solid products is important but also breastfeeding provides a very broad multifactorial anti-inflammatory defence for the infant. In the present thesis we did not show a (preventive) effect of TGF- $\beta 1, \mathrm{SCD} 14$ and IL-12 on the development of allergic disease. However, it is known that breastfeeding protects against diarrhoea, otitis media and respiratory infections.(42) We considered our finding that breastfeeding protects against wheeze in the second year of life as a confirmation of a masked protection against respiratory infections.

Since we found no significant associations between maternal $C D 14$ polymorphisms and the concentration of $\mathrm{sCD}_{14}$ in breast milk but only a lower risk of the $C D_{14}$ 
gene (SNP CD14/-1619) and infant eczema at the age of 2 years, we conclude that breast milk sCD14 levels do not modify the effect of the $C D 14$ genotype on the development of atopic manifestations at age 2 years.

\section{FUTURE DIRECTIONS}

Breastfeeding has several important health benefits and should be encouraged. Its beneficial role in the prevention of atopic manifestations is an ongoing matter of debate. Besides the role of infant feeding habits, there are many facets regarding unravelling the aetiology of atopic manifestations that were not addressed in this thesis. For example, in the KOALA study we have previously shown that breastfeeding influences the bacterial composition of the gut microbiota, and that its composition is associated with atopic manifestations and sensitization. $(43,44)$ Also, the role of different lifestyle factors, other than feeding habits, have been addressed in previous studies to elucidate the individual risk factors for atopic manifestations i.e. antibiotics, vaccinations and organic food consumption.(4547)

Reverse causation is an important issue that needs to be addressed in future studies by taking into account those individuals that are still at risk by means of risk-period specific analyses. Previously, Miettinen (48) put forth principles of non-experimental assessment of excess risks. In such a design, risk difference is assessed by estimating the denominators of the proportions of cases among exposed and comparable unexposed subjects by means of a representative sample from the base population of the study.(49) Future research should focus on both risk-periods and integrating models to determine excess risk.

It is desirable that the search for modifying effects of factors present in breast milk on the development of atopic manifestations should continue. Not only immune factors in breast milk seem to enhance the infant's host defence but also other nutritional factors. For example, derivates of long chain PUFA may be involved in the regulation of inflammatory processes and immune cell functional responses through eicosanoid production.(50) Furthermore, it is known that one of the most pronounced dietary changes that has paralleled the increased prevalence of atopic diseases over the past decades is the altered consumption of polyunsaturated fatty acids (PUFA). In another Dutch Birth Cohort Study (51), 
it has been shown that in children of mothers with allergy, breast milk $n-3$ long chain polyunsaturated fatty acids and the ratio between n-3 and n-6 long chain polyunsaturated fatty acids were inversely associated with asthma and with persistent symptoms (eczema at age 1 year and eczema at age 4 years and/or asthma at age 4 years), but no associations between breast milk fatty acids and sensitization were observed. Also, in children of mothers with allergy, also trans fatty acids tended to be inversely associated with allergic symptoms. However, in children of mothers without allergy, no associations between breast milk fatty acids and allergic symptoms were observed, but alpha-linolenic acid (18:3n3) was positively associated with sensitization.(51) Previously, we have shown consumption of organic dairy products (i.e. produced and processed according to 'organic' principles) was associated with lower eczema risk (OR 0.64 (95\% $\mathrm{Cl} 0.44,0.93)$ ), but there was no association of organic meat, fruit, vegetables or eggs, or the proportion of organic products within the total diet with the development of eczema, wheeze or atopic sensitization.(46) It can be postulated that not only infants consumed organic foods but also mothers. Therefore the intake of dairy fatty may also be determined via maternal routes (via breastfeeding and/or intrauterine). In the KOALA Birth Cohort Study, we are currently further investigating the role of fatty acids in breast milk on the development of atopic manifestations.

More extensive gene-environment interaction studies are necessary in studying the aetiology of atopic diseases. Candidate genes are for instance genes encoding for pattern recognition receptors on cells of the innate immune system such as TLR4 and $C D 14$ both involved in lipopolysaccharide signalling, TLR2 involved in the signalling complex to a wide range of microbial components. $(52,53)$ For example, in two independent populations, a polymorphism in the toll-like receptor (TLR) 4 gene that influences TLR4-mediated LPS signaling was associated with bronchial hyperresponsiveness and allergies, respectively, but only in those subjects heavily exposed to endotoxin. $(52,54)$ The detection of new gene by environment interactions may lead to various public health consequences. It could help stratify disease risks and focus interventions to achieve populations health benefits; it could identify new environmental factors for disease development or severity; and it could help our understanding of the natural history and severity of disease.(55) The limited subjects studied in the present thesis demand larger studies to elucidate gene-environment interactions. 
With respect to the timing of introduction of cow's milk or other food products, we need more evidence to support our hypothesis that early introduction may lead to the induction of 'oral tolerance'. Currently, it seems undesirable that recommendations of e.g. the World Health Organisation (i.e. exclusive breastfeeding for the first 6 months of life and the introduction of solids thereafter)(56) are questioned by the findings of several observational studies. The findings of these observational studies first need more experimental confirmation. From a public health perspective, it may be recommended to set up a intervention study in which breastfeeding mothers will be randomly allocated into 'early' versus 'late' introduction of cow's milk or certain other food products. 


\section{REFERENCES}

1. Fiocchi A, Assa'ad A, Bahna S. Food allergy and the introduction of solid foods to infants: a consensus document. Adverse Reactions to Foods Committee, American College of Allergy, Asthma and Immunology. Ann Allergy Asthma Immunol 2006;97(1):10-20; quiz 21, 77.

2. Rey Nores JE, Bensussan A, Vita N, Stelter F, Arias MA, Jones M, et al. Soluble CD14 acts as a negative regulator of human T cell activation and function. Eur J Immunol 1999;29(1):265-76.

3. Labeta MO, Vidal K, Nores JE, Arias M, Vita N, Morgan BP, et al. Innate recognition of bacteria in human milk is mediated by a milk-derived highly expressed pattern recognition receptor, soluble CD14. Journal of experimental medicine 2000;191(10):1807-12.

4. Romagnani S. Regulatory T cells: which role in the pathogenesis and treatment of allergic disorders? Allergy 2006;61(1):3-14.

5. Kummeling I, Thijs C, Penders J, Snijders BE, Stelma F, Reimerink J, et al. Etiology of atopy in infancy: the KOALA Birth Cohort Study. Pediatr Allergy Immunol 2005;16(8):679-84.

6. Wacholder S. When measurement errors correlate with truth: surprising effects of nondifferential misclassification. Epidemiology 1995;6(2):157-61.

7. Oddy WH, Peat JK. Breastfeeding, asthma, and atopic disease: an epidemiological review of the literature. J Hum Lact 2003;19(3):250-61; quiz 262-6.

8. Filteau SM. Milk components with immunomodulatory potential. Adv Nutr Res 2001;10:32750.

9. Asher MI, Keil U, Anderson HR, Beasley R, Crane J, Martinez F, et al. International Study of Asthma and Allergies in Childhood (ISAAC): rationale and methods. Eur Respir J 1995;8(3):483-91.

10. Worldwide variation in prevalence of symptoms of asthma, allergic rhinoconjunctivitis, and atopic eczema: ISAAC. The International Study of Asthma and Allergies in Childhood (ISAAC) Steering Committee. Lancet 1998;351(9111):1225-32.

11. Williams HC, Burney PG, Hay RJ, Archer CB, Shipley MJ, Hunter J), et al. The U.K. Working Party's Diagnostic Criteria for Atopic Dermatitis. I. Derivation of a minimum set of discriminators for atopic dermatitis. British journal of dermatology 1994;131(3):383-96.

12. Kusel MM, Holt PG, de Klerk N, Sly PD. Support for 2 variants of eczema. Journal of allergy and clinical immunology 2005;116(5):1067-72.

13. van Schayck CP, Knottnerus JA. Can the 'hygiene hypothesis' be explained by confounding by behavior? J Clin Epidemiol 2004;57(5):435-7.

14. Kummeling I, Thijs C, Stelma F, Huber M, Brandt PA, Dagnelie PC. Do parents with an atopic family history adopt a 'prudent' lifestyle for their infant? (KOALA Study). Clin Exp Allergy 2006;36(4):489-94. 


\section{CHAPTER 7}

15. Zutavern A, Brockow I, Schaaf B, Bolte G, von Berg A, Diez U, et al. Timing of Solid Food Introduction in Relation to Atopic Dermatitis and Atopic Sensitization: Results From a Prospective Birth Cohort Study. Pediatrics 2006;117(2):401-411.

16. Bergmann RL, Diepgen TL, Kuss O, Bergmann KE, Kujat J, Dudenhausen JW, et al. Breastfeeding duration is a risk factor for atopic eczema. Clinical and experimental allergy journal of the British Society for Allergy and Clinical Immunology 2002;32(2):205-9.

17. Kull I, Almqvist C, Lilja G, Pershagen G, Wickman M. Breast-feeding reduces the risk of asthma during the first 4 years of life. J Allergy Clin Immunol 2004;114(4):755-60.

18. Laubereau B, Brockow I, Zirngibl A, Koletzko S, Gruebl A, von Berg A, et al. Effect of breastfeeding on the development of atopic dermatitis during the first 3 years of life--results from the GINI-birth cohort study. J Pediatr 2004;144(5):602-7.

19. Benn CS, Michaelsen KF. Does the effect of breast-feeding on atopic dermatitis depend on family history of allergy? J Pediatr 2005;147(1):128-9; author reply 129.

20. Wickman M, Kull I, Pershagen G, Nordvall SL. The BAMSE project: presentation of a prospective longitudinal birth cohort study. Pediatr Allergy Immunol 2002;13 Suppl 15:113.

21. Wright AL, Holberg CJ, Taussig LM, Martinez F. Maternal asthma status alters relation of infant feeding to asthma childhood. Adv Exp Med Biol 2000;478:131-7.

22. Duchen K, Yu G, Bjorksten B. Atopic sensitization during the first year of life in relation to long chain polyunsaturated fatty acid levels in human milk. Pediatr Res 1998;44(4):47884.

23. Thijs C, Houwelingen A, Poorterman I, Mordant A, van den Brandt P. Essential fatty acids in breast milk of atopic mothers: comparison with non-atopic mothers, and effect of borage oil supplementation. Eur J Clin Nutr 2000;54(3):234-8.

24. Guerra S, Carla Lohman I, LeVan TD, Wright AL, Martinez FD, Halonen M. The Differential Effect of Genetic Variation on Soluble CD14 Levels in Human Plasma and Milk. Am J Reprod Immunol 2004;52(3):204-11.

25. Sariachvili M, Droste J, Dom S, Wieringa M, Vellinga A, Hagendorens M, et al. Is breast feeding a risk factor for eczema during the first year of life? Pediatr Allergy Immunol 2007;18(5):410-7.

26. Mandhane PJ, Greene JM, Sears MR. Interactions between breast-feeding, specific parental atopy, and sex on development of asthma and atopy. J Allergy Clin Immunol 2007;119(6):1359-66.

27. Filipiak B, Zutavern A, Koletzko S, von Berg A, Brockow I, Grubl A, et al. Solid Food Introduction in Relation to Eczema: Results from a Four-Year Prospective Birth Cohort Study. The Journal of Pediatrics 2007; In Press, Corrected Proof. 
28. Kalliomaki M, Ouwehand A, Arvilommi H, Kero P, Isolauri E. Transforming growth factorbeta in breast milk: a potential regulator of atopic disease at an early age. Journal of allergy and clinical immunology 1999;104(6):1251-7.

29. Taylor A, Verhagen J, Akdis CA, Akdis M. T regulatory cells in allergy and health: a question of allergen specificity and balance. Int Arch Allergy Immunol 2004;135(1):73-82.

30. Bottcher MF, Jenmalm MC, Bjorksten B. Cytokine, chemokine and secretory IgA levels in human milk in relation to atopic disease and IgA production in infants. Pediatr Allergy Immunol 2003;14(1):35-41.

31. Hawkes JS, Bryan DL, Gibson RA. Variations in transforming growth factor beta in human milk are not related to levels in plasma. Cytokine 2002;17(4):182-6.

32. Bottcher MF. Cytokines and chemokines in breast milk from allergic and nonallergic mothers. ACI International 2000;12(4):153-160.

33. Bottcher MF, Jenmalm MC, Garofalo RP, Bjorksten B. Cytokines in breast milk from allergic and nonallergic mothers. Pediatric research 2000;47(1):157-62.

34. Oddy WH, Halonen M, Martinez FD, Lohman IC, Stern DA, Kurzius-Spencer M, et al. TGF-beta in human milk is associated with wheeze in infancy. J Allergy Clin Immunol 2003;112(4):7238.

35. Rudloff S, Niehues T, Rutsch M, Kunz C, Schroten H. Inflammation markers and cytokines in breast milk of atopic and nonatopic women. Allergy 1999;54(3):206-11.

36. Garofalo R, Chheda S, Mei F, Palkowetz KH, Rudloff HE, Schmalstieg FC, et al. Interleukin10 in human milk. Pediatr Res 1995;37(4 Pt 1):444-9.

37. Koopman LP, Savelkoul H, van Benten IJ, Gerritsen J, Brunekreef B, H JN. Increased serum IL-10/IL-12 ratio in wheezing infants. Pediatr Allergy Immunol 2003;14(2):112-9.

38. Bryan DL, Hawkes JS, Gibson RA. Interleukin-12 in human milk. Pediatr Res 1999;45(6):8589.

39. Jones CA, Holloway JA, Popplewell EJ, Diaper ND, Holloway JW, Vance GHs, et al. Reduced soluble CD14 levels in amniotic fluid and breast milk are associated with the subsequent development of atopy, eczema, or both. Journal of allergy and clinical immunology 2002;109(5):858-66.

40. Vercelli D. Learning from discrepancies: CD14 polymorphisms, atopy and the endotoxin switch. Clin Exp Allergy 2003;33(2):153-5.

41. Vercelli D. Genetics, epigenetics, and the environment: Switching, buffering, releasing. J Allergy Clin Immunol 2004;113(3):381-386.

42. Hanson LA. Session 1: feeding and infant development Breast-feeding and immune function. Proc Nutr Soc 2007;66(3):384-96.

43. Penders J, Thijs C, van den Brandt PA, Kummeling I, Snijders B, Stelma F, et al. Gut 


\section{CHAPTER 7}

microbiota composition and development of atopic manifestations in infancy: the KOALA birth cohort study. Gut 2006.

44. Penders J, Thijs C, Vink C, Stelma FF, Snijders B, Kummeling I, et al. Factors influencing the composition of the intestinal microbiota in early infancy. Pediatrics 2006;118(2):511-21.

45. Kummeling I, Stelma FF, Dagnelie PC, Snijders BE, Penders J, Huber M, et al. Early life exposure to antibiotics and the subsequent development of eczema, wheeze, and allergic sensitization in the first 2 years of life: the KOALA Birth Cohort Study. Pediatrics 2007;119(1):e225-31.

46. Kummeling I, Thijs C, Huber M, van de Vijver LP, Snijders BE, Penders J, et al. Consumption of organic foods and risk of atopic disease during the first 2 years of life in the Netherlands. Br J Nutr 2007:1-8.

47. Kummeling I, Thijs C, Stelma F, Huber M, van den Brandt PA, Dagnelie PC. Diphtheria, pertussis, poliomyelitis, tetanus, and Haemophilus influenzae type b vaccinations and risk of eczema and recurrent wheeze in the first year of life: the KOALA Birth Cohort Study. Pediatrics 2007;119(2):e367-73.

48. Miettinen OS. Striving to deconfound the fundamentals of epidemiologic study design. J Clin Epidemiol 1988;41(8):709-13.

49. Nurminen M. Assessment of excess risks in case-base studies. I Clin Epidemiol 1992;45(10):1081-92.

50. Calder PC, Krauss-Etschmann S, de Jong EC, Dupont C, Frick JS, Frokiaer H, et al. Early nutrition and immunity - progress and perspectives. Br J Nutr 2006;96(4):774-90.

51. Wijga AH, van Houwelingen AC, Kerkhof M, Tabak C, de Jongste JC, Gerritsen J, et al. Breast milk fatty acids and allergic disease in preschool children: the Prevention and Incidence of Asthma and Mite Allergy birth cohort study. J Allergy Clin Immunol 2006;117(2):440-7.

52. Eder W, von Mutius E. Hygiene hypothesis and endotoxin: what is the evidence? Curr Opin Allergy Clin Immunol 2004;4(2):113-7.

53. Eder W, Klimecki W, Yu L, von Mutius E, Riedler J, Braun-Fahrlander C, et al. Association between exposure to farming, allergies and genetic variation in CARD4/NOD1. Allergy 2006;61(9):1117-24.

54. Werner M, Topp R, Wimmer K, Richter K, Bischof W, Wjst M, et al. TLR4 gene variants modify endotoxin effects on asthma. J Allergy Clin Immunol 2003;112(2):323-30.

55. Koppelman GH. Gene by environment interaction in asthma. Curr Allergy Asthma Rep 2006;6(2):103-11.

56. WHO. Fifty-fourt World Health Assemby. WHA54.2. Agenda item 13.1. Infant and young children nutrition 
Summary 
Allergic asthma, hay fever (and other airway allergies), eczema and food allergy are collectively known as 'atopic diseases'. A largely unexplained increase in the prevalence of these diseases was noted during the past decades. Currently, atopy is present in about $40 \%$ of the westernised world's population. Asthma and other atopic disorders are thought to be the result of complex interactions between genetic predisposition and multiple environmental influences. However, the marked increase in asthma prevalence over recent decades is unlikely to be due to genetic changes, highlighting the contribution of environmental factors. In the present thesis, we have investigated how environment, lifestyle and biological factors such as infant feeding may play a (protective) role in the development of allergic diseases.

All studies that are described in this thesis were carried out within the framework of the KOALA Birth Cohort Study. This ongoing prospective birth cohort study aims to identify factors that influence the clinical expression of atopic disease in early infancy. From October 2000, pregnant women $(n=2834)$ were recruited during pregnancy and early childhood by repeated questionnaires.

A subgroup of participants complied to sampling of maternal blood $(n=1355)$, breast milk $(n=315)$ and faeces of the infant at 1 month post-partum $(n=1176)$, capillary blood at age 1 year $(n=956)$, venous blood at the age of 2 years $(n=829)$, and buccal swabs for DNA isolation from child-parent trios $(n=1637)$. Furthermore parents were asked to consent to a physical examination of their child on manifestation of atopic dermatitis at the age of two years $(n=826)$.

Previous studies on the effects of breastfeeding on the development of allergy have yielded controversial results, some studies indicating an allergy-preventive effect, while others could not confirm this, or the protective effect has been limited to early childhood, long-term follow-up indicating increased atopic symptoms among the breastfed subjects. In this thesis we aimed to study the relationship between breastfeeding and infant atopic manifestations during the first two years of life.

In chapter $\mathbf{2}$ we observed no association between breastfeeding and the development of eczema in the first year of life but only a tendency towards a lower risk of eczema from age 4 months and onwards. Surprisingly, breastfeeding was associated with a tendency for a higher risk of eczema before 4 months of age. In 
chapter 3 we have shown that longer duration of breastfeeding in the first year was associated with a decreased risk of eczema for infants of mothers without allergy or asthma in the second year of life. Considering recurrent wheeze in the first two years of life, it appeared that longer breastfeeding duration was associated with a decreased risk.

More recently, several studies have focussed on the perspective of the timing of introducing cow's milk or other food products rather than the duration of (exclusive) breastfeeding. A delayed introduction of cow's milk or other food products has been proposed for the prevention of atopic disease. However, scientific evidence to support this has been scarce. In chapter 4 we have demonstrated that a delayed introduction of cow's milk products was associated with an increased risk of eczema and recurrent wheeze. Also, a delayed introduction of other food products was associated with an increased risk of eczema and this was confirmed by our findings with atopic dermatitis by UK-WP. In addition, a delayed introduction of other food products was associated with an increased risk of recurrent wheeze, atopic sensitization and in particular, inhalant allergen sensitization. Based on these findings, we suggested that early introduction of foods in combination with continuing breastfeeding helps in the induction of oral tolerance.

In chapter 5 and 6 , the focus of this thesis shifted towards hypotheses that were more based on biological mechanisms i.e. the immunology of breast milk (chapter 5) and gene-environment interactions (chapter 6).

In chapter 5, we have focussed on a selection of immune factors in breast milk i.e. soluble $\mathrm{CD}_{14}$ (the soluble form of the $\mathrm{CD} 14$ receptor) which plays an important role in the recognition of gram negative bacteria in innate immunity, TGF- $\beta 1$ and IL-10 both secreted by regulatory T cells and finally IL-12. First, we were interested whether the selected immune factors could be a reflection of the allergic status of the mother. Indeed higher levels of $\mathrm{SCD} 14$ were seen in mothers with a maternal allergic history and sensitization. No other of such associations were found. None of the immune factors (TGF- $\beta 1, \mathrm{SCD} 14$ and IL-12) in breast milk were associated with infant's wheeze and atopic outcomes. In chapter 6 , we have focussed on gene environment interaction. The CD14 gene is one of the many genes that is currently in the focus of asthma and allergy research. Different $C D_{14}$ polymorphisms have been associated with atopic phenotypes in infants. In addition, $C D 14$ genotypes of breastfeeding mothers have been associated with soluble CD14 (sCD14) 
levels in breast milk. We studied the interaction between the $C D 14$ genotype and soluble CD14 present in breast milk. It appeared that breast milk SCD14 levels did not modify the effect of the $C D 14$ genotype on the development of atopic manifestations at age 2 years. However, we have shown a protective association for CC homozygocity (SNP CD14/-1619) on eczema until the age of 2 years.

In this thesis we have tried to address several methodological explanations for the inconsistent results which are outlined below.

\section{Reverse causation:}

Bias as a result of reverse causation has been proposed as one of the explanations of the unsolved controversy. This means that the relationship between breastfeeding and infant atopic outcomes may be disturbed since it is known that mothers may alter their feeding behaviour to what is their perception to be the best for their infant. In chapter 2, we have explored whether our data have been prone to reverse causation by assessing the relationship between breastfeeding and eczema in the first year of life by a risk-period specific analyses, i.e. taking into account only those infants that develop symptoms after the occurrence of the exposure (breastfeeding). We have demonstrated that our conclusion was strengthened by risk-period specific analysis which made the influence of reverse causation unlikely i.e. the results were not very different compared to overall analysis. Furthermore, in chapter 4 we aimed to evaluate any associations between the introduction of cow's milk products / other solid food products and infant atopic manifestations in the second year of life, taking into account reverse causation. Exclusion of infants with early symptoms of eczema and recurrent wheeze (in order to avoid reverse causation) did not essentially change our main results. We concluded that although breastfeeding remains beneficial for the infant's health, delaying the introduction of cow's milk or other food products may not be favourable in preventing the development of atopy.

\section{Effect modification:}

Another explanation that has been proposed for the inconsistent findings on breastfeeding and atopy is effect modification. In chapter $\mathbf{3}$ we investigated potential effect modification by maternal allergic status on the relation between breastfeeding duration and infant atopic manifestations in the first two years of life. The findings implicate that only the relationship between breastfeeding 
and infant eczema in the first two years of life may be modified by maternal allergic status. Also, we found that longer breastfeeding duration lowers the risk on recurrent wheeze independent of maternal allergy or asthma status. This protective effect of breastfeeding on recurrent wheeze may be the result of protection against respiratory infections.

In chapter $\mathbf{5}$ we investigated whether the controversies could be explained by different immunoprotection conferred by human milk between allergic and nonallergic mothers. In other words, we assessed whether the selected immune factors in breast milk are influenced by maternal atopic constitution and hence modify the effect on development of atopic manifestations in infants. Only higher levels of $\mathrm{sCD} 14$ were seen in mothers with a positive versus negative allergic history and in mothers who were sensitized versus non-sensitized.

In chapter 6 we have focused on the question whether there may be effect modification (i.e. interaction) between genetic constitution and effect of immune factors in breast milk. This interaction may provide a link between maternal genetic constitution and the child's allergic risk explaining the stronger transfer of allergy through the maternal line. We found that CC homozygotes (SNP CD14/-1619) showed a lower risk of eczema versus $\Pi$ homozygotes. Also, we found that breast milk sCD14 levels did not significantly modify the effect of the $C D_{14}$ genotype on atopy development. Maternal $C D 14$ SNPs were not significantly associated with sCD14 levels in breast milk. Hence, we did not find evidence of gene-environment interactions for any of the studied outcomes

In chapter 7 the main findings of the studies presented in this thesis are discussed. Study design and validity of measurements of both determinants and outcomes were reviewed. We also addressed several methodological viewpoints (i.e. reverse causation and effect modification) in an attempt to shed light on the controversy concerning the role of breastfeeding with respect to atopic disease development. In general, breastfeeding has several important health benefits and should be encouraged. Its beneficial role in the prevention of atopic manifestations is an ongoing matter of debate. Finally, we have provided some suggestions for future research. We would strongly suggest that more evidence is needed to support our hypothesis that early introduction may lead to the induction of 'oral tolerance'. Therefore it would be highly desirable to set up a intervention study in which breastfeeding mothers will be randomly allocated into 'early' versus 'late' introduction of cow's milk and/or certain other food products. 

Samenvatting 
Allergisch astma, hooikoorts (en andere luchtwegallergieën), atopisch eczeem en voedselallergie behoren samen tot de 'atopische aandoeningen', welke in de volksmond ook wel 'allergische aandoeningen' worden genoemd. In de afgelopen decennia vond er een sterke stijging plaats in het vóórkomen van deze aandoeningen. De oorzaken van deze stijging zijn (nog) onbekend. In de huidige westerse wereld lijdt op dit moment ongeveer $40 \%$ van de bevolking aan een allergische aandoening. Men denkt dat astma en andere allergische aandoeningen ontstaan als het gevolg van complexe interacties tussen genetische factoren en diverse omgevingsfactoren. Echter, de snelle stijging in het vóórkomen van allergische aandoeningen in de afgelopen decennia, kan onmogelijk het resultaat zijn van snelle veranderingen in het genetische profiel van mensen, wat duidt op een belangrijke rol voor omgevingsfactoren. In dit proefschrift hebben we gekeken op welke manier omgevingsfactoren, leefstijl en biologische factoren zoals de voeding van het kind, een rol kunnen spelen in een (mogelijk beschermend) effect op de ontwikkeling van allergische aandoeningen bij kinderen tot de leeftijd van 2 jaar.

De deelstudies die zijn beschreven in dit proefschrift maakten deel uit van de KOALA geboortecohort studie. KOALA is een afkorting voor Kind, Ouder en gezondheid, Aandacht voor Leefwijzen en Aanleg. De studie had als algemeen doel het bestuderen van factoren die een rol spelen bij de ontwikkeling van allergische aandoeningen bij kinderen. In Oktober van het jaar 2000 ging het KOALA onderzoek van start met de werving van zwangere vrouwen. Dit resulteerde in de deelname van 2834 pasgeborenen. De verzameling van gegevens vond plaats gedurende de zwangerschap en de eerste twee levensjaren van het kind middels het afnemen van herhaalde vragenlijsten. Aan een gedeelte van de groep deelnemers werd toestemming gevraagd om lichaamsmateriaal af te nemen. Het ging hierbij om bloed van de moeder $(n=1355)$, moedermelk $(n=315)$, een ontlastingmonster van het kind op de leeftijd van 1 maand $(n=1176)$, bloed verkregen via een vingerprikje bij het kind op de leeftijd van 1 jaar $(n=956)$, veneus bloed op de leeftijd van 2 jaar $(n=829)$ en wangslijmvlies van zowel de ouders als het kind voor het isoleren van DNA $(n=1637)$. Verder werd toestemming gevraagd om het kind op 2-jarige leeftijd thuis te onderzoeken (door getraind personeel) op de aanwezigheid van atopisch eczeem $(n=826)$.

De allergische aandoeningen die in dit proefschrift staan beschreven zijn onder te verdelen in drie uitkomstmaten. Dit zijn 'eczeem' (een terugkerende jeukende 
huiduitslag op bepaalde plekken), 'piepen op de borst' (een piepend geluid vanuit de luchtwegen geproduceerd tijdens de ademhaling) en 'allergische sensitisatie' (verhoogde niveaus in het bloed van Immunoglobuline E (IgE), dit zijn antistoffen die aangemaakt worden na het in contact komen van bepaalden stoffen (allergenen) in de voeding of in de lucht).

Eerdere studies die zijn gedaan naar de rol van borstvoeding op de ontwikkeling van allergische aandoeningen hebben geleid tot controversiële resultaten. Uit de resultaten van sommige studies bleek dat borstvoeding een beschermende rol zou spelen, terwijl dit niet in andere studies kon worden bevestigd, en soms werd zelfs een verhoogd risico gevonden. In dit proefschrift hebben we de relatie bestudeerd tussen het geven van borstvoeding en het ontwikkelen van allergische aandoeningen bij kinderen tot de leeftijd van 2 jaar.

In hoofdstuk 2 beschrijven we dat we geen associaties vonden tussen borstvoeding en de ontwikkeling van eczeem gedurende het eerste levensjaar. Wel vonden we een tendens naar een lager risico op eczeem vanaf de leeftijd van 4 maanden. Opvallend was dat borstvoeding juist gepaard ging met een hoger risico op eczeem tot de leeftijd van 4 maanden. In hoofdstuk 3 hebben we beschreven dat een langere duur van borstvoeding gepaard ging met een lager risico op eczeem gedurende de eerste 2 levensjaren bij kinderen van moeders die zelf geen allergie of astma hadden. Ook vonden we dat het langer geven van borstvoeding gepaard ging met een lager risico op 'piepen op de borst'.

Recentelijk hebben verschillende studies de relatie tussen borstvoeding en allergische aandoeningen benaderd vanuit een ander perspectief. In plaats van de duur van (exclusief) borstvoeding als uitgangspunt te nemen hebben deze studies juist gekeken naar het tijdstip dat het kind voor het eerst in aanraking kwam met koemelk- of andere voedingsproducten (bijvoorbeeld: kunstmatige flesvoeding of fruithapjes). De algemene gedachte hierbij is dat het introduceren van deze producten maar het beste zolang mogelijk uitgesteld moet worden ter voorkoming van allergische reacties bij het kind. Echter, wetenschappelijk bewijs voor deze theorie is zeer beperkt. In hoofdstuk 4 laten we zien dat juist het uitstellen van het introduceren van koemelkproducten gepaard ging met een hoger risico op eczeem en 'piepen op de borst'. Hetzelfde vonden we als we keken naar het uitstellen van andere voedingsproducten, en deze bevindingen werden bevestigd door onze resultaten voor atopisch eczeem. Tot slot zagen we dat het uitstellen van 
het geven van andere voedingsmiddelen ook gepaard ging met een hoger risico op 'piepen op de borst' en 'allergische sensitisatie'. Al deze bevindingen samen suggereren dat het op vroege leeftijd introduceren van voedselproducten in combinatie met het continueren van borstvoeding helpt bij het tot stand brengen van 'orale tolerantie' (dit mechanisme zorgt ervoor dat ons lichaam normaal gesproken geen allergische reactie vertoont als we voedingsmiddelen tot ons nemen).

In hoofdstuk 5 en 6, lag de nadruk meer op vraagstellingen op het gebied van biologische mechanismen zoals de rol van immuunfactoren in moedermelk bij de bescherming tegen allergie, en de verklaring van verschillen in de kans op allergie bij kinderen (hoofdstuk 5). In hoofdstuk 6 lag de nadruk op interacties tussen genetische vatbaarheid en omgevingsfactoren.

In hoofdstuk 5 hebben we gekeken naar een selectie van immuunfactoren in moedermelk, namelijk 'oplosbaar CD14' (de oplosbare vorm van een receptor van het aangeboren afweersysteem - genaamd $\mathrm{CD}_{14}$ receptor - welke een belangrijke rol speelt bij de herkenning van gram- negatieve bacteriën), en de volgende signaalstoffen: TGF-beta1, interleukine-10 en interleukine-12.

Op de eerste plaats wilden we weten of de aanwezigheid van bepaalde hoeveelheden immuunfactoren in de moedermelk een afspiegeling konden zijn van de allergische status van de moeder. Met andere woorden: hebben allergische moeders misschien meer of juist minder van deze immuunfactoren in hun moedermelk in vergelijking met niet-allergische moeders? Inderdaad vonden we dat allergische moeders meer oplosbaar CD14 hadden in hun moedermelk. Voor de andere immuunfactoren bleek dit niet het geval.

Ten tweede vroegen wij ons af of deze immuunfactoren in moedermelk, welke het kind dus via de borstvoeding binnenkrijgt, mogelijk van invloed waren op de ontwikkeling van allergische aandoeningen bij het kind. Dit bleek niet het geval. Daarmee konden wij eerdere buitenlandse resultaten niet bevestigen. Dit is mogelijk een verklaring voor de gevonden verschillen in het beschermende effect van borstvoeding afhankelijk van de allergiestatus van de moeder.

In hoofdstuk 6 lag de nadruk op de interactie tussen genetische vatbaarheid en omgevingsfactoren. Het gen dat codeert voor de hierboven beschreven CD14 receptor (het $\mathrm{CD}_{14}$ gen) is één van de vele genen die momenteel in de belangstelling staan als het gaat om allergie en astma. Bij dergelijke genetische variaties zijn we 
vooral geïnteresseerd in varianten die in meer dan $1 \%$ van de bevolking voorkomen en deze varianten worden 'polymorfismen' genoemd. Er zijn verschillende polymorfismen beschreven van het $C D_{14}$ gen ( $C D_{14}$ polymorfismen) welke gerelateerd zijn aan het tot uiting komen van allergische aandoeningen bij kinderen. Bovendien zijn in een eerdere studie $C D 14$ genotypes (d.w.z. de erfelijke informatie over de tot uiting komen van de $\mathrm{CD} 14$ receptor) van moeders die borstvoeding gaven gerelateerd aan de hoeveelheid oplosbaar CD14 in hun moedermelk. In dit proefschrift bestudeerden wij de interactie tussen het $C D 14$ genotype en het gehalte van de oplosbare vorm van de CD14 receptor in de moedermelk (als omgevingsfactor voor het kind). We vonden dat de interactie tussen enerzijds de verschillende niveaus van de oplosbare receptor CD14 in moedermelk en anderzijds het $C D 14$ genotype, geen invloed had op de ontwikkeling van allergische aandoeningen op de leeftijd van 2 jaar. Echter, we zagen wel dat een van de $C D 14$ polymorfismen (genaamd $C D_{14} /$-1619) geassocieerd was met het krijgen van eczeem gedurende de eerste 2 levensjaren.

De al eerder beschreven inconsistente resultaten over de relatie tussen borstvoeding en de ontwikkeling van allergische aandoeningen hebben we in dit proefschrift getracht te benaderen vanuit twee hieronder beschreven methodologische invalshoeken.

\section{Reverse causation (omgekeerde causaliteit)}

Reverse causation is een vorm van bias (vertekening van de resultaten) en wordt gezien als één van de verklaringen voor de inconsistente bevindingen van de al dan niet beschermende effecten van borstvoeding in de literatuur. Concreet houdt deze vorm van bias in dat de relatie tussen borstvoeding en allergische aandoeningen bij kinderen verstoord wordt door het feit dat moeders hun gedrag (ten aanzien van de voeding voor hun kind) veranderen door wat in hun perceptie het beste is voor het kind. Bijvoorbeeld de moeder zou kunnen besluiten om langer door te gaan met het geven van borstvoeding indien zij merkt dat haar kind last heeft van eczeem en zij gelooft dat het wellicht beter is voor het kind om het geven van flesvoeding zo lang mogelijk uit te stellen. In hoofdstuk $\mathbf{2}$ hebben we onderzocht of de door ons gebruikte gegevens ook aan deze vorm van bias onderhevig waren. We hebben dit onderzocht door middel van zogenaamde 'risico-periode specifieke analyses'. In deze analyse werden alléén kinderen meegenomen waarvan we zeker weten dat zij op het moment dat ze borstvoeding kregen, (nog) 
geen symptomen van eczeem hadden. Middels deze analyse konden wij laten zien dat de conclusies die we trekken in hoofdstuk 2 niet onderhevig zijn aan 'reverse causation'. In hoofdstuk 4 hebben we zoals boven beschreven gekeken of er associaties waren tussen de introductie van koemelkproducten en/of andere voedingsmiddelen en de ontwikkeling van allergische reacties in de eerste twee levensjaren van het kind. Ook bij het bestuderen van deze relatie hebben we getracht rekening te houden met 'reverse causation'. Het uitsluiten van kinderen met vroege symptomen van eczeem en een 'piepende ademhaling' (om vertekening als gevolg van 'reverse causation' te voorkomen) heeft onze resultaten niet wezenlijk veranderd.

\section{Effect modificatie}

Een andere verklaring die wordt gegeven om de inconsistente bevindingen met betrekking tot de relatie tussen borstvoeding en allergische aandoeningen te verklaren is 'effect modificatie' (dit is het verschijnsel dat de sterkte van een verband wordt beïnvloed (gemodificeerd) door een andere factor (welke effect-modificator wordt genoemd). In hoofdstuk $\mathbf{3}$ hebben we gekeken of de allergische status van de moeder (als effect-modificator) de relatie tussen de duur van borstvoeding en de ontwikkeling van allergische aandoeningen gedurende de eerste 2 levensjaren heeft beïnvloed. Onze resultaten impliceerden dat alléén de relatie tussen borstvoeding en de ontwikkeling van eczeem beïnvloed werd door de allergische status van de moeder. De overige relaties hingen niet af van de allergische status van de moeder. Verder vonden we dat een langere duur van borstvoeding gepaard ging met een lager risico op 'piepen op de borst', onafhankelijk van de allergische status van de moeder. Dit beschermende effect van borstvoeding op 'piepen op de borst' zou het gevolg kunnen zijn van bescherming tegen luchtweginfecties en deze hangt dus niet af van allergie van de moeder.

In hoofdstuk 5 hebben we bekeken of de inconsistenties verklaard konden worden door een verschil in bescherming door immuunfactoren in moedermelk tussen allergische en niet-allergische moeders. Met andere woorden, we hebben bepaald of de door ons geselecteerde immuunfactoren in moedermelk beïnvloed zijn door de allergische status van de moeder en daarmee de relatie met de ontwikkeling van allergische aandoeningen modificeert. We vonden hogere niveaus van oplosbaar $\mathrm{CD}_{14}$ in allergische moeders ten opzichte van niet allergische moeders. In hoofdstuk 6 lag de nadruk op de vraag of er sprake kon zijn van effect modificatie (hier gen-omgevings interactie) door genetische variatie ( $C D_{14}$ polymorfis- 
men) en de omgeving (immuun factoren) in moedermelk. Deze (gen-omgevings) interactie tussen genetica en 'omgeving' zou een link kunnen vormen tussen de genetische invloed van de moeder en het risico op allergische aandoeningen bij het kind, daarmee een verklaring vormend voor het feit dat allergie vaker via de moeder wordt overgedragen dan via de vader. Het $C D_{14}$ genotype van de moeder had geen invloed op de hoeveelheid oplosbaar CD14 in moedermelk. We concludeerden dat de interactie tussen enerzijds de verschillende niveaus van de oplosbare receptor $C_{14}$ in moedermelk en anderzijds het $C D_{14}$ genotype, geen invloed had op de ontwikkeling van allergische aandoeningen op de leeftijd van 2 jaar. In andere woorden, wij vonden geen bewijs voor gen-omgevings interacties voor de door ons bestudeerde uitkomsten van allergische aandoeningen.

In hoofdstuk 7 worden de belangrijkste bevindingen van dit proefschrift gepresenteerd en bediscussieerd. De studieopzet en de validiteit zijn daarbij in beschouwing genomen. Verder is in hoofdstuk 7 aandacht besteed aan de verschillende methodologische invalshoeken ('reverse causation' en 'effect modificatie') in een poging de controversiële bevindingen tussen het geven van borstvoeding en de ontwikkeling van allergische aandoeningen te verklaren.

Wij concludeerden dat borstvoeding de voorkeursvoeding blijft in verband met de algemene voordelige effecten op de gezondheid van het kind (o.a. minder infecties) maar het uitstellen van de introductie van koemelkproducten of andere voedingsmiddelen ter preventie van allergische aandoeningen minder bevorderlijk lijkt. De rol van borstvoeding ter preventie van allergische aandoeningen blijft onder voortdurende discussie. Tot slot doen we aanbevelingen voor toekomstig onderzoek. Wij stellen dat er meer bewijs nodig is voor onze hypothese dat 'vroege introductie' van koemelk of andere voedingsmiddelen mogelijk leidt tot de inductie van 'orale tolerantie' en daarmee vermoedelijk een bescherming tegen het ontstaan van voedselallergie. We doen daarom een aanbeveling om een interventie studie op te zetten waarin moeders die borstvoeding geven willekeurig worden verdeeld in een groep met 'vroege introductie' versus een groep met 'late introductie' van koemelk en andere voedingsproducten om vervolgens te kijken naar het verschil in risico op allergische aandoeningen bij het kind tussen beide groepen. 



\section{DANKWOORD}

In het wellicht meest populaire hoofdstuk van een proefschrift, wil ik graag iedereen bedanken die heeft bijgedragen aan de totstandkoming van dit proefschrift.

In het bijzonder wil ik alle 2834 deelnemende families aan het KOALA onderzoek bedanken, hun vrijwillige en enthousiaste bijdrage aan ons onderzoek is onmisbaar geweest.

Mijn promotor Piet van den Brandt en co-promotoren Carel Thijs en Foekje Stelma wil ik graag bedanken voor hun wetenschappelijke bijdrage en opbouwende kritiek. Piet, bedankt voor het overzicht dat je hield de afgelopen jaren en het zetten van de puntjes op de i van mijn stukken. Carel, bedankt voor de tijd die je nam om mijn stukken te becommentariëren en al mijn vragen te beantwoorden. Dat ik voor de allerkleinste dingen altijd bij je kon binnenvallen heb ik zeer gewaardeerd. Foekje, jou wil ik met name bedanken voor je inspanningen bij de opzet van het project en je oneindige enthousiasme, met name voor de genetica.

Ischa Kummeling en John Penders, mijn 2 mede KOALA aio's. Bedankt voor al jullie wijze adviezen en gezelligheid in de afgelopen jaren. Het was bijzonder fijn om jullie al die tijd in de buurt te hebben en 'ups' en 'downs' met elkaar te delen. Ik vond het een groot genoegen dat ik naast jullie in de aula mocht staan en ben zeer vereerd dat jullie nu naast mij willen staan en we samen nog één keer het KOALA 'aio-trio' vormen. Echt super dat jullie mijn paranimfen zijn!

Dan al die anderen die hebben bijgedragen aan ons project. Nicole Custers wil ik graag bedanken als onderzoeksassistente op het moedermelk-project. Nicole, zonder jouw hulp was het me nooit gelukt om in relatief korte tijd ruim 300 buizen met verse moedermelk kris kras door het land op te halen. Elke zilvergrijze Ford Focus doet me, tot op de dag van vandaag, aan jou en deze periode terugdenken! Verder alle dames die onze (niet altijd functionerende) KOALA-bus, bestuurden: Brigitte Winants, Chantal Delnoy, Karen Groot en Petra Cuijpers. Bedankt voor al die duizenden kilometers die jullie maakten ten behoeve van al die bloedmonsters en vragenlijst scores die voor ons zo belangrijk waren! Ook degenen die niet 
op de weg zaten waren onmisbaar: Cobie Martens, ontzettend bedankt voor alles dat je draaiende hield op logistiek en administratief gebied. Willeke Hendrikx, uiteraard wil ik ook jou bedanken voor je logistieke hulp.

ledereen van de KOALA project- en stuurgroep wil bedanken voor hun bijdrage. Voor de bijdrage aan inhoudelijk interessante discussies wil ik met name bedanken: Luc Smits, Monique Mommers, Margje Jansen, Johan Reijmerink, Marion Koopmans, Jan de Vries, Anne Schaafsma, Machteld Huber, Huub Savelkoul en Ronald van Ree.

De dames van de Biobank: Corine Coorens en Hasibe Aydeniz, bedankt dat bij jullie al onze monsters in goede handen waren. Astrid van Leeuwen (Sanquin) wil ik bedanken voor de IgE bepalingen.

Verder gaat mijn dank uit naar de onderzoekers van de PPBS Studie en de medewerkers van het MEMIC. Ook bedank ik: Annemie Mordant, Ton van Moergastel, Jos Slagen, Harry van Montfort, Nathalie Baltus, Ria Franke, Yvonne Jaegers, Trix Voogd en Monique Koekkelkoren.

Ik wil iedereen bedanken van de afdeling Klinische Immunologie in het AZM. Met name Jan Damoiseaux wil ik bedanken voor het feit dat ik op zijn lab mocht werken. Beste Jan, natuurlijk ook bedankt voor je nuchtere wetenschappelijke kijk op stukken over immunologie die ik bij je mocht inleveren. Mia Vaessen wil ik bedanken voor alle praktische uitleg op het lab. Mia, bedankt dat je bereid was om met veel enthousiasme een droge epidemioloog wegwijs te maken op het lab! Alle anderen bedankt voor de gezelligheid tijdens de koffiepauzes vaak tijdens één van die ellenlang durende incubatietijden van mijn bepalingen.

Van het Allergenic poject, vanuit het UMC Groningen, wil ik een aantal mensen bedanken. Allereerst Gerard Koppelman. Beste Gerard, bedankt voor je enthousiaste begeleiding bij het $C D_{14}$ artikel. Jouw onmetelijke kennis over $C D_{14}$ gaf mij vaak weer nieuwe moed om verder te gaan. Renske Bottema wil ik bedanken voor haar inzet bij het verzamelen van de DNA monsters. Naomi Reijmerink en Marjan Kerkhof wil ik bedanken voor hun wetenschappelijke adviezen. Dirkje Postma wil ik bedanken voor haar enthousiasme en het zetten van de puntjes op de i. Tevens vanuit het UMC Groningen wil ik zeker ook de volgende 2 personen bedanken: 
Gerrit van der Steege en Marcel Mulder vanwege hun gastvrijheid en bereidheid om alles rondom genotyperen en Taqman's aan mij uit te leggen. Marcel, bedankt voor het analyseren van de monsters van 188 KOALA moeders!

Uiteraard wil ik alle (oud-)collega's van de afdeling Epidemiologie bedanken. Alle (voormalige) aio's wil ik bedanken voor de gezelligheid, wijze tips en luisterende oren tijdens lunchpauzes in AZM/UNS40 of bij mooi weer op de befaamde trappen bij de vijver, maar ook tijdens promovendi overleggen en/of aio-etentjes. Speciaal wil ik bedanken: Boukje, Margreet (leuk dat je weer 'om de hoek' woont...), Mirian, Kim \& Saskia (die Randstad etentjes houden we erin!). Verder wil ik Pieter Leffers bedanken voor methodologische adviezen. Pieter Dagnelie wil ik bedanken voor zijn interesse in mijn voortgang. Christel van Gool, ook jou wil ik bedanken voor je interesse, je bent toch mijn voorganger op het gebied van borstvoeding en atopie. Bedankt ook voor het 4 jaar lang sturen van al die BBC linkjes! Luc, bedankt dat ik altijd bij je mocht binnenlopen om verhaal te doen (of te halen), al gingen die (gelukkig) niet altijd over werk. En dan natuurlijk Bas, leuk dat we elkaar in het zuiden weer tegenkwamen en collega's werden. Bedankt voor je interesse en adviezen over uiteenlopende onderwerpen van genetica tot aan de voorkant van mijn proefschrift! Onwijs bedankt voor je mooie kunstwerk!

Om het hoekje van de afdeling Statistiek, wil ik graag Frans Tan bedanken voor het beantwoorden van vragen en voor het geven van advies bij statistische probleempjes. Om hetzelfde hoekje van de afdeling Huisartsgeneeskunde, wil ik met name Tanja Maas bedanken voor het aanleveren van gegevens m.b.t. Allergenic en voor haar persoonlijke interesse in mijn project.

Jos Bruystens wil ik graag hartelijk bedanken voor de professionele en prachtige lay-out!

Dan naar mijn huidige werkplek in die mooie stad achter de duinen. Allereerst wil ik mijn leidinggevende, Sabine Straus, bedanken. Sabine, hoewel de woorden 'geneesmiddel' en 'bijwerking' in dit proefschrift niet voorkomen, ben ik je zeer erkentelijk voor je interesse in mijn proefschrift en stimulerende gesprekjes. Alle anderen van de afdeling GMB wil ik bedanken voor hun interesse en ontspanning tijdens onze (teambuilding-) lunchpauzes bij VWS. Anja wil ik speciaal bedanken voor het stimuleren en onderhouden van 'workflows'! 
DANKWOORD

Marjolein, Thijs en Charlotte wens ik veel succes met hun eigen onderzoek en proefschrift! Ook dank ik mijn (oud-)collega's van FT4, met speciale dank aan (mijn Surinaamse 'moeder') Justine.

Familie en kennissen wil ik bedanken voor hun interesse in wat ik doe. Tim \& Esther wil ik hiervoor speciaal bedanken.

Tegen mijn vrienden kan ik roepen: 'Jaaa, dat boekje is eiiindelijk af!' Uiteraard bedankt voor jullie interesse en niet geheel onbelangrijk; de door jullie geboden ontspanning in vrije tijd!

Casper, dankjewel voor die laatste duwtjes in de rug..., je geduld, begrip en interesse!

Pap \& mam, mijn grootste dank gaat natuurlijk uit naar jullie! Bedankt voor jullie altijd aanwezige interesse en onvoorwaardelijke steun bij alles wat ik doe!

Den Haag, februari 2008

Bianca

166 


\section{ABOUT THE AUTHOR}

Bianca E.P. Snijders (23 November 1977) grew up in Landgraaf and completed secondary school (HAVO and VWO) at Eijkhagen College (Landgraaf) in 1997. From 1997-2002 she studied Biomedical (Health) Science at Radboud University Nijmegen where she gained a masters in Epidemiology. She obtained research experience during three internships at the Department of Epidemiology and Biostatistics, Radboud University Nijmegen. Two of those projects were in collaboration with the Department of Pediatrics and the Department of Urology of the University Medical Centre St Radboud, respectively. Additional research experience was obtained during an internship at the National Cancer Registry of the South African Institute of Medical Research in Johannesburg, South Africa. From September 2002-September 2006, she worked as a PhD-student at the Department of Epidemiology of Maastricht University, resulting in the present thesis. From October 2006 she works at the Department of Pharmacovigilance of the Medicines Evaluation Board in The Haque. 



\section{LIST OF PUBLICATIONS}

Snijders BE, Thijs C, Dagnelie PC, Stelma F, Mommers M, Kummeling I, Penders J, van Ree R, van den Brandt PA. Breastfeeding duration and infant atopic manifestations by maternal allergic status, in the first two years of life (KOALA Study)

J Pediatrics 2007;151(4):347-51

Snijders BE, Thijs C, Kummeling I, Penders J, van den Brandt PA. Breastfeeding and eczema in the first year of life in the KOALA Birth Cohort Study, a risk-period specific analysis

Pediatrics 2007;119:e137-e141

Snijders BE, Damoiseaux J, Penders J, Kummeling I, Stelma F, van Ree R, van den Brandt PA, Thijs C. Cytokines and soluble CD14 in breast milk in relation with atopic manifestations in mother and infant (KOALA study)

Clin Exp Allergy 2006;36, 1609-15

Kummeling I, Thijs C, Huber M, van de Vijver LP, Snijders BE, Penders J, Stelma F, van Ree R, van den Brandt PA, Dagnelie PC. Consumption of organic Foods and risk of atopic disease during the first 2 years of life in the Netherlands

BrJ Nutr 2007 Aug(29);1-8

Kummeling I, Stelma FF, Dagnelie PC, Snijders BE, Penders J, Huber M, van Ree R, van den Brandt PA, Thijs C. Early life exposure to antibiotics and the subsequent development of eczema, wheeze, and allergic sensitization in the first 2 years of life: the KOALA Birth Cohort Study Pediatrics 2007;/an;119(1):e225-31

Kummeling I, Thijs C, Penders J, Snijders BE, Stelma F, Reimerink J, Koopmans M, Dagnelie PC, Huber M, Jansen MC, de Bie R, van den Brandt PA. Etiology of atopy in infancy: the KOALA Birth Cohort Study Pediatr Allergy Immunol 2005;16(8):679-84

Penders J, Thijs C, van den Brandt PA, Kummeling I, Snijders B, Stelma F, Adams H, van Ree R, Stobberingh EE. Gut microbiota composition and the development of taopic manifestations in infancy: the KOALA Birth Cohort Study

Gut 2007;56(5):661-7 


\section{LIST OF PUBLICATIONS}

Penders J, Thijs C, Vink C, Stelma FF, Snijders B, Kummeling I, van den Brandt PA, Stobberingh EE. Factors influencing the composition of intestinal microbiota in early infancy Pediatrics 2006;118(2):511-21

Rist L, Mueller A, Barthel C, Snijders B, Jansen M, Simoes-Wust AP, Huber M, Kummeling I, von Mandach U, Steinhart H, Thijs C. Influence of organic die ton the amount of conjugated linoleic acids in breast milk of lactating women in the Netherlands

BrJ Nutr 2007 Apr97(4):735-43 

